\title{
Genetic Analysis of Bphse: a Novel Gene Complementing Resistance to Bordetella PERTUSSIS-INDUCEd Histamine Sensitization
}

\author{
Abbas Raza ${ }^{1}$, Sean A. Diehl ${ }^{2}$, Laure K. Case ${ }^{3}$, Dimitry N. Krementsov ${ }^{4}$, Dawei Li², Jason \\ Kost $^{2}$, Robyn L. Ball ${ }^{3}$, Elissa J. Chesler ${ }^{3}$, Vivek M. Philip ${ }^{3}$, Rui Huang ${ }^{5}$, Yan Chen ${ }^{5}$, Runlin \\ $\mathrm{Ma}^{5}$, Anna L. Tyler ${ }^{3}$, J. Mathew Mahoney ${ }^{3,6}$, Elizabeth P. Blankenhorn7, \\ and Cory Teuscher ${ }^{1,8, *}$
}

Departments of Medicine ${ }^{1}$, Microbiology and Molecular Genetics ${ }^{2}$, Biomedical and Health Sciences $^{4}$, Neurological Sciences ${ }^{6}$, Pathology and Laboratory Medicine $^{8}$, University of Vermont, Burlington, VT, USA 05405

The Jackson Laboratory³, Bar Harbor, Maine, USA 04609

School of Life Sciences ${ }^{5}$, University of the Chinese Academy of Sciences, Beijing, China 100049

Department of Microbiology and Immunology, Drexel University College of Medicine, Philadelphia, Pennsylvania, USA 19129

*Address correspondence to: Cory Teuscher, PhD C331 Given Medical Building 89 Beaumont Avenue University of Vermont Burlington, Vermont, 05405, USA E-mail: c.teuscher@med.uvm.edu 


\section{Short title: Bphse complements resistance to HA shock}

Keywords: histamine, Bordetella pertussis, pertussis toxin, anaphylaxis, vascular permeability, shock

Abbreviations: B. pertussis, Bordetella pertussis; Bphs/Bphs, Bordetella pertussis induced histamine sensitization; Bphse, enhancer of Bordetella pertussis induced histamine sensitization; Bpss, Bordetella pertussis induced serotonin sensitization; Bpbs, Bordetella pertussis induced bradykinin sensitization; HA, histamine; Histh/Histh, non-Bordetella pertussis induced histamine hypersensitivity; Hrh1/HRH1, histamine receptor $\mathrm{H}_{1}$; PTX, pertussis toxin; T1H, type 1 hypersensitivity; VP, vascular permeability; LD, linkage disequilibrium; GPCR, Gprotein coupled receptor; ER, endoplasmic reticulum; EMC, endoplasmic membrane protein complex; ERAD, endoplasmic reticulum-associated degradation; MGP, mouse genomes project; MPD mouse phenome database. 


\section{Abstract}

Histamine is a bioactive amine associated with a plethora of normal and pathophysiological processes, with the latter being dependent on both genetic and environmental factors including infectious agents. Previously, we showed in mice that susceptibility to Bordetella pertussis and pertussis toxin (PTX) induced histamine sensitization (Bphs) is controlled by histamine receptor $\mathrm{H}_{1}(\mathrm{Hrh} 1 / \mathrm{HRH} 1)$ alleles. Bphs susceptible and resistant alleles (Bphss/Bphs') encode for two-conserved protein haplotypes. Given the importance of $\mathrm{HRH} 1$ signaling in health and disease, we sequenced Hrh1 across an extended panel of laboratory and wild-derived inbred strains and phenotyped them for Bphs. Unexpectedly, eight strains homozygous for the Bphs ${ }^{r}$ allele phenotyped as Bphs ${ }^{s}$, suggesting the existence of a modifying locus segregating among the strains capable of complementing Bphs $^{r}$. Genetic analyses mapped this modifier locus to mouse chromosome 6; designated Bphs-enhancer (Bphse), within a functional linkage disequilibrium domain encoding multiple loci controlling responsiveness to histamine (Bphs/Hrh1 and Histh1-4). Interval-specific singlenucleotide polymorphism (SNP) based association testing across 50 laboratory and wildderived inbred mouse strains and functional prioritization analyses resulted in the identification of candidate genes for Bphse within a 5.5 Mb interval (Chr6:111.0-116.4 Mb), including Atg7, Plxnd1, Tmcc1, Mkrn2, Il17re, Pparg, Lhfpl4, Vgll4, Rho and Syn2. Taken together, these results demonstrate the power of combining network-based computational methods with the evolutionarily significant diversity of wild-derived inbred mice to identify novel genetic mechanisms controlling susceptibility and resistance to histamine shock. 


\section{INTRODUCTION}

Histamine (2-[4-imidazole]-ethylamine; $\mathrm{HA})$ is an endogenous biogenic monoamine that is synthesized, stored intracellularly within granules; following cellular activation $\mathrm{HA}$ is released by mast cells, basophils, platelets, neurons, and enterochromaffin-like cells in the stomach [1]. After release, free HA mediates its pleiotropic effects by binding to four different seven-transmembrane G-protein-coupled receptors (GPCRs): histamine receptor $\mathrm{H}_{1}-\mathrm{H}_{4}(\mathrm{HRH} 1, \mathrm{HRH} 2, \mathrm{HRH3}$, and $\mathrm{HRH} 4)$, differentially expressed on target cells in various tissues [2]. HA acting through these receptors influences a diverse array of physiological processes, including brain function, neurotransmission, secretion of pituitary hormones, cell proliferation and differentiation, hematopoiesis, embryonic development, wound healing and regeneration, and the regulation of gastrointestinal, cardiovascular, and secretory functions [2]. In addition, HA plays a major role in inflammation and the regulation of innate and adaptive immune responses in both normal and pathologic states $[\underline{3}, \underline{4}]$.

Historically, HA is most well-known for its role in shock and anaphylaxis []․ It was first isolated from the parasitic mold ergot of rye (Claviceps purpurea) and then synthesized by the decarboxylation of histidine [6-8]. HA was shown to elicit anaphylactic shock-like symptoms when injected into mammals, including bronchiolar constriction, constricted cardiac and pulmonary arteries, and stimulated cardiac contraction [9-11]. Further research firmly established HA as a natural constituent of the body and a mediator of anaphylactic shock [5]. There is significant variability in susceptibility to HA-shock among animal species, with guinea pigs and rabbits being highly susceptible, versus mice and rats which are generally remarkably tolerant to in vivo injections of HA [12]. 
Interestingly, prior exposure to Bordetella pertussis (B. pertussis) or purified pertussis toxin (PTX) overcomes HA resistance among a subset of laboratory derived inbred strains of mice [13]. This phenotype is designated Bphs for B. pertussis-induced HA sensitization $\left[\underline{14}, \underline{15}\right.$. Bphs-susceptible $\left(\right.$ Bphs $\left.^{\mathrm{s}}\right)$ strains die within 30 minutes following HA injection; which is thought to result from hypotensive and hypovolemic shock while Bphs-resistant $\left(\right.$ Bphs $\left.^{r}\right)$ strains remain healthy [16]. The sensitizing activity elicited by exposure to $B$. pertussis is a function of PTX-catalyzed adenosine diphosphate-ribosylation of the alpha subunit of heterotrimeric guanine nucleotide-binding protein ( $\left.\mathrm{Ga}_{\mathrm{i} / \mathrm{o}}\right)$, specifically $\mathrm{G}_{\mathrm{i} 1 / 3}$ [17, 18]. In addition to HA sensitization, PTX-treated mice exhibit increased systemic vascular permeability and sensitization to serotonin (Bpss) and bradykinin (Bpbs) [17, 19].

Our previous genetic studies mapped the autosomal dominant Bphs locus controlling susceptibility to mouse chromosome 6 (Chr6) and identified it as histamine receptor $\mathrm{H}_{1}(H r h 1 / H R H 1)[\underline{15}, \underline{20}$. Susceptibility segregates with two conserved Hrh1/HRH1 haplotypes, mice with the Hrh1s/HRH1 s allele (encoding $\mathrm{Pro}^{263}, \mathrm{Val}^{312}, \mathrm{Pro}^{330}$ ) phenotype as Bphs ${ }^{s}$ while mice with the $H r h 1^{r} / H R H 1^{r}$ allele (encoding $\mathrm{Leu}^{263}$, Met $^{312}$, Ser $^{330}$ ) are Bphs ${ }^{r}$. These amino acid changes occur within the third intracellular loop of this G protein-coupled receptor (GPCR): a domain implicated in signal transduction, protein folding, and trafficking. Functionally, $\mathrm{HRH}^{\mathrm{s}}$ and $\mathrm{HRH}^{\mathrm{r}}$ alleles equally activate $\mathrm{Ga}_{\mathrm{q} / 11}$, the $\mathrm{G}$ protein family members that couple HRH1 signaling to second messenger signaling pathways, indicating that the genetic control of susceptibility and resistance to Bphs is not inherently due to differential activation of either $\mathrm{Ga}_{\mathrm{q}}$ or $\mathrm{Ga}_{11}$ [21]. However, the two alleles exhibit differential cell surface expression and altered intracellular trafficking, with the $\mathrm{HRH}^{\mathrm{r}}$ allele selectively retained within the endoplasmic reticulum 
(ER). Importantly, all three amino acid residues (Leu ${ }^{263}$, Met $^{312}$, Ser $^{330}$ ) comprising the $\mathrm{HRH} 1^{r}$ haplotype are required for altered expression [21].

In this study, we carried out an expanded phenotype screen for Bphs susceptibility and resistance that included previously unstudied wild-derived inbred strains of mice, and identified eight Bphs strains, despite carrying the $\mathrm{Bphs}^{\mathrm{R}} \mathrm{Hrh} 1^{r} / \mathrm{HRH} 1^{r}$ allele. Genetic analyses identified a dominant modifying locus linked to Bphs/Hrh1 capable of complementing $H r h 1^{r} / \mathrm{HRH} 1^{r}$ to create a Bphs ${ }^{S}$ phenotype. We have designated this locus Bphse for Bphs-enhancer. Interval-specific single nucleotide polymorphism (SNP) based association testing and functional enrichment is used to identify candidate genes for Bphse. 


\section{RESULTS}

Hrh1/HRH1 alleles are highly conserved in mice. We undertook a genetic approach to screen for evolutionarily selected mechanisms that may be capable of modifying the Bphs ${ }^{r}$ phenotype. Toward this end, we sequenced $~-500$ bp stretch of genomic DNA encompassing the third intracellular loop of Hrh1/HRH1 across 91 laboratory and wild-derived inbred strains of mice (Table 1). Surprisingly, other than the three amino acid changes $\left(\operatorname{PrO}^{263}, \mathrm{Val}^{312}, \mathrm{PrO}^{330} \rightarrow \mathrm{Leu}^{263}, \mathrm{Met}^{312}, \mathrm{Ser}^{330}\right.$ ) described earlier as "susceptible" (Hrh1s/HRH1s) and "resistant" (Hrh1r/HRH1') haplotypes [15], we did not identify any additional non-synonymous amino acid changes. Of the 91 strains, 22 carry the $H r h 1^{r} / \mathrm{HRH}^{r}$ allele, whereas 69 carry the $H r h 1^{s} / \mathrm{HRH} 1^{\text {s }}$ allele (Table 1 ). We next mapped the evolutionary distribution of the two alleles onto a mouse phylogenetic tree (Supplementary Figure 1) [22]. The $H r h 1^{r} / \mathrm{HRH}^{\mathrm{r}}$ allele was primarily restricted to wildderived group 7 strains and a select sub-branch of group 1 Bagg albino derivatives, whereas the $\mathrm{Hrh}_{1} \mathrm{~s} / \mathrm{HRH}^{\text {s }}$ allele was distributed across groups 2-6, which encompasses Swiss mice, Japanese and New Zealand inbred strains, C57/58 strains, Castle mice, C.C. Little DBA and related strains.

Compared to classical inbred strains, wild-derived mice exhibit sequence variation at approximately every 100-200 base pairs and are, in general, more resistant to a variety of pathogens [23-27]. Group 7 strains exemplify this genetic diversity in that it includes representatives of Mus musculus (M. m) domesticus (PERA, PERC, WSB, ZALENDE and TIRANO), M. m. musculus (PWK, PWD, CZECHI, and CZECHII), M. m. castaneus (CAST), M. m. molossinus (JF1, MSM, MOLF, MOLD, MOLC), M. m. hortulanus (PANCEVO), M. m. spretus (SPRET), M. m. praetextus (IS), or hybrids of M. m. musculus 
and M. m. domesticus (SKIVE), M. m. musculus and M. m. poschiavinus (RBF) and of $M$. m. castaneus and M. m. domesticus (CALB) [28-30]. This genetic variability represents a rich source of evolutionarily selected diversity and has the potential to lead to the identification of genes controlling novel regulatory features arising from host-pathogen co-evolutionary adaptations.

To screen for functional modifying loci capable of complementing $H r h 1^{r} / \mathrm{HRH}^{r}$, we phenotyped a panel of group 1 (Bagg albino derivatives) and 7 (wild-derived) mice that genotyped as $H r h 1^{r} / \mathrm{HRH}^{r}$ for susceptibility to Bphs. While nine $H r h 1^{r} / \mathrm{HRH} 1^{r}$ strains tested were Bphs ${ }^{r}$ as expected, we found eight that were remarkably susceptible to Bphs (Table 2). Importantly, these Bphs ${ }^{s}$ strains are confined primarily to group 7 wild-derived strains (Supplementary Figure 1) in contrast to $H r h 1^{r} / \mathrm{HRH} 1^{r}$ strains from Group 1 that were mostly Bphs'. Moreover, comparison of the entire Hrh1 gene (Chr6:114,397,936$114,483,296 \mathrm{bp})$ between several of the Group 1 and Group 7 phenotyped strains found no segregating non-synonymous structural variants (data not shown) between Bphs ${ }^{\mathrm{s}}$ and Bphs $^{r}$ strains suggesting that the complimenting locus/loci in Group 7 is independent of additional previously unidentified $H r h 1 s / H R H 1$ s structural variants.

To confirm the existence of a modifying locus capable of restoring Bphs ${ }^{s}$ in mice with a $H r h 1^{r} / \mathrm{HRH}^{r}$ allele and to assess its heritability, we selected a subset of Bphs ${ }^{\mathrm{s}}$ Hrh1r/HRH1 $1^{r}$ (MOLF, PWK) and Bphs'-Hrh1r/HRH1 ${ }^{r}$ (AKR, CBA, C3H, MRL) strains for follow-up studies. We studied $\mathrm{F}_{1}$ hybrids between the select strains of interest and HRH1knockout B6 mice (HRH1KO), which lack a functional Hrh1s/HRH1s gene required for Bphs $^{s}[\underline{31}]$. These mice can, however, provide potential complementing genetic elements in trans. $(\mathrm{B} 6 \times \mathrm{HRH} 1 \mathrm{KO}) \mathrm{F}_{1}$ and $\left(\mathrm{C} 3 \mathrm{H} . \mathrm{Bphs}^{\mathrm{SJL}} \times \mathrm{HRH} 1 \mathrm{KO}\right) \mathrm{F}_{1}$ harbor the Hrh1 $1^{\mathrm{s} / / \mathrm{HRH} 1^{\mathrm{s} /}}$ 
allele while $(\mathrm{C} 3 \mathrm{H} \times \mathrm{HRH} 1 \mathrm{KO}) \mathrm{F}_{1},(\mathrm{CBA} \times \mathrm{HRH} 1 \mathrm{KO}) \mathrm{F}_{1},(\mathrm{MRL} \times \mathrm{HRH} 1 \mathrm{KO}) \mathrm{F}_{1}$ and $(\mathrm{AKR}$

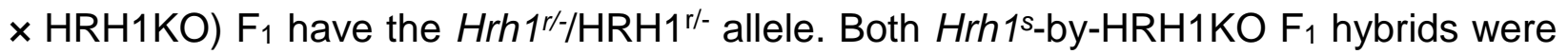
Bphs $^{\text {s }}$, whereas the Hrh1r-by-HRH1KO F 1 hybrids were Bphs' (Table 3), in agreement

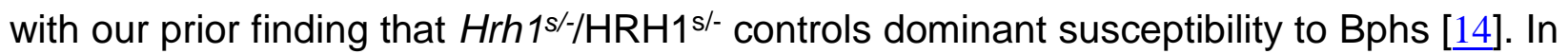
contrast, (MOLF $\times$ HRH1KO) $F_{1}$ and $(P W K \times H R H 1 K O) F_{1}$ hybrids, that harbor the Hrh1 ${ }^{r /-}$ $/ H R H 1^{r /-}$ allele, were Bphs ${ }^{s}$. This data supports the existence of one or more dominant loci in MOLF and PWK capable of complementing Bphs ${ }^{r}$ in $H r h 1^{r /-/ H R H} 1^{r /-}$ mice.

\section{A functional linkage disequilibrium (LD) domain on Chr6 encodes multiple}

loci controlling HA-shock. Given the evidence from inbred strains of mice indicating that a quarter or more of the mammalian genome consists of chromosomal regions containing clusters of functionally related genes, i.e., functional linkage disequilibrium (LD) domains [32, 33], we hypothesized that the dominant locus complementing $H r h 1^{r} / H R H 1^{r}$ may reside within such a LD domain. Support for the existence of a functional LD domain controlling responsiveness to HA is supported by our recent finding that Histh1-4, four QTL on Chr6:45.9-127.9 Mb controlling age- and inflammationdependent susceptibility to HA-shock in SJL/J, FVB/NJ, NU/J, and SWR/J mice, are in strong LD with Bphs/Hrh1 (Chr6:114,397,936-114,483,296 bp) [푸, 35].

To test this, we generated $114($ MOLF $\times$ HRH1KO) $\times$ HRH1KO backcross $(B C)$ mice (Table 3), genotyped their Hrh1 alleles, and phenotyped them for Bphs. As expected, none of the 54 homozygous HRH1KO mice phenotyped as Bphss . Of the 114 BC mice studied, 54 (47\%) were Bphss, which is consistent with genetic control by a single locus. Furthermore, of the $60 \mathrm{HRH} 1^{\mathrm{MOLF}}\left(\mathrm{Hrh} 1^{r} / \mathrm{HRH} 1^{r}\right)$ mice, 54 were Bphs ${ }^{\mathrm{s}}$ and 6 
were Bphs ${ }^{r}$, indicating that the locus capable of complementing Bphs ${ }^{r}$ is in fact linked to Bphs/Hrh1. We have designated this locus Bphse for Bphs-enhancer.

To further test the hypothesis that Bphse is linked to Hrh1, we generated a cohort of Bphs-phenotyped $(\mathrm{AKR} \times \mathrm{PWK}) \times \mathrm{AKR} B \mathrm{BC1}$ mice and performed linkage analysis using informative markers across a $\sim 70 \mathrm{Mb}$ region encompassing Hrh1. Both AKR and PWK mice carry the $H r h 1^{r} / \mathrm{HRH}^{r}$ allele; however, unlike AKR mice, which are Bphs ${ }^{r}$, PWK mice are Bphs ${ }^{\text {s }}$ (Table 2). Overall, 83 of $168(49 \%)(A K R \times P W K) \times A K R$ BC1 mice were Bphs ${ }^{s}$ (Table 4). This is in agreement with the segregation of Bphse in (MOLF $\times$ $\mathrm{HRH} 1 \mathrm{KO}) \times \mathrm{HRH} 1 \mathrm{KO} B C 1$ mice and provides further evidence that Bphse is in LD with Bphs/Hrh1. Marker loci from rs36385580 thru D6MiT135 (Chr6: 59.3-128.8 Mb) exhibited significant linkage to Bphs $^{s}$ with maximal linkage across the interval bounded by D6MiT102 (Chr6:93,463,949-93,464,093 bp) and rs31698248 (Chr6:120,207,213 bp) encompassing Hrh1 (Chr6:114,397,936-114,483,296 bp).

We next confirmed the existence and physical location of Bphse by congenic mapping. Marker-assisted selection was used to introgress the Bphse ${ }^{M O L F}$ and Bphse ${ }^{P W K}$ intervals onto the Bphs ${ }^{r} \mathrm{C} 3 \mathrm{H}$ and AKR backgrounds, respectively. Starting at N5 through N10, heterozygous and homozygous BC mice were phenotyped for Bphs (Figure 1). Compared to $\mathrm{C} 3 \mathrm{H}\left(\mathrm{C} 3 \mathrm{H}\right.$ and $\mathrm{C} 3 \mathrm{H}$. Bphse $\left.^{\mathrm{C} 3 H / C 3 H}\right)$ and AKR (AKR and AKR.Bphse ${ }^{A K R / A K R}$ ) mice, both C3H.Bphse ${ }^{C 3 H / M O L F}$ and AKR.Bphse ${ }^{A K R / P W K}$ mice were Bphs ${ }^{s}$. Overall, Bphse ${ }^{C 3 H / M O L F}$ and Bphse ${ }^{A K R / P W K}$ mice were significantly more susceptible to Bphs than Bphse ${ }^{C 3 H / C 3 H}$ and Bphse ${ }^{A K R / A K R}$ mice $\left(\mathrm{X}^{2}=60.63, \mathrm{df}=1, p<0.0001\right)$. The physical mapping results confirm the linkage of Bphse to Bphs/Hrh1 and Histh1-4 (Chr6:45.9-127.9 Mb) [프, 35], and importantly provide strong support for the existence of a functional LD domain 
on Chr6 encoding multiple loci controlling susceptibility to HA-shock following exposure to environmental factors and infectious agents, including influenza $A$ [35].

Identification of candidate genes for Bphse. Given that many laboratory and few wild-derived inbred strains have undergone deep sequencing (30-60x genome coverage) with publicly available variant datasets in Mouse Phenome Database (MPD;

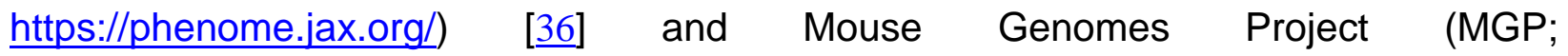
https://www.sanger.ac.uk/data/mouse-genomes-project/) [37], we retrieved all coding and non-coding single nucleotide polymorphism (SNP) data available across the Bphse congenic interval (Chr6:59.3-128.8 Mb) among our seventeen Bphs phenotyped Hrh1r/HRH1 $1^{r}$ mouse strains (Table 2). As expected, this dataset lacked SNP coverage for several of the wild-derived inbred strains (>98\% SNP missing compared with C57BL/6J) that were phenotyped for Bphs in this study. To complement our dataset, we utilized Chr6 region capture sequencing (see Materials and Methods) to sequence and identify SNPs within the Bphse interval, and integrated these SNPs with the publicly available dataset. This approach yielded a total of 1,303,072 SNPs among which 13,257 SNPs had 100\% coverage (no missing genotypes) across all seventeen strains.

To identify variants that segregate with $\mathrm{Bphs}^{\mathrm{s}}$ among $\mathrm{Hrh} 1^{r} / \mathrm{HRH}{ }^{\mathrm{r}}$ strains, we used efficient mixed-model association (EMMA) [38] and both the larger dataset of 1,303,072 SNPs as well as the smaller dataset of 13,257 SNP with the anticipation that having complete genotypes would increase the power to detect segregating variants. However, both datasets yielded no significant or suggestive associations (data not shown) which led us to speculate that perhaps the number of mouse strains available for genetic association analysis may be a limiting factor. To test this, we asked if we could identify 
genetic variants that segregate with Bphs ${ }^{s}$ independent of $H r h 1 / \mathrm{HRH} 1$ haplotype with the rationale that this approach will identify Bphs/Hrh1 (positive control) as well as polymorphic gene candidates for Bphse. Moreover, Bphse expressivity requires Hrh1/HRH1. This method greatly enhanced the number of mouse strains for genetic association analysis, as numerous mouse strains have been phenotyped for Bphs over the years by us and others $[\underline{15}, \underline{17}, \underline{19}, \underline{39}, \underline{40]}$.

To accomplish this, we generated SNP datasets as before but across a larger panel of 50 inbred mouse strains $\left(H r h 1^{r} / \mathrm{HRH}^{r}\right.$ and $\left.H r h 1^{\mathrm{s}} / \mathrm{HRH} 1^{\mathrm{s}}\right)$ (Supplementary Table 1). Using this approach, we identified 3 SNPs in Atg7 as significant with a stringent cut-off $(p<3.81 E-06)$ and another 163 SNPs in 27 genes with a moderate cut-off $(p<5.00 E-02)$ that were associated with Bphs ${ }^{\text {s }}$ (Figure 2A and Supplementary Table 2). There was no difference in predicted candidate genes using either the smaller dataset $(13,257$ SNPs) or the larger dataset $(1,303,072$ SNPs). It is important to reiterate that this approach of combining both $H r h 1^{r} / \mathrm{HRH}^{r}$ and $H r h 1^{s} / \mathrm{HRH}^{\mathrm{s}}$ mouse strains may predict candidates for both Bphs and Bphse. Thus, Hrh1, which is a positive control for this analysis and whose polymorphism has been earlier shown to underlie Bphs among laboratory inbred strains [15], was among the candidate genes supporting the predictions from this analysis. We also know that the DNA sequence of the entire Hrh1 gene ( 85 kb) among several $H r h 1^{r} / \mathrm{HRH}^{\mathrm{r}}$ strains harbor no additional segregating nonsynonymous structural variants (data not shown) between Bphs $^{s}$ and Bphs $^{r}$ mice, excluding involvement of any previously unidentified $H r h 1 / \mathrm{HRH} 1$ structural alleles underlying Bphse. 
The Bphse predicted candidate genes cluster in a narrow interval of $\sim 5.5 \mathrm{Mb}$ on Chr6:111.0-116.4 Mb (Figure 2A). Given that our larger dataset (1,303,072 SNPs) includes several thousand SNPs in this shortlisted region of $\sim 5.5 \mathrm{Mb}$, we asked if we could impute the missing SNPs and do a high-dimensional association run. To impute missing SNPS, we utilized the Viterbi algorithm implemented in HaploQA [41, 42] and generated a complete dataset of 78,334 SNPs across Chr6:111.0-116.4 Mb. Using this, we ran a high-resolution genetic association analysis and found Atg7, Tmcc1, II17re, Vgll4, and several others as top hits for Bphse $(p<5.00 E-02)$ (Figure 2B-C; Supplementary Table 3).

As a complementary approach to identify positional candidates for Bphse, we employed machine-learning computation, using functional genomic networks [43] to identify network-based signatures of biological association. To this end, we used prior knowledge to generate a list of Bphs-associated biological processes and retrieved gene sets functionally associated with each term. The terms and their justifications are as follows:

- Type I hypersensitivity/anaphylaxis: The death response following systemic HA challenge exhibits symptoms of type I hypersensitivity/anaphylaxis including respiratory distress, vasodilation, and anaphylactic shock [44].

- Cardiac: There is evidence suggesting that anaphylactic shock in mice is caused by decreased cardiac output, rather than systemic vasodilation [45].

- Histamine: Bphs is induced by a systemic HA challenge [15].

- G-protein coupled receptor: HRH1 signaling is required for the Bphs phenotype, and all HA receptors belong to the family of G-protein coupled receptors [46]. 
- Pertussis toxin: Bphs is induced in mouse strains by PTX [12].

- Vascular permeability (VP): Hypersensitivity to HA exhibits vascular leakage in skin and muscles $[\underline{34}, \underline{35}]$.

- Endoplasmic reticulum (ER)/endoplasmic membrane protein complex (EMC), and endoplasmic reticulum-associated degradation (ERAD): The two $\mathrm{HRH} 1$ alleles exhibit differential protein trafficking and cell surface expression with the $H R H 1^{r}$ allele primarily retained in the ER [21]. The EMC and ERAD are intimately involved in regulating GPCR translocation to the plasma membrane $[\underline{47}, \underline{48}]$.

Each of the seven gene sets define a putative Bphs-related process that forms a distinct subnetwork of the full functional genomic network. Using this approach, we identified several hundred genes within the Bphse congenic locus that are functionally associated with each biological process, and thus could be gene candidates (Supplementary Table 4).

Genes that are predicted to be highly functionally related to a trait may not have functional variant alleles segregating in the study population, and may therefore be unlikely to drive the observed strain differences in $\mathrm{Bphs}^{\mathrm{s}}$. Using the list of polymorphic genes identified through high-resolution genetic association testing (Figure 2), we normalized and plotted the respective genetic association score $\left(-\log _{10} p_{E M M A}\right)$ with functional enrichment $\left(-\log _{10} F P R\right)$ to focus on genes that overlap both approaches (Figure 3A). The final ranking was calculated by defining a final gene score $\left(S_{c g}\right)$ for each gene, which is the sum of the (normalized) $-\log _{10}(F P R)$ and the $-\log _{10}\left(p_{E M M A}\right)$ (Figure 3B). The top ten candidates for Bphse as ranked using $S_{c g}$ are: Atg7, Plxnd1, Tmcc1, Mkrn2, II17re, Pparg, Lhfpl4, Vgll4, Rho and Syn2. It is interesting to note that the predicted 
candidates for Bphse not only overlap Bphs/Hrh1 but two additional QTLs, Histh3 (Chr6:99.5-112.3 Mb) and Histh4 (Chr6:112.3-127.9 Mb), controlling age- and inflammation-dependent susceptibility to HA shock in SJL/J, FVB/NJ, NU/J, and SWR/J mice [34, 35]. Importantly, our findings support the existence of a smaller functional LD domain on Chr6:111.0-116.4 Mb ( 5.5 Mb interval) that controls susceptibility to HAshock elicited by both PTX dependent and independent mechanisms (Supplementary Figure 2). 


\section{Discussion}

B. pertussis and PTX elicit in vivo a variety of immunologic and inflammatory responses, including systemic vascular hypersensitivity to serotonin (Bpss), bradykinin (Bpbs), and HA (Bphs) [17]. Utilizing classical laboratory derived inbred strains of mice, we and others showed that susceptibility to Bpss, Bpbs, and Bphs are under unique genetic control with Bpss ${ }^{\mathrm{s}}$ and $\mathrm{Bpbs}^{\mathrm{s}}$ being recessive traits $[\underline{17}, \underline{19]}$ and Bphs controlled by the single autosomal dominant locus Bphs $[\underline{14}, \underline{49}]$, which we subsequently identified

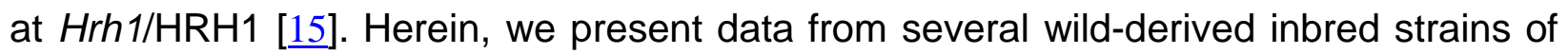
mice that harbor the $H r h 1^{r} / \mathrm{HRH} 1^{r}$ allele which nevertheless phenotype as Bphss. This is suggestive of the existence of an evolutionarily selected modifying locus that can complement $H r h 1^{r} / \mathrm{HRH}^{r}$ and is supported by the unique phylogenetic distribution of such strains (Supplementary Figure 1).

Our results with the genetic cross $[(\mathrm{MOLF} \times \mathrm{C} 3 \mathrm{H}) \times \mathrm{C} 3 \mathrm{H} \mathrm{BC}$ mice] confirm the existence of a dominant modifying locus (Bphse) capable of complementing Bphs ${ }^{\mathrm{s}}$ in mice with an $H r h 1^{r} / \mathrm{HRH}^{r}$ allele. We also found that Bphse requires $\mathrm{Hrh} 1 / \mathrm{HRH} 1$, as no $\mathrm{BC} 1$ mice that genotype as $\mathrm{Hrh}^{-1-}$ were $\mathrm{Bphs}^{\mathrm{s}}$ (Table 3). Among BC1 mice that genotype as Hrh1 $1^{\text {MOLF/- }}, 10 \%$ of mice phenotyped as Bphs ${ }^{r}$ indicating that Bphse is in LD with Bphs/Hrh1. Linkage scans using microsatellite markers validated significant linkages to Chr6, with maximal significance around Bphs/Hrh1 (Table 4). In addition, we mapped the physical location of this locus by making congenic mice $\left(\mathrm{C} 3 \mathrm{H} . B p h s e^{\mathrm{MOLF}+\text { - }}\right.$ and AKR.Bphse $e^{\mathrm{PWK}+-}$ ) that captured the Bphse locus on Chr6 (59.3-128.8 Mb, Figure 1) and replicated the phenotype. To our knowledge, this is the first study assessing Bphs ${ }^{\mathrm{s}}$ in 
multiple wild-derived inbred strains of mice, and clearly establish their utility in identifying novel genetic mechanisms controlling HA-shock.

Aside from genetics, several factors could influence HA sensitivity after exposure to $B$. pertussis and PTX including age, sex, and route of sensitization/challenge [12]. In our phenotyping experiments, we used 8-12-week-old mice of each sex and did not find any sex differences. This agrees with earlier studies that found no sex differences in Bphs $^{\text {[ }}$ 47]. We also tested the route of administration of PTX and HA challenge using the intraperitoneal and intravenous routes and found no difference (data not shown). We have not tested the effect of age on Bphss amongst the various strains; however, work from Munoz and others have reported a significant effect of age [12]. It is possible that some of the strains that are Bphs ${ }^{r}$ will exhibit Hisths as they age or following treatment with complete Freund's adjuvant [포 $\underline{35}]$.

The region encoding Bphse is very large and contains hundreds of genes (Chr6:59.3-128.8 Mb). Until recently, interval specific recombinant congenic mapping was the gold standard to delimit large QTLs associated with a phenotype [48]. Of the thousands of QTLs for various phenotypes and diseases, only a small fraction of genes have been identified through sub-congenic mapping, phenotyping and sequencing. The identification of candidate genes from large genomic regions has been revolutionized with the advent of advanced sequencing technologies and genome wide association studies (GWAS) [50]. For example, the Sanger Institute has sequenced 16 inbred laboratory and wild-derived mouse genomes and The Jackson Laboratory, in conjunction with the University of North Carolina, has genotyped several hundred laboratory inbred strains using the Mouse Diversity Array, that altogether provides an almost complete picture of 
genetic variation among the various strains. Our approach, however, is different from other mouse GWAS studies that have been done to identify candidate loci for several diseases [51]. Instead of running a full genome scan across a large panel of Bphs phenotyped strains, we tested association of susceptibility exclusively across the Bphse locus (Chr6:59.3-128.8 Mb). This allowed us to use the information gathered from the genetic cross and congenic mapping and delimit the region to be screened for association.

Our first screen using genotype and phenotype data across seventeen $H r h 1^{r} / \mathrm{HRH}^{\mathrm{r}}$ mouse strains did not yield any significant hits, due to limitation in the number of strains used. To overcome this problem, we excluded Hrh1 genotype as a covariate. Given that several dozen laboratory inbred mouse strains (Group 2, 3 and 4) have been phenotyped for Bphs $[\underline{15}, \underline{17}, \underline{19}, \underline{39}, \underline{40}]$ and also to circumvent the sample size limitation in genetic association testing, we searched for genetic polymorphism across the 50 mouse strains that could explain overall Bphs ${ }^{s}$. Hrh1, which is our positive control and associated with Bphs ${ }^{s}$ among classical laboratory inbred strains [15], was identified as a significant hit supporting the validity of this approach. The use of imputed datasets across 50 phenotyped strains further refined the SNPs associated with Bphs ${ }^{\text {s }}$ (Figure 2).

Recently, a quantitative trait gene prediction tool has been described that utilizes functional genomics information (gene co-expression, protein-protein binding data, ontology annotation and other functional data) to rank candidate genes within large QTLs associated with a respective phenotype [43]. This methodology uses biological prior knowledge to predict candidate genes that could influence multiple pathways affecting the phenotype. We utilized this approach for Bphs, which is known to involve cardiac, 
vascular, and anaphylactic mechanisms [44, 45]. Because the selection of phenotypeassociated gene sets is critical for final gene predictions, several terms were used to incorporate sub-phenotypes equivalent to Bphs in the expectation that use of multiple terms would help identify candidate loci for Bphse. Integration of functional predictions with genetic association ( $S_{c g}$, Figure 3) allowed us to focus on only those candidates that reached significance in both approaches.

Given that there is differential cell surface expression of $\mathrm{HRH} 1$ depending on the haplotype, it is tempting to speculate that Bphse may aid in the folding, trafficking and/or surface delivery of $\mathrm{HRH} 1[\underline{51}, \underline{52}]$. In this regard, Tmcc1 (transmembrane and coiled-coil domain family 1) and Atg7 (autophagy related 7) are promising candidates because of their known roles in protein trafficking in cells. Tmcc1 is an ER membrane protein that regulates endosome fission and subsequent cargo trafficking to the Golgi [ㅍ]. Similarly, Atg7 is implicated in translocation of cystic fibrosis transmembrane conductance regulator (CFTR) to the surface [54]. CFTR is a multi-pass membrane GPCRs like HRH1 in that both protein classes pass several time through the cell membrane, thus it is tempting to suggest Atg7 may act in a similar fashion to translocate HRH1 to the surface thereby resulting in the Bphs ${ }^{s}$ phenotype. It will be interesting to test the surface expression of $\mathrm{HRH} 1$ among the Hrh1 $1^{\mathrm{r}} / \mathrm{HRH} 1^{r}$ strains that phenotype as Bphs ${ }^{\mathrm{s}}$ (Table 2). Results using bone marrow chimeras suggest that Bphs ${ }^{s}$ is a function of the non-hematopoietic compartments [48], so several cell types (endothelial, epithelial, stromal cells) are potential candidates for this cell surface expression analysis.

In addition to Tmcc1 and Atg7, several other predicted candidates for Bphse may have potential relevance to phenotypes associated with Bphs including anaphylaxis and 
mast cell degranulation, and cardiovascular effects (Supplementary Table 4). Proliferator-activated receptor-gamma (Pparg) encodes a nuclear receptor protein belonging to the peroxisome proliferator-activated receptor (Ppar) family. Activation of PPARy suppresses mast cell maturation and is involved in allergic disease [도, $\underline{56}$. Because mast cells are major drivers of pathological events in anaphylaxis [57], Pparg may be highly relevant to Bphs. In addition, increased PPARY expression is associated with cardiac dysfunction [57]. It will be interesting to quantify the mRNA expression of some of these candidates between $\mathrm{Bphs}^{\mathrm{s}}$ and Bphs ${ }^{\mathrm{r}}$ strains and investigate whether they interact with HRH1.

Importantly, the fact that Bphse resides within a smaller functional LD that includes Histh3 and Histh4 (Supplementary Figure 2) is of potential clinical significance. Histh is an autosomal recessive genetic locus that controls susceptibility to $B$. pertussis and PTXindependent, age- and inflammation-dependent HA-shock in SJL/J mice [34, 35]. Four sub-QTLs (Histh1-4) define Histh, each contributing 17\%, 19\%, 14\%, and 10\%, respectively, to the overall penetrance of Histh. Importantly, Histh is syntenic to the genomic locus most strongly associated with systemic capillary leak syndrome (SCLS) in humans (3p25.3). SCLS or Clarkson disease is a rare disease of unknown etiology characterized by recurrent episodes of vascular leakage of proteins and fluids into peripheral tissues, resulting in whole-body edema and hypotensive shock. Additionally,

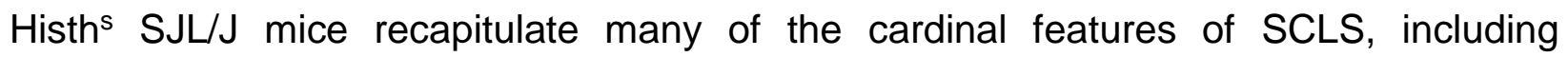
susceptibility to HA- and infection-triggered vascular leak and the clinical diagnostic triad of hypotension, elevated hematocrit, and hypoalbuminemia and as such makes them a natural occurring animal model for SCLS [34, 35]. Clearly, detailed genetic analysis and 
identification of the causative genes underlying Bphse, Histh3, and Histh4 may reveal orthologous candidate genes and or pathways that contribute not only to SCLS, but also to normal and dysregulated mechanisms underling vascular barrier function more generally. 


\section{Materials AND Methods}

Animals. AKR/J (AKR), BPL/1J, C3H/HeJ (C3H), C3H/HeN, CAST/EiJ, C57BL/6J (B6), CBA/J (CBA), CBA/N, CZECHII/EiJ, I/LnJ, JF1/MsJ, MOLD/EiJ, MOLF/EiJ (MOLF), MRL/MpJ (MRL), MSM/Ms, PWD/PhJ, PWK/PhJ (PWK), RF/J, SF/CamEiJ, and SKIVE/EiJ were purchased from the Jackson Laboratory (Bar Harbor, Maine). B6.129P$H_{r h 1} 1^{\text {tm1Wat }}(\mathrm{HRH} 1 \mathrm{KO})$ [31], C3H.Bphs ${ }^{\mathrm{SJL}}\left(\mathrm{C} 3 \mathrm{H} . B p h s^{\mathrm{s}}\right)$ [15], $(\mathrm{B} 6 \times \mathrm{HRH} 1 \mathrm{KO}) \mathrm{F}_{1},(\mathrm{C} 3 \mathrm{H} \times$ $\mathrm{HRH} 1 K O) \mathrm{F}_{1},(\mathrm{CBA} \times \mathrm{HRH} 1 K O) \mathrm{F}_{1},(\mathrm{AKR} \times \mathrm{HRH} 1 K O) \mathrm{F}_{1},(M R L \times H R H 1 K O) \mathrm{F}_{1},(A K R \times$ $P W K) F_{1},(C 3 H \times M O L F) F_{1},(M O L F \times H R H 1 K O) \times H R H 1 K O,(A K R \times P W K) \times A K R,(C 3 H$ $\times$ MOLF) $\times \mathrm{C} 3 \mathrm{H}, \mathrm{C} 3 \mathrm{H} \cdot B p h s^{\mathrm{MOLF}+/}, \mathrm{C} 3 \mathrm{H} \cdot B p h s e^{\mathrm{C} 3 \mathrm{H}}, \mathrm{AKR} \cdot$ Bphse $\mathrm{PWK}^{\mathrm{P}+-}$ and AKR.Bphse $\mathrm{AKR}$ were generated and maintained under specific pathogen free conditions in the vivarium of the Given Medical Building at the University of Vermont according to National Institutes of Health guidelines. All animal studies were approved by the Institutional Animal Care and Use Committee of the University of Vermont.

Bphs Phenotyping. Bphs phenotyping was carried out as previously described [15]. Briefly, mice were injected with purified PTX (List Biological Laboratories, Inc.) in $0.025 \mathrm{M}$ Tris buffer containing $0.5 \mathrm{M} \mathrm{NaCl}$ and $0.017 \%$ Triton $\mathrm{X}-100, \mathrm{pH}$ 7.6. Control animals received carrier. Three days later, mice were challenged by injection with histamine (milligrams per kilogram of body weight [dry weight], free base) suspended in phosphate-buffered saline (PBS). Deaths were recorded at 30 min post-challenge. The results are expressed as the number of animals dead over the number of animals studied.

DNA sequencing of third intracellular loop of Hrh1. DNA for 91 inbred laboratory and wild-derived strains of mice was purchased from the Mouse DNA resource at The Jackson Laboratory (www.jax.org) and used in an Hrh1 specific PCR reaction 
using the following primer sets: forward-740F, 5'-TGCCAAGAAACCTGGGAAAG-3', and reverse-1250R, 5'-CAACTGCTTGGCTGCCTTC-3' that amplify the third intracellular loop of Hrh1. Thermocycling was carried out for a $15 \mu \mathrm{l}$ reaction mix with $2 \mathrm{mM} \mathrm{MgCl} 2,200$ $\mu \mathrm{M}$ dNTPs, $0.2 \mu \mathrm{M}$ primers, 1 unit of Taq polymerase and $\sim 50 \mathrm{ng}$ of genomic DNA together with an initial $2-\min 97^{\circ} \mathrm{C}$ denaturation followed by 35 cycles of $97^{\circ} \mathrm{C}$ for $30 \mathrm{sec}$, $58^{\circ} \mathrm{C}$ for $30 \mathrm{sec}$ and $72^{\circ} \mathrm{C}$ for $30 \mathrm{sec}$. The final extension was for 5 min at $72^{\circ} \mathrm{C} . \mathrm{Hrh} 1$ amplicons from each mouse strain were gel purified (Qiagen Cat\# 28115) and DNA sequencing reactions were performed with the BigDye terminator cycle sequencing kit (Applied Biosystems, Foster City, CA) using 740F or $1250 \mathrm{~F}$ reverse primers. The reaction products were resolved on an ABI Prism 3100 DNA sequencer at the DNA analysis facility at the University of Vermont. DNA sequencing data were assembled and analyzed using MultiAlign [58]. Each potential nucleotide sequence polymorphism was confirmed by comparing it with the actual chromatographic profiles using Chromas v2.6.5 (https://technelysium.com.au/wp/)

DNA isolation and genotyping. DNA was isolated from mouse tail clippings as previously described [13]. Briefly, individual tail clippings were incubated with cell lysis buffer (125 mg/ml proteinase K, 100 mM NaCl, 10 mM Tris-HCl (pH 8.3), 10 mM EDTA, $100 \mathrm{mM} \mathrm{KCl}, 0.50 \% \mathrm{SDS}, 300 \mathrm{ml})$ overnight at $55^{\circ} \mathrm{C}$. The next day, $6 \mathrm{M} \mathrm{NaCl}(150 \mathrm{ml})$ was added followed by centrifugation for $10 \mathrm{~min}$ at $4^{\circ} \mathrm{C}$. The supernatant layer was transferred to a fresh tube containing $300 \mu$ isopropanol. After centrifuging for 2 min, the supernatant was discarded, and the pellet washed with $70 \%$ ethanol. After a final 2 min centrifugation, the supernatant was discarded, and DNA was air dried and resuspended 
in TE. Genotyping was performed using microsatellite, sequence specific, and Hrh1 primers (Supplemental Table 5).

Microsatellite primers: Polymorphic microsatellites were selected to have a minimum polymorphism of 8 bp for optimal identification by agarose gel electrophoresis. Briefly, primers were synthesized by IDT-DNA (Coralville, IA) and diluted to a concentration of $10 \mathrm{uM}$. PCR amplification was performed using Promega GoTaq according standard conditions and amplicons were subjected to $2 \%$ agarose gel electrophoresis and visualized by ethidium bromide and UV light.

Sequence-specific primers: Genotyping was performed using sequence specific primers that differ only at the 3' nucleotide corresponding to each allele of the identified SNP [59]. Each primer set was designed using Primer3 to have a Tmelt of $58-60^{\circ} \mathrm{C}$ and synthesized by IDT-DNA (Coralville, IA) and used at a concentration of $100 \mathrm{uM}$. PCR reactions were subjected to cycling conditions as described and if found to be necessary, the annealing temperature at each stage was adjusted to accommodate the optimal Tmelt. Amplicons were electrophoresed with 10 ul Orange G loading buffer on a 1.5\% agarose gel stained with ethidium bromide and visualized by UV light. The presence of a SNP specific allele was scored by observing an amplicon of the expected size in either reaction.

HRH1KO mice genotyping: Wild-type and Hrh1-- alleles were genotyped as previously described [15]. Approximately 60 ng of DNA was amplified (GeneAmp PCR system 9700, Applied Biosystems, Foster City, CA). The DNA was amplified by incubation at $94^{\circ} \mathrm{C}$ for 3 min followed by 35 cycles of $94^{\circ} \mathrm{C}$ for $30 \mathrm{sec}, 62^{\circ} \mathrm{C}$ for $30 \mathrm{sec}$, and $72^{\circ} \mathrm{C}$ for $30 \mathrm{sec}$. At the end of the 35 cycles, the DNA was incubated at $72^{\circ} \mathrm{C}$ for 10 min and $4^{\circ} \mathrm{C}$ 
for 10 min. The amplified DNA was analyzed by gel electrophoresis in a $1.5 \%$ agarose gel. The DNA was visualized by staining with ethidium bromide.

Linkage analysis and generation of Bphse congenic. Segregation of genotype frequency differences with susceptibility and resistance to Bphs in (MOLF $\times \mathrm{HRH} 1 \mathrm{KO}) \times$ $\mathrm{HRH} 1 \mathrm{KO}$ and $(\mathrm{AKR} \times \mathrm{PWK}) \times \mathrm{AKR}$ mice were tested by $\mathrm{X}^{2}$ in $2 \times 2$ contingency tables. C3H.Bphse $\mathrm{MOLF}^{+/-}, \mathrm{C} 3 \mathrm{H} . B p h s e^{\mathrm{C} 3 \mathrm{H}}, \mathrm{AKR} . B p h s e^{\mathrm{PWK}+-}$ and AKR.Bphse ${ }^{\mathrm{AKR}}$ congenic mice were derived by marker assisted selection. $(A K R \times P W K) \times A K R$ and $(C 3 H \times M O L F) \times$ $\mathrm{C} 3 \mathrm{H}$ mice that were heterozygous across the Bphse interval at $\mathrm{N} 2$ and at each successive BC generation were selected for continued breeding. Bphse congenic mice were maintained as heterozygotes.

\section{Low-resolution interval-specific targeted genetic association testing.} Genotype data (SNPs in both coding and non-coding) of 50 mouse strains (Supplementary Table 1) that were phenotyped for Bphs either by us or described in the literature $[\underline{12}, \underline{15}, \underline{17}, \underline{19}, \underline{40]}$, was retrieved from public databases at the Sanger Institute (https://www.sanger.ac.uk/science/data/mouse-genomes-project) and The Jackson Laboratory (https://phenome.jax.org/). The lack of representation of several inbred strains especially wild-derived strains in these databases were compensated by genotyping using chromosome region capture sequencing [59] as follows:

DNA Fragmentation: For chromosome region capture sequencing, $3 \mu \mathrm{g}$ of genomic DNA from BPN/3J, BPL/1J, CASA/RkJ, CAST/EiJ, CBA/J, C3H/HeN, CZECHII/EiJ, JF1/Ms, MOLD/EiJ, MOLF/EiJ, MRL/MpJ, MSM/Ms, NU/J, PWD/PhJ, SF/CamEiJ and SKIVE/EiJ mice was sheared into fragments of approximately $200 \mathrm{bp}$ with the Covaris E220 system (Covaris, USA). The sheared DNA fragments were then 
purified for each of the 16 mice strains using AMPure XP Beads (Beckman, USA), following the instructions of the reagent supplier.

DNA Library Construction: DNA libraries of the purified fragments were constructed with SureSelect Library Prep Kit (Agilent, USA). In brief, DNA end-repair was performed for the fragments from each muse strain using 10× End Repair Buffer, dNTP Mix, T4 DNA Polymerase, Klenow DNA Polymerase, and T4 Polynucleotide Kinase. After incubation of the mixture at $20^{\circ} \mathrm{C}$ for $30 \mathrm{~min}$, Addition of nucleotide $\mathrm{A}$ at the $3^{\prime}$ end of the sequence was performed using 10×Klenow Polymerase Buffer, dATP and Exo(-) Klenow, at $37^{\circ} \mathrm{C}$ for $30 \mathrm{~min}$. Ligation reaction was then conducted using T4 DNA Ligase Buffer, SureSelect Adaptor Oligo Mix, and T4 DNA Ligase at $20^{\circ} \mathrm{C}$ for $15 \mathrm{~min}$. The adaptorligated library was finally amplified through using SureSelect Primer, SureSelect ILM Indexing Pre Capture PCR Reverse Primer, 5X Herculase II Rxn Buffer, 100 mM dNTP Mix, and Herculase II Fusion DNA Polymerase. The condition for the amplification was fixed as: initial denaturation at $98^{\circ} \mathrm{C}$ for $2 \mathrm{~min}$, followed by 30 cycles of reactions at $98^{\circ} \mathrm{C}$ for $30 \mathrm{Sec}, 65{ }^{\circ} \mathrm{C}$ annealing for $30 \mathrm{Sec}, 72{ }^{\circ} \mathrm{C}$ extension $30 \mathrm{Sec}$. Purification of the amplified products was performed with 1.8X Agencourt AMPure XP beads for each of the libraries. The average insert length for the adaptor-ligated libraries ranged between 225 $\sim 275 b p s$.

Hybridization capture: The libraries were subjected for the hybridization capture using the SureSelect Target Enrichment Kit (Agilent, USA), following the instruction of the reagent supplier. The prepared library were then reacted with SureSelect Block Mix at $95^{\circ} \mathrm{C}$ for $5 \mathrm{~min}$, followed by holding at $65^{\circ} \mathrm{C}$, and the Hybridization Buffer plus capture library mix were added and maintained at $65^{\circ} \mathrm{C}$ for $24 \mathrm{hrs}$. Finally, Dynabeads 
M-280 streptavidin (Life, USA) was used for the enrichment of the Captured DNA libraries $[60, \underline{61]}$.

Index amplification: For each enriched captured DNA library, the index amplification was performed with 5X Herculase II Rxn Buffer, 100 mM dNTP Mix, SureSelect ILM Indexing Post Capture Forward PCR Primer, and Herculase II Fusion DNA Polymerase. The reaction procedure was: $98^{\circ} \mathrm{C}$ Pre-denaturation for 2 Min, $98^{\circ} \mathrm{C}$ denaturation for $30 \mathrm{Sec}, 57^{\circ} \mathrm{C}$ annealing for $30 \mathrm{Sec}, 72{ }^{\circ} \mathrm{C}$ extension for $30 \mathrm{Sec}$, amplification for 12 rounds, followed by purification using 1.8 times the volume of AMPure XP Beads. DNA libraries of 250-350 bp range were obtained for the subsequent sequencing [60].

DNA Sequencing: A 10 ng library was used for cluster generation in cBot with the TruSeq PE Cluster Kit (illumina, USA) followed by bidirectional sequencing in an Illumina Hiseq 2500 to obtain the data of $2 \times 150 \mathrm{bp}$.

Data processing and SNP calls: To ensure the quality of subsequent information analysis, the original sequence was filtered with the software SolexaQA to get high quality Clean Reads [62]. Efficient high-quality sequencing data was mapped to the reference genome mm10 by the BWA software [63], samtools [64] was used for sorting, picard tools was used for duplicate read removal, and GATK was used for realignment around indels and base quality score recalibration [65]. Finally, GATK HaplotypeCaller was used for SNP detection.

All SNP datasets (MPD, Chromosome region capture sequencing) were collated to yield a total of 1,303,072 SNPs across the Bphse interval (Chr6: 59-129 Mb), among which 13,257 SNPs had 100\% coverage (no missing genotypes) across all strains. 
To calculate associations between genetic polymorphisms and Bphs, we used efficient mixed-model association (EMMA) [38]. This method treats genetic relatedness as a random variable in a linear mixed model to account for population structure, thereby reducing false associations between SNPs and the measured trait. We used the likelihood ratio test function (emma.ML.LRT) to generate $p$-values. Significance was assessed with Bonferroni multiple correction testing. The -log transformed $p$-values were plotted using GraphPad Prism7 and genomic coordinates included for each SNP using the latest mouse genome build GRCm38.p5/mm10.

Genotype imputation methodology. A merged SNP dataset over the Chr6 region 111.0-116.4 Mb (GRCm38 / mm10 and dbSNP build 142) was constructed from the 11 SNP genotyping datasets available (see Supplementary Table 6) on the Mouse Phenome Database (MPD) [41, $\underline{42}, \underline{66-71]}$. This MPD-derived merged genotype dataset of 577 strains was then merged with the genotype data for 50 strains generated earlier for low resolution mapping (see "low resolution interval-specific targeted genetic association testing"). We leveraged the genotype data from over 577 strains to impute genotypes for missing SNP states across the region for the 50 strains of interest (see Supplementary Table 1). To impute genotypes on a target strain, we utilized the Viterbi algorithm implemented in HaploQA [ $\underline{41}, \underline{42}]$ where the input was a subset of strains most phylogenetically similar to the target strain. This imputation strategy resulted in a dataset of 78,334 SNPs in the genomic region of interest. Across all 50 strains, the median number of missing SNP genotypes after imputation was $2.45 \%$ with a maximum missing of only $5.4 \%$ for one of the strains. 
Trait-related gene sets. The positional candidate genes were ranked based on their predicted association with seven functional terms related to the Bphs phenotype: "Cardiac", "G-protein coupled receptor", "Histamine", "Pertussis toxin", "Type I hypersensitivity", "Vascular Permeability", and "ER/EMC/ERAD". Gene Weaver [72] was used to identify genes annotated with each term. Each term was entered the Gene Weaver homepage (https://geneweaver.org)and search restricted to human, rat, and mouse genes, and to curated lists only. Mouse homologs for each gene were retrieved using the batch query tool in MGI (http://www.informatics.jax.org/batch_data.shtml). In addition, using the Gene Expression Omnibus (GEO) and PubMed, additional gene expression data sets were retrieved for each phenotype term. Final gene lists consisted of the unique set of genes associated with each process term.

Functional enrichment and ranking of Bphs associated genes. We associated genes with Bphs-related functions as described in Tyler et al. [34]. Briefly, we used the connectivity weights in the Functional Network of Tissues in Mouse (FNTM) as features for training support vector machines [73]. Each feature consisted of the connection weights from a given gene to genes in the functional module. To improve classification and reduce over-generalization we clustered each functional gene set into modules, each less than 400 genes [43]. For each of these modules, we trained 100 SVMs to classify the module genes from a balanced set of randomly chosen genes from outside the module. We used 10-fold cross validation and a linear kernel. We also trained each SVM over a series of cost parameters identified by iteratively narrowing the cost parameter window to identify a series of eight cost parameters that maximized classification accuracy. We then used the training modules to score each positional candidate gene in the Bphse locus. 
To compare scores across multiple trained models, we converted SVM scores to false positive rates.

Combined gene score. To create the final ranked list of positional candidate genes, we combined the SNP association scores with the functional predictions derived from the SVMs. We scaled each of these scores by its maximum value across all positional candidates and summed them together to derive a combined gene score $\left(S_{c g}\right)$ that incorporated both functional predictions and genetic influence:

where the denominators of the two terms on the right-hand side are the maximum values of $-\log _{10}(p E M M A)$ and $-\log _{10}\left(F P R_{S V M}\right)$ over all positional candidates in Bphse, respectively, which normalizes the functional and positional scores to be comparable to each other. SNPs were assigned to the nearest gene within $1 \mathrm{Mb}$. If more than one SNP was assigned to a gene, we used the maximum negative $\log _{10} p$ value among all SNPs assigned to the gene. 


\section{ACKNOWLEDGEMENTS}

Anna Tyler and Mathew Mahoney are supported by a grant (R21 LM012615) from the National Library of Medicine of the United States National Institutes of Health (NIH). Abbas Raza, Dimitry Krementsov, Elizabeth Blankenhorn, and Cory Teuscher were supported by grants from the NIH and the National Multiple Sclerosis Society (NMSS). Dimitry Krementsov was supported by $\mathrm{NIH}$ grants from the National Institute of Neurological Disease and Stroke (R01 NS097596), National Institute of Allergy and Infectious Disease (R21 Al145306), and the NMSS (RR-1602-07780).

We would like to thank Keith Sheppard and Molly Bogue for their assistance with genomic imputation as well as the Mouse Phenome Database web resource (RRID:SCR_003212). We also are grateful for the assistance of Laura Cort in the genotyping of the backcross progeny. 


\section{REFERENCES}

1. Panula, P., et al., International Union of Basic and Clinical Pharmacology. XCVIII. Histamine Receptors. Pharmacol Rev, 2015. 67(3): p. 601-55.

2. Parsons, M.E. and C.R. Ganellin, Histamine and its receptors. Br J Pharmacol, 2006. 147 Suppl 1: p. S127-35.

3. Branco, A., et al., Role of Histamine in Modulating the Immune Response and Inflammation. Mediators Inflamm, 2018. 2018: p. 9524075.

4. Moya-Garcia, A.A., et al., Histamine, Metabolic Remodelling and Angiogenesis: A Systems Level Approach. Biomolecules, 2021. 11(3).

5. Peavy, R.D. and D.D. Metcalfe, Understanding the mechanisms of anaphylaxis. Curr Opin Allergy Clin Immunol, 2008. 8(4): p. 310-5.

6. Emanuel, M.B., Histamine and the antiallergic antihistamines: a history of their discoveries. Clin Exp Allergy, 1999. 29 Suppl 3: p. 1-11; discussion 12.

7. Lee, M.R., The history of ergot of rye (Claviceps purpurea) II: 1900-1940. J R Coll Physicians Edinb, 2009. 39(4): p. 365-9.

8. Lee, M.R., The history of ergot of rye (Claviceps purpurea) I: from antiquity to 1900. J R Coll Physicians Edinb, 2009. 39(2): p. 179-84.

9. Windaus, A. and W. Vogt, Synthese des Imidazolyl-äthylamins. Berichte der deutschen chemischen Gesellschaft, 1907. 40(3): p. 3691-3695.

10. Barger, G. and H.H. Dale, The presence in ergot and physiological activity of betaimidazolylethylamine. 1910.

11. Dale, H.H. and P.P. Laidlaw, The physiological action of $\beta$-iminazolylethylamine. The Journal of physiology, 1910. 41(5): p. 318-344.

12. Munoz, J. and R.K. Bergman, Histamine-sensitizing factors from microbial agents, with special reference to Bordetella pertussis. Bacteriol Rev, 1968. 32(2): p. 10326.

13. Parfentjev, I.A. and M.A. Goodline, Histamine shock in mice sensitized with Hemophilus pertussis vaccine. J Pharmacol Exp Ther, 1948. 92(4): p. 411-3.

14. Sudweeks, J.D., et al., Locus controlling Bordetella pertussis-induced histamine sensitization (Bphs), an autoimmune disease-susceptibility gene, maps distal to T- 
cell receptor beta-chain gene on mouse chromosome 6. Proc Natl Acad Sci U S A, 1993. 90(8): p. 3700-4.

15. Ma, R.Z., et al., Identification of Bphs, an autoimmune disease locus, as histamine receptor H1. Science, 2002. 297(5581): p. 620-3.

16. Iff, E.T. and N.M. Vaz, Mechanisms of anaphylaxis in the mouse. Similarity of shock induced by anaphylaxis and by mixtures of histamine and serotonin. Int Arch Allergy Appl Immunol, 1966. 30(4): p. 313-22.

17. Diehl, S.A., et al., G proteins Galphai1/3 are critical targets for Bordetella pertussis toxin-induced vasoactive amine sensitization. Infect Immun, 2014. 82(2): p. 77382.

18. Katada, T. and M. Ui, ADP ribosylation of the specific membrane protein of C6 cells by islet-activating protein associated with modification of adenylate cyclase activity. J Biol Chem, 1982. 257(12): p. 7210-6.

19. Gao, J.F., et al., Analysis of the role of Bphs/Hrh1 in the genetic control of responsiveness to pertussis toxin. Infect Immun, 2003. 71(3): p. 1281-7.

20. Wardlaw, A.C., Inheritance of responsiveness to pertussis HSF in mice. Int Arch Allergy Appl Immunol, 1970. 38(6): p. 573-89.

21. Noubade, R., et al., Autoimmune disease-associated histamine receptor $\mathrm{H} 1$ alleles exhibit differential protein trafficking and cell surface expression. J Immunol, 2008. 180(11): p. 7471-9.

22. Petkov, P.M., et al., An efficient SNP system for mouse genome scanning and elucidating strain relationships. Genome Res, 2004. 14(9): p. 1806-11.

23. Poltorak, A., S. Apalko, and S. Sherbak, Wild-derived mice: from genetic diversity to variation in immune responses. Mamm Genome, 2018. 29(7-8): p. 577-584.

24. Bearoff, F., et al., Natural genetic variation profoundly regulates gene expression in immune cells and dictates susceptibility to CNS autoimmunity. Genes Immun, 2016. 17(7): p. 386-395.

25. Dejager, L., C. Libert, and X. Montagutelli, Thirty years of Mus spretus: a promising future. Trends Genet, 2009. 25(5): p. 234-41.

26. Harper, J.M., Wild-derived mouse stocks: an underappreciated tool for aging research. Age (Dordr), 2008. 30(2-3): p. 135-45. 
27. Guenet, J.L. and F. Bonhomme, Wild mice: an ever-increasing contribution to a popular mammalian model. Trends Genet, 2003. 19(1): p. 24-31.

28. Bult, C.J., et al., Mouse Genome Database (MGD) 2019. Nucleic Acids Res, 2019. 47(D1): p. D801-d806.

29. Beck, J.A., et al., Genealogies of mouse inbred strains. Nat Genet, 2000. 24(1): p. 23-5.

30. Boursot, P., et al., The Evolution of House Mice. Annual Review of Ecology and Systematics, 1993. 24(1): p. 119-152.

31. Inoue, I., et al., Impaired locomotor activity and exploratory behavior in mice lacking histamine $\mathrm{H} 1$ receptors. Proc Natl Acad Sci U S A, 1996. 93(23): p. 1331620.

32. Graber, J.H., et al., Patterns and mechanisms of genome organization in the mouse. J Exp Zool A Comp Exp Biol, 2006. 305(9): p. 683-8.

33. Petkov, P.M., et al., Evidence of a large-scale functional organization of mammalian chromosomes. PLoS Genet, 2005. 1(3): p. e33.

34. Tyler, A.L., et al., Network-Based Functional Prediction Augments Genetic Association To Predict Candidate Genes for Histamine Hypersensitivity in Mice. G3 (Bethesda), 2019. 9(12): p. 4223-4233.

35. Raza, A., et al., A natural mouse model reveals genetic determinants of systemic capillary leak syndrome (Clarkson disease). Commun Biol, 2019. 2: p. 398.

36. Grubb, S.C., et al., Mouse phenome database. Nucleic Acids Res, 2009. 37(Database issue): p. D720-30.

37. Adams, D.J., et al., The Mouse Genomes Project: a repository of inbred laboratory mouse strain genomes. Mamm Genome, 2015. 26(9-10): p. 403-12.

38. Kang, H.M., et al., Efficient control of population structure in model organism association mapping. Genetics, 2008. 178(3): p. 1709-23.

39. Munoz, J. and L.F. Schuchardt, Studies on the sensitivity of mice to histamine following injection of hemophilus pertussis. I. Effect of strain and age of mice. $\mathrm{J}$ Allergy, 1953. 24(4): p. 330-4. 
40. Linthicum, D.S. and J.A. Frelinger, Acute autoimmune encephalomyelitis in mice. II. Susceptibility is controlled by the combination of $\mathrm{H}-2$ and histamine sensitization genes. J Exp Med, 1982. 156(1): p. 31-40.

41. Morgan, A.P., et al., The Mouse Universal Genotyping Array: From Substrains to Subspecies. G3 (Bethesda), 2015. 6(2): p. 263-79.

42. 1/1/2020]; Available from: https://github.com/TheJacksonLaboratory/haploqa.

43. Guan, Y., et al., Functional genomics complements quantitative genetics in identifying disease-gene associations. PLoS Comput Biol, 2010. 6(11): p. e1000991.

44. Munoz, J. and R.K. Bergman, Mechanism of Anaphylactic Death in the Mouse. Nature, 1965. 205: p. 199-200.

45. Wang, M., et al., Mouse anaphylactic shock is caused by reduced cardiac output, but not by systemic vasodilatation or pulmonary vasoconstriction, via PAF and histamine. Life Sci, 2014. 116(2): p. 98-105.

46. Seifert, R., et al., Molecular and cellular analysis of human histamine receptor subtypes. Trends Pharmacol Sci, 2013. 34(1): p. 33-58.

47. Fink, M.A. and M.V. Rothlauf, Variations in sensitivity to anaphylaxis and to histamine in inbred strains of mice. Proc Soc Exp Biol Med, 1954. 85(2): p. 336-8.

48. Lu, C., et al., Endothelial histamine $\mathrm{H1}$ receptor signaling reduces blood-brain barrier permeability and susceptibility to autoimmune encephalomyelitis. Proc Natl Acad Sci U S A, 2010. 107(44): p. 18967-72.

49. Meeker, N.D., et al., Physical mapping of the autoimmune disease susceptibility locus, Bphs: co-localization with a cluster of genes from the TNF receptor superfamily on mouse chromosome 6. Mamm Genome, 1999. 10(9): p. 858-63.

50. Kelly, N.J., et al., Mouse Genome-Wide Association Study of Preclinical Group II Pulmonary Hypertension Identifies Epidermal Growth Factor Receptor. Am J Respir Cell Mol Biol, 2017. 56(4): p. 488-496.

51. Klein, A.D., et al., Identification of Modifier Genes in a Mouse Model of Gaucher Disease. Cell Rep, 2016. 16(10): p. 2546-2553.

52. Chitwood, P.J., et al., EMC Is Required to Initiate Accurate Membrane Protein Topogenesis. Cell, 2018. 175(6): p. 1507-1519 e16. 
53. Hoyer, M.J., et al., A Novel Class of ER Membrane Proteins Regulates ERAssociated Endosome Fission. Cell, 2018. 175(1): p. 254-265 e14.

54. Noh, S.H., et al., Specific autophagy and ESCRT components participate in the unconventional secretion of CFTR. Autophagy, 2018. 14(10): p. 1761-1778.

55. Tachibana, M., et al., Activation of peroxisome proliferator-activated receptor gamma suppresses mast cell maturation involved in allergic diseases. Allergy, 2008. 63(9): p. 1136-47.

56. Ushio, H., et al., Crucial role for autophagy in degranulation of mast cells. J Allergy Clin Immunol, 2011. 127(5): p. 1267-76 e6.

57. Son, N.H., et al., Cardiomyocyte expression of PPARgamma leads to cardiac dysfunction in mice. J Clin Invest, 2007. 117(10): p. 2791-801.

58. Corpet, F., Multiple sequence alignment with hierarchical clustering. Nucleic Acids Res, 1988. 16(22): p. 10881-90.

59. Bunce, M., et al., Phototyping: comprehensive DNA typing for $H L A-A, B, C, D R B 1$, DRB3, DRB4, DRB5 \& DQB1 by PCR with 144 primer mixes utilizing sequencespecific primers (PCR-SSP). Tissue Antigens, 1995. 46(5): p. 355-67.

60. Gnirke, A., et al., Solution hybrid selection with ultra-long oligonucleotides for massively parallel targeted sequencing. Nat Biotechnol, 2009. 27(2): p. 182-9.

61. Mamanova, L., et al., Target-enrichment strategies for next-generation sequencing. Nat Methods, 2010. 7(2): p. 111-8.

62. Cox, M.P., D.A. Peterson, and P.J. Biggs, SolexaQA: At-a-glance quality assessment of Illumina second-generation sequencing data. BMC Bioinformatics, 2010. 11: p. 485.

63. Li, H. and R. Durbin, Fast and accurate short read alignment with Burrows-Wheeler transform. Bioinformatics, 2009. 25(14): p. 1754-1760.

64. Li, H., et al., The Sequence Alignment/Map format and SAMtools. Bioinformatics, 2009. 25(16): p. 2078-9.

65. McKenna, A., et al., The Genome Analysis Toolkit: a MapReduce framework for analyzing next-generation DNA sequencing data. Genome Res, 2010. 20(9): p. 1297-303. 
66. Kirby, A., et al., Fine mapping in 94 inbred mouse strains using a high-density haplotype resource. Genetics, 2010. 185(3): p. 1081-95.

67. Yang, H., et al., Subspecific origin and haplotype diversity in the laboratory mouse. Nat Genet, 2011. 43(7): p. 648-55.

68. Frazer, K.A., et al., A sequence-based variation map of 8.27 million SNPs in inbred mouse strains. Nature, 2007. 448(7157): p. 1050-3.

69. Keane, T.M., et al., Mouse genomic variation and its effect on phenotypes and gene regulation. Nature, 2011. 477(7364): p. 289-94.

70. Eskin, E. 6/25/2020]; Available from: http://mouse.cs.ucla.edu/mousehapmap/beta/index.html.

71. Srivastava, A., et al., Genomes of the Mouse Collaborative Cross. Genetics, 2017. 206(2): p. 537-556.

72. Baker, E.J., et al., GeneWeaver: a web-based system for integrative functional genomics. Nucleic Acids Res, 2012. 40(Database issue): p. D1067-76.

73. Goya, J., et al., FNTM: a server for predicting functional networks of tissues in mouse. Nucleic Acids Res, 2015. 43(W1): p. W182-7. 
Table 1. Distribution of $\mathrm{Hrh}^{\mathrm{s}}$ and $\mathrm{Hrh}^{r}$ alleles in laboratory and wild-derived inbred mouse strains.

\begin{tabular}{|c|c|c|c|}
\hline & $\begin{array}{l}\text { usceptible Haplotype } \\
\text { Pro }^{263}, \text { Val }^{312}, \text { Pro }^{330} \text { ) } \\
\text { Hrh1 }\end{array}$ & & $\begin{array}{c}\text { Resistant Haplotype } \\
\left(\text { Leu }^{263}, \text { Met }^{312}, \text { Ser }^{330}\right) \\
\text { Hrh }^{r}\end{array}$ \\
\hline $129 \times 1 / S v J$ & C57BR/cdJ & $\mathrm{P} / \mathrm{J}$ & $A K R / J$ \\
\hline 129S1/SvImJ & C57L/J & PANCEVO/EiJ & BPL/1J \\
\hline 129T2/SvEmsJ & C58/J & PERA/EiJ & $\mathrm{C} 3 \mathrm{H} / \mathrm{HeJ}$ \\
\hline $\mathrm{A} / \mathrm{HeJ}$ & CALB/RkJ & PERC/EiJ & $\mathrm{C} 3 \mathrm{H} / \mathrm{HeN}$ \\
\hline$A / J$ & CE/E & $\mathrm{PL} / \mathrm{J}$ & CASA/RkJ \\
\hline A/WySnJ & DBA/1J & RBF/DnJ & CAST/EiJ \\
\hline ALR/LtJ & DBA/2J & RIIIS/J & $\mathrm{CBA} / \mathrm{J}$ \\
\hline ALS/LtJ & DDY/JclSidSeyFrkJ & SB/LeJ & CBA/N \\
\hline B10.S/DvTee & EL/SuzSeFrkJ & SEA/GnJ & CZECHI/EiJ \\
\hline B10.S/McdgJ & $\mathrm{FVB} / \mathrm{NCr}$ & SEC/1ReJ & CZECHII/EiJ \\
\hline BALB/cByJ & IS/CamRkJ & SENCARA/PtJ & I/LnJ \\
\hline $\mathrm{BALB} / \mathrm{cJ}$ & $\mathrm{KK} / \mathrm{HIJ}$ & SENCARB/PtJ & JF1/Ms \\
\hline $\mathrm{BDP} / \mathrm{J}$ & LEWES/EiJ & SENCARC/PtJ & MOLC/RkJ \\
\hline $\mathrm{BPH} / 2 \mathrm{~J}$ & LG/J & SJL/J & MOLD/RkJ \\
\hline BPL/1J & $\mathrm{LP} / \mathrm{J}$ & SJL/BmJ & MOLF/EiJ \\
\hline $\mathrm{BPN} / 3 \mathrm{~J}$ & MA/MyJ & $\mathrm{SM} / \mathrm{J}$ & MRL/MpJ \\
\hline BTBRT+ & MOR/RkJ & SPRET/EiJ & MSM/Ms \\
\hline BXSB/MpJ & NOD/LtJ & ST/BJ & PWD/PhJ \\
\hline C57BL/10J & NON/LtJ & SWR/J & PWK/PhJ \\
\hline C57BL/10SnJ & NOR/LtJ & SWXL-4/TyJ & $\mathrm{RF} / \mathrm{J}$ \\
\hline C57BL/6ByJ & NZB//BINJ & TIRANO/EiJ & SF/CamEiJ \\
\hline C57BL/6J & NZO/HILtJ & YBR/EiJ & SKIVE/EiJ \\
\hline C57BLKS/J & NZW/LacJ & ZALENDE/EiJ & \\
\hline
\end{tabular}


Table 2. Bphs susceptibility of mice with the $H r h 1^{r} / H R H 1^{r}$ allele.

\begin{tabular}{|c|c|c|c|c|c|c|c|}
\hline \multirow[b]{2}{*}{ Strain } & \multirow[b]{2}{*}{ Group $^{a}$} & \multicolumn{3}{|c|}{ Histamine (mg/kg) } & \multirow[b]{2}{*}{ Total } & \multirow[b]{2}{*}{$\%$ Aff } & \multirow[b]{2}{*}{$p$-value ${ }^{\mathrm{b}}$} \\
\hline & & 100 & 50 & 25 & & & \\
\hline $\mathrm{C} 3 \mathrm{H} / \mathrm{HeJ}$ & 1 & $0 / 3$ & $0 / 2$ & $0 / 2$ & $0 / 7$ & 0 & \\
\hline $\mathrm{C} 3 \mathrm{H} / \mathrm{HeN}$ & 1 & $0 / 2$ & $0 / 2$ & $0 / 2$ & $0 / 6$ & 0 & \\
\hline $\mathrm{C} 3 \mathrm{H}$ & & $0 / 5$ & $0 / 4$ & $0 / 4$ & $0 / 13$ & 0 & \\
\hline$A K R / J$ & 1 & $1 / 3$ & $0 / 2$ & $0 / 2$ & $1 / 7$ & 14 & 0.4 \\
\hline CAST/EiJ & 7 & $1 / 3$ & $0 / 3$ & $0 / 3$ & $1 / 9$ & 11 & 0.4 \\
\hline $\mathrm{CBA} / \mathrm{J}$ & 1 & $0 / 3$ & $0 / 2$ & $0 / 2$ & $0 / 7$ & 0 & \\
\hline CBA/N & 1 & $0 / 3$ & $0 / 2$ & $0 / 2$ & $0 / 7$ & 0 & \\
\hline CBA & & $0 / 6$ & $0 / 4$ & $0 / 4$ & $0 / 14$ & 0 & 1.0 \\
\hline I/LnJ & 6 & $2 / 7$ & $0 / 3$ & - & $2 / 10$ & 20 & 0.2 \\
\hline MSM/Ms & 7 & $0 / 3$ & $0 / 3$ & - & $0 / 6$ & 0 & 1.0 \\
\hline MRL/MpJ & 1 & $0 / 3$ & $0 / 2$ & $0 / 2$ & $0 / 7$ & 0 & 1.0 \\
\hline SF/CamEiJ & 1 & $0 / 4$ & $0 / 2$ & - & $0 / 6$ & 0 & 1.0 \\
\hline SKIVE/EiJ & 7 & $2 / 7$ & $1 / 6$ & $0 / 2$ & $3 / 15$ & 20 & 0.2 \\
\hline BPL/1J & 5 & $1 / 2$ & $2 / 2$ & $2 / 2$ & $5 / 6$ & 83 & 0.0005 \\
\hline CZECHII/EiJ & 7 & $4 / 4$ & $2 / 4$ & $2 / 2$ & $8 / 10$ & 80 & $<0.0001$ \\
\hline JF1/MsJ & 7 & $2 / 3$ & $2 / 3$ & - & $4 / 6$ & 67 & 0.004 \\
\hline MOLD/EiJ & 7 & $2 / 2$ & $1 / 2$ & $2 / 2$ & $5 / 6$ & 83 & 0.0005 \\
\hline MOLF/EiJ & 7 & $2 / 2$ & $5 / 5$ & $5 / 5$ & $12 / 12$ & 100 & $<0.0001$ \\
\hline PWD/PhJ & 7 & $5 / 7$ & - & - & $5 / 7$ & 71 & 0.001 \\
\hline PWK/PhJ & 7 & $2 / 2$ & $2 / 2$ & $2 / 2$ & $6 / 6$ & 100 & $<0.0001$ \\
\hline $\mathrm{RF} / \mathrm{J}$ & 1 & $2 / 2$ & $2 / 2$ & $2 / 2$ & $6 / 6$ & 86 & $<0.0001$ \\
\hline
\end{tabular}

Mice were injected with $200 \mathrm{ng}$ of PTX on D0. Three days later the animals were challenged with the indicated dose of HA (mg dry weight free base/kg body weight) by intraperitoneal injection and deaths recorded as number of animals dead/number of animals tested at 30 minutes post HA challenge. ${ }^{a}$ according to mouse family tree (adapted from Petkov et al. [22]). ${ }^{b}$ Relative to $\mathrm{C} 3 \mathrm{H}$ mice 
Table 3. Bphs susceptibility of $H r h 1^{\text {s }}$ and $H r h 1^{r}$ by $H \mathrm{RH} 1 \mathrm{KO} \mathrm{F}_{1}$ hybrid mice.

\section{Histamine $(\mathrm{mg} / \mathrm{kg})$}

\begin{tabular}{|c|c|c|c|c|c|c|c|c|}
\hline Strain & 100 & 50 & 25 & 12.5 & 6.25 & Total & $\%$ Aff & $p$-value \\
\hline $\mathrm{HRH} 1 \mathrm{KO}$ & $0 / 2$ & $0 / 2$ & $0 / 2$ & $0 / 2$ & $0 / 2$ & $0 / 10$ & 0 & \\
\hline C57BL/6J & $3 / 3$ & $3 / 3$ & $3 / 3$ & $2 / 2$ & $1 / 2$ & $12 / 15$ & 90 & $<0.0001$ \\
\hline$(\mathrm{B} 6 \times \mathrm{HRH} 1 \mathrm{KO}) \mathrm{F}_{1}$ & $4 / 4$ & $4 / 4$ & $4 / 4$ & $3 / 4$ & $3 / 3$ & $18 / 19$ & 95 & $<0.0001$ \\
\hline $\mathrm{C} 3 \mathrm{H} . B p h s^{\mathrm{SJL}}$ & $3 / 3$ & $2 / 2$ & $2 / 2$ & $2 / 2$ & $2 / 2$ & $11 / 11$ & 100 & $<0.0001$ \\
\hline$\left(B p h s^{\mathrm{SJL}} \times \mathrm{HRH} 1 \mathrm{KO}\right) \mathrm{F}_{1}$ & $2 / 2$ & $2 / 2$ & $2 / 2$ & $2 / 2$ & $2 / 2$ & $10 / 10$ & 100 & $<0.0001$ \\
\hline $\mathrm{C} 3 \mathrm{H} / \mathrm{HeJ}$ & $1 / 3$ & $0 / 2$ & $0 / 2$ & $0 / 2$ & $0 / 2$ & $1 / 11$ & 9 & \\
\hline$(\mathrm{C} 3 \mathrm{H} \times \mathrm{HRH} 1 \mathrm{KO}) \mathrm{F}_{1}$ & $0 / 2$ & $0 / 2$ & $0 / 2$ & $0 / 2$ & $0 / 2$ & $0 / 10$ & 0 & \\
\hline $\mathrm{CBA} / \mathrm{J}$ & $0 / 3$ & $0 / 2$ & $0 / 2$ & $0 / 2$ & $0 / 2$ & $0 / 11$ & 0 & \\
\hline$(\mathrm{CBA} \times \mathrm{HRH} 1 \mathrm{KO}) \mathrm{F}_{1}$ & $0 / 2$ & $0 / 3$ & $0 / 2$ & $0 / 2$ & $0 / 2$ & $0 / 11$ & 0 & \\
\hline $\mathrm{AKR} / \mathrm{J}$ & $1 / 3$ & $0 / 2$ & $0 / 2$ & $0 / 2$ & $0 / 2$ & $1 / 11$ & 9 & \\
\hline$(\mathrm{AKR} \times \mathrm{HRH} 1 \mathrm{KO}) \mathrm{F}_{1}$ & $0 / 2$ & $0 / 2$ & $0 / 2$ & $0 / 2$ & $0 / 2$ & $0 / 10$ & 0 & \\
\hline MRL/MpJ & $0 / 3$ & $0 / 2$ & $0 / 2$ & $0 / 2$ & $0 / 2$ & $0 / 11$ & 0 & \\
\hline$(\mathrm{MRL} \times \mathrm{HRH} 1 \mathrm{KO}) \mathrm{F}_{1}$ & $2 / 3$ & $0 / 2$ & $0 / 2$ & $0 / 2$ & $0 / 2$ & $2 / 11$ & 18 & \\
\hline $\mathrm{PWK} / \mathrm{PhJ}$ & $3 / 3$ & $3 / 3$ & $2 / 2$ & $1 / 2$ & $0 / 2$ & $9 / 12$ & 75 & 0.0005 \\
\hline$(\mathrm{PWK} \times \mathrm{HRH} 1 \mathrm{KO}) \mathrm{F}_{1}$ & $3 / 3$ & $2 / 2$ & $2 / 2$ & $1 / 2$ & $1 / 2$ & $11 / 13$ & 85 & $<0.0001$ \\
\hline MOLF/MpJ & $2 / 2$ & $2 / 2$ & $2 / 2$ & $2 / 2$ & $0 / 2$ & $8 / 10$ & 80 & $<0.0001$ \\
\hline$(\mathrm{MOLF} \times \mathrm{HRH} 1 \mathrm{KO}) \mathrm{F}_{1}$ & $2 / 2$ & $2 / 2$ & $2 / 2$ & $2 / 2$ & $0 / 2$ & $8 / 10$ & 80 & $<0.0001$ \\
\hline
\end{tabular}

(MOLF x HRH1KO) $x$ HRH1KO

$\mathrm{HRH} 1^{-1-}$

$\mathrm{HRH} 1$ MOLF/-

\section{Aff Unaff}

$\begin{array}{lllll}54 & 0 & 54 & 0 / 54 & 0 \%\end{array}$

$60 \quad 54 \quad 6$

Mice were injected with $200 \mathrm{ng}$ of PTX on D0. Three days later the animals were challenged with the indicated dose of HA (mg dry weight free base $/ \mathrm{kg}$ body weight) by intraperitoneal injection and deaths recorded as number of animals dead/number of animals tested at 30 minutes post $\mathrm{HA}$ challenge. aRelative to $\mathrm{HRH} 1 \mathrm{KO}$ mice 
Table 4. Linkage of Chr6 marker loci to Bphse.

\begin{tabular}{|c|c|c|c|c|c|c|c|c|}
\hline Marker & bp & $x^{2}$ & $p$-value & A Ho & A He & Un Ho & Un He & Total \\
\hline rs36385580 & $59,353,905$ & 28.8 & 7.95E-08 & 28 & 52 & 65 & 20 & 165 \\
\hline$r s 38650989$ & $72,592,521$ & 30.6 & $3.21 \mathrm{E}-08$ & 28 & 52 & 66 & 19 & 165 \\
\hline D6Mit186 & $73,387,511$ & 29.5 & 5.49E-08 & 30 & 53 & 66 & 19 & 168 \\
\hline D6Mit102 & $93,463,949$ & 38.2 & $6.36 \mathrm{E}-10$ & 25 & 58 & 66 & 19 & 168 \\
\hline D6Mit65 & $101,387,523$ & 42.3 & $7.92 \mathrm{E}-11$ & 25 & 58 & 68 & 17 & 168 \\
\hline D6Mit149 & $106,005,405$ & 38.5 & $5.44 \mathrm{E}-10$ & 27 & 56 & 68 & 17 & 168 \\
\hline Hrh1 & $114,397,936$ & & & & & & & \\
\hline rs31698248 & $120,207,163$ & 41.6 & $1.09 \mathrm{E}-10$ & 26 & 56 & 69 & 16 & 167 \\
\hline D6Mit254 & $125,356,646$ & 35.6 & 2.42E-09 & 26 & 56 & 66 & 19 & 167 \\
\hline rs30853093 & $125,365,703$ & 34.5 & 4.32E-09 & 26 & 57 & 65 & 20 & 168 \\
\hline$r s 30662734$ & $125,370,997$ & 34.5 & 4.32E-09 & 26 & 57 & 65 & 20 & 168 \\
\hline rs36868180 & $127,629,804$ & 32.7 & 1.06E-08 & 27 & 56 & 65 & 20 & 168 \\
\hline D6Mit135 & $128,834,894$ & 29.2 & 6.53E-08 & 27 & 56 & 63 & 22 & 168 \\
\hline \multicolumn{9}{|c|}{ 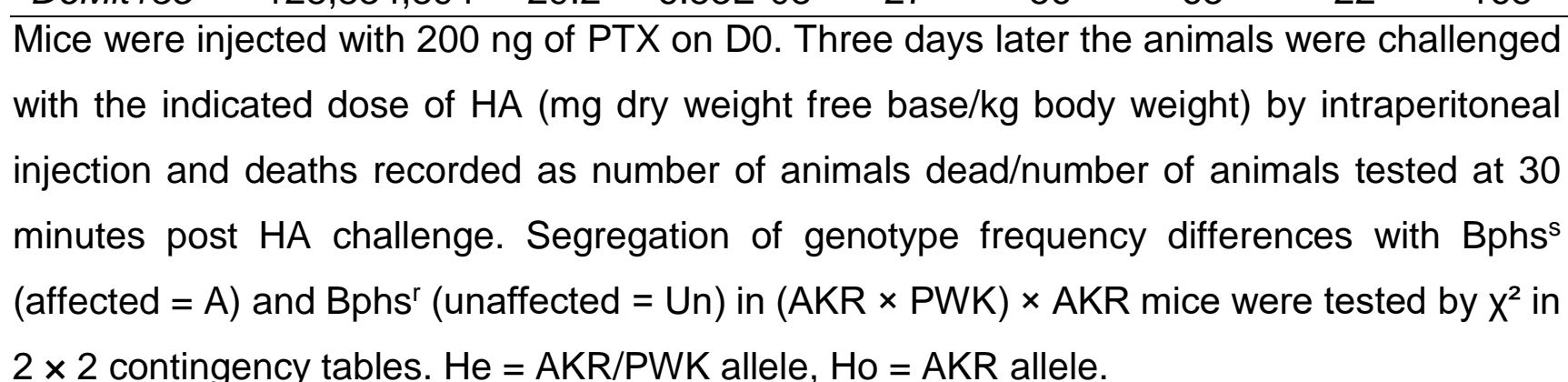 } \\
\hline
\end{tabular}


Figure 1. Congenic mapping confirms linkage of Bphse to Bphs/Hrh1.

\begin{tabular}{|c|c|c|c|c|c|c|c|c|c|c|c|c|c|c|}
\hline \multirow[b]{2}{*}{ Strain } & \multicolumn{10}{|c|}{ Marker (bp) } & \multirow[b]{2}{*}{ 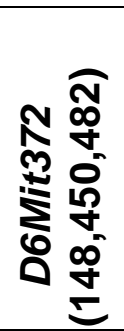 } & \multirow[b]{2}{*}{ Bphs } & \multirow[b]{2}{*}{ Aff } & \multirow[b]{2}{*}{$p$-value } \\
\hline & 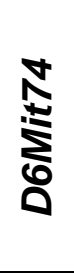 & 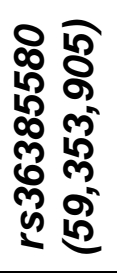 & 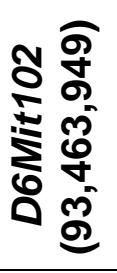 & 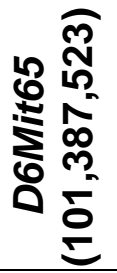 & 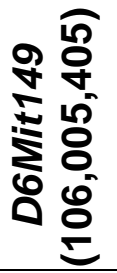 & 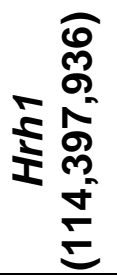 & 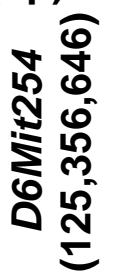 & 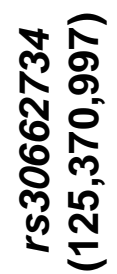 & 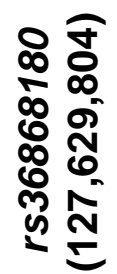 & 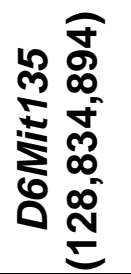 & & & & \\
\hline $\mathrm{C} 3 \mathrm{H} / \mathrm{HeJ}$ & $\mathrm{C}$ & C & C & C & C & C & C & $\mathrm{C}$ & $\mathrm{C}$ & C & C & $4 / 30$ & 13 & \\
\hline MOLF/MpJ & $\mathrm{M}$ & M & M & M & M & M & M & M & M & M & M & $20 / 22$ & 90 & $\begin{array}{c}<0.0001 \\
a\end{array}$ \\
\hline С3H.Bphse $e^{\mathrm{C} 3 \mathrm{H} / \mathrm{C} 3 \mathrm{H}}$ & $\mathrm{C}$ & C & C & C & C & C & C & C & C & C & C & $7 / 50$ & 14 & \\
\hline C3H.Bphse ${ }^{\mathrm{C} 3 \mathrm{H} / \mathrm{MOLF}}$ & $\mathrm{C}$ & $\mathrm{He}$ & $\mathrm{He}$ & $\mathrm{He}$ & $\mathrm{He}$ & $\mathrm{He}$ & $\mathrm{He}$ & $\mathrm{He}$ & $\mathrm{He}$ & $\mathrm{He}$ & $\mathrm{C}$ & $19 / 32$ & 60 & $\begin{array}{c}<0.0002 \\
a\end{array}$ \\
\hline $\mathrm{AKR} / \mathrm{J}$ & $A$ & $A$ & $A$ & $A$ & $A$ & $A$ & $A$ & $A$ & $A$ & $A$ & $A$ & $5 / 30$ & 16 & \\
\hline $\mathrm{PWK} / \mathrm{J}$ & $\mathrm{P}$ & $P$ & $P$ & $P$ & $P$ & $P$ & $P$ & $\mathrm{P}$ & $\mathrm{P}$ & $\mathrm{P}$ & $\mathrm{P}$ & $15 / 18$ & 83 & $<\underset{b}{0.0001}$ \\
\hline AKR.Bphse AKR/AKR & $A$ & A & $A$ & $A$ & A & A & A & A & $A$ & $A$ & $A$ & $8 / 47$ & 17 & \\
\hline AKR.Bphse AKR/PWK & $A$ & $\mathrm{He}$ & $\mathrm{He}$ & $\mathrm{He}$ & $\mathrm{He}$ & $\mathrm{He}$ & $\mathrm{He}$ & $\mathrm{He}$ & $\mathrm{He}$ & $\mathrm{He}$ & A & $35 / 40$ & 88 & $<\underset{b}{0.0001}$ \\
\hline $\mathrm{C} 3 \mathrm{H}+\mathrm{AKR}$ & & & & & & & & & & & & $9 / 60$ & 15 & \\
\hline MOLF+PWK & & & & & & & & & & & & $35 / 40$ & 88 & $<\underset{c}{<0.0001}$ \\
\hline Bphse ${ }^{\mathrm{C} 3 \mathrm{H} / \mathrm{C} 3 \mathrm{H}}+$ Bphse $^{\mathrm{AKR} / \mathrm{AKR}}$ & & & & & & & & & & & & $15 / 97$ & 15 & \\
\hline Bphse ${ }^{\mathrm{C} 3 \mathrm{H} / \mathrm{MOLF}}+$ Bphse $^{\mathrm{AKR} / \mathrm{PWK}}$ & & & & & & & & & & & & $54 / 72$ & 75 & $<\underset{c}{<0.0001}$ \\
\hline
\end{tabular}

Mice were injected with 200 ng of PTX on D0. Three days later the animals were challenged with the indicated dose of HA (mg dry weight free base/kg body weight) by intraperitoneal injection and deaths recorded as number of animals dead/number of animals tested at 30 minutes post HA challenge. Marker loci and their location $(\mathrm{mm} 10)$ are listed along with the respective genotypes: $\mathrm{C}=\mathrm{C} 3 \mathrm{H}, \mathrm{M}=\mathrm{MOLF}$,

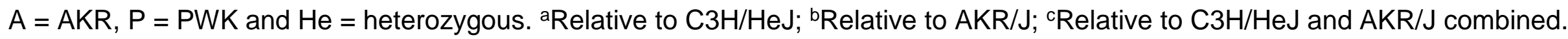


Figure 2. Genetic association with Bphs ${ }^{\mathrm{s}}$ was tested using a (A) low-resolution 13,257 SNP panel across Chr6:45.0-130.0Mb followed by (B) a high-resolution 78,334 imputed SNP panel across Chr6:111.0-116.4 Mb. Both plots show negative log-transformed $p$ values of each SNP tested using Efficient Mixed Model Association (EMMA) on the $y$ axis. Each filled circle denotes a single SNP. Significance thresholds are shown with a dotted line in each panel. The x-axis denotes Mb coordinates for Chr6 (mm10). (C) Gene names are included for SNPs that crossed $p$-value cut-off of $5.00 \times 10^{-3}$.

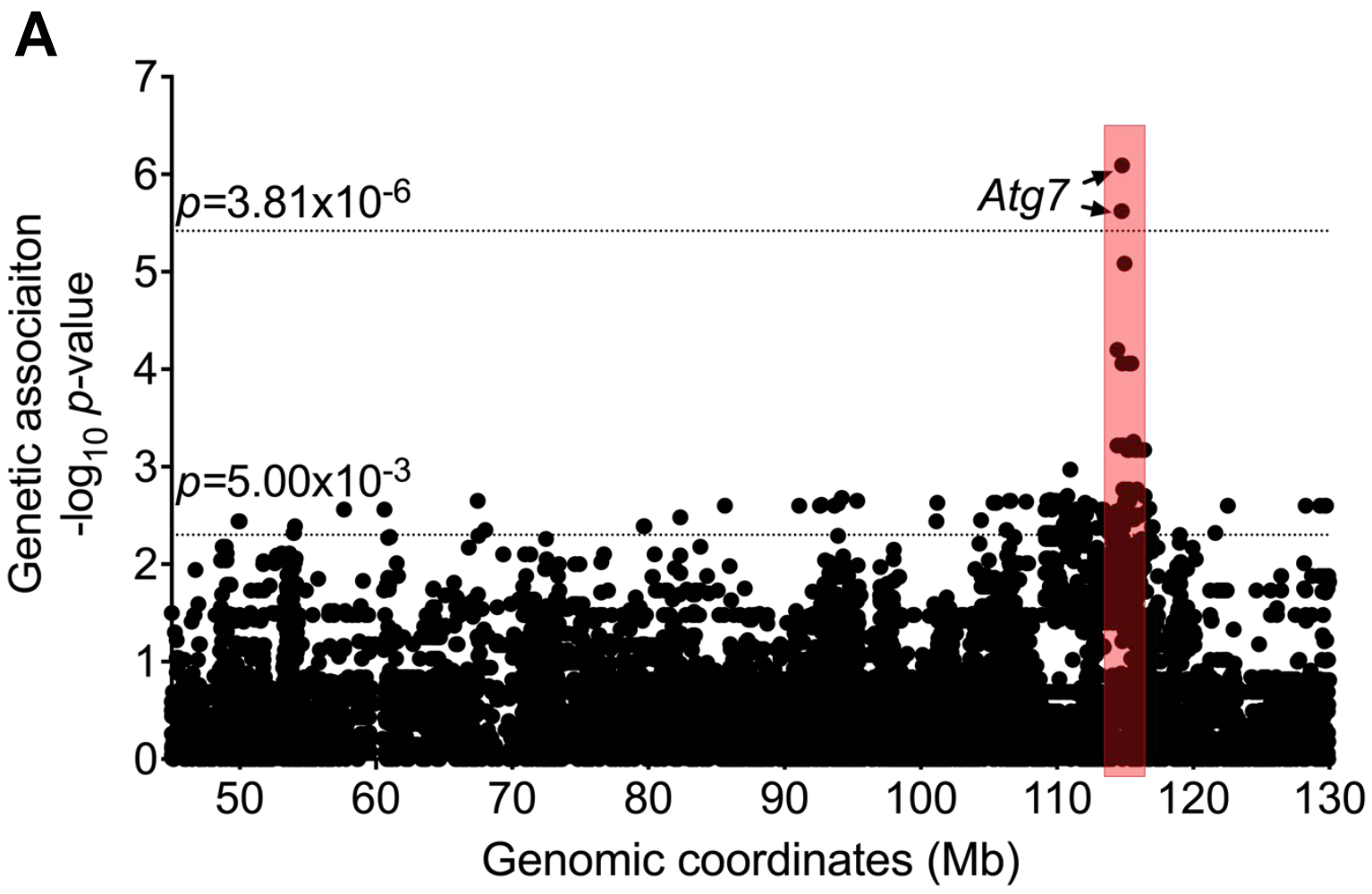



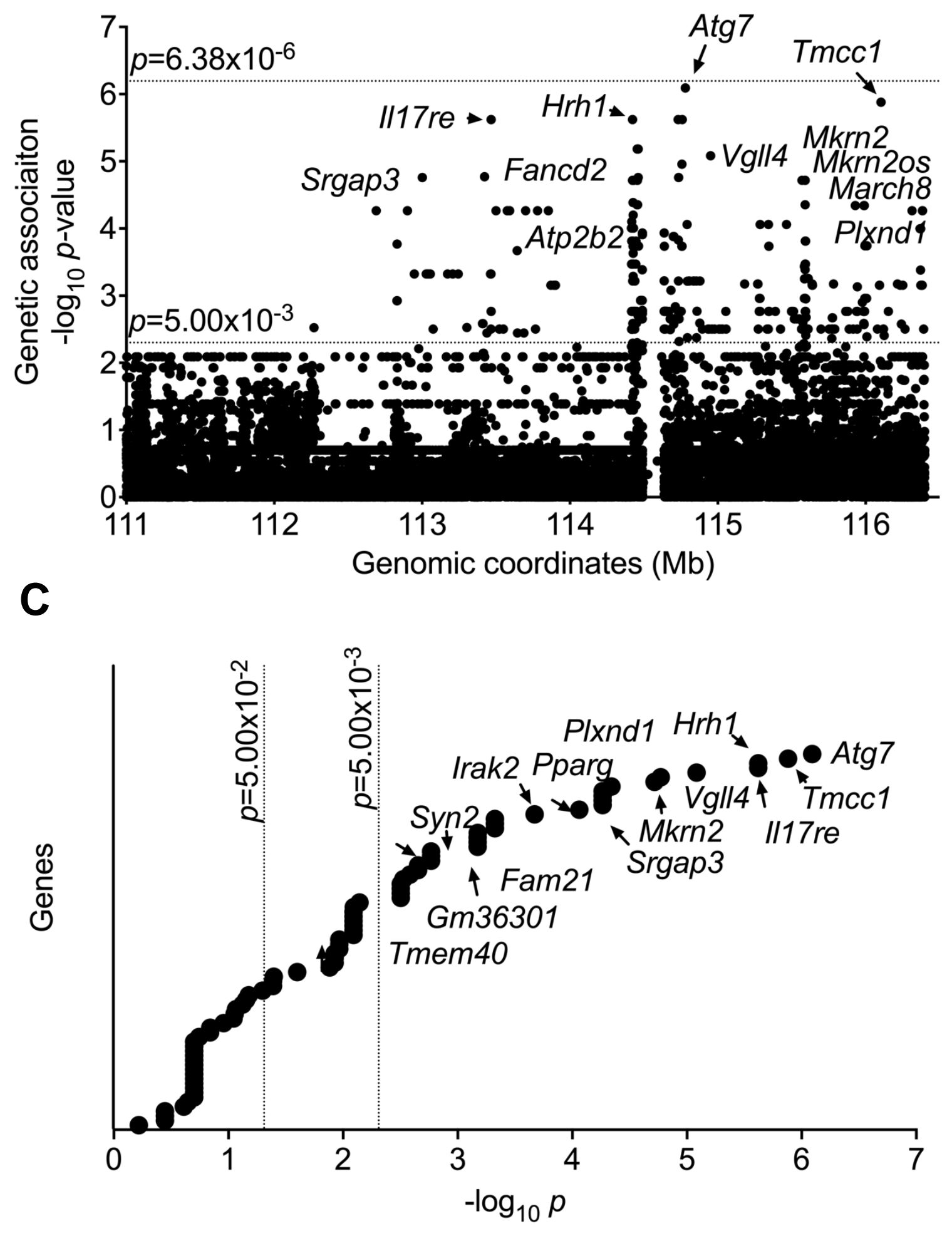
Figure 3. Integration of genetic and functional mapping approaches to predict candidates for Bphse. (A). The plot shows normalized negative log-transformed false positive rate of maximum functional enrichment $\left(-\log _{10} F P R\right)$ on the $y$-axis. The $x$-axis denotes the corresponding normalized negative log-transformed genetic association scores. Candidates that were common across both approaches are shown. (B) The list of gene candidates as predicted by both genetic and functional approaches are ranked using a final gene score $\left(S_{c g}\right)$ on $x$-axis and the gene names of top 20 candidates listed on y-axis. Bphs/Hrh1 association is shown in red bar.

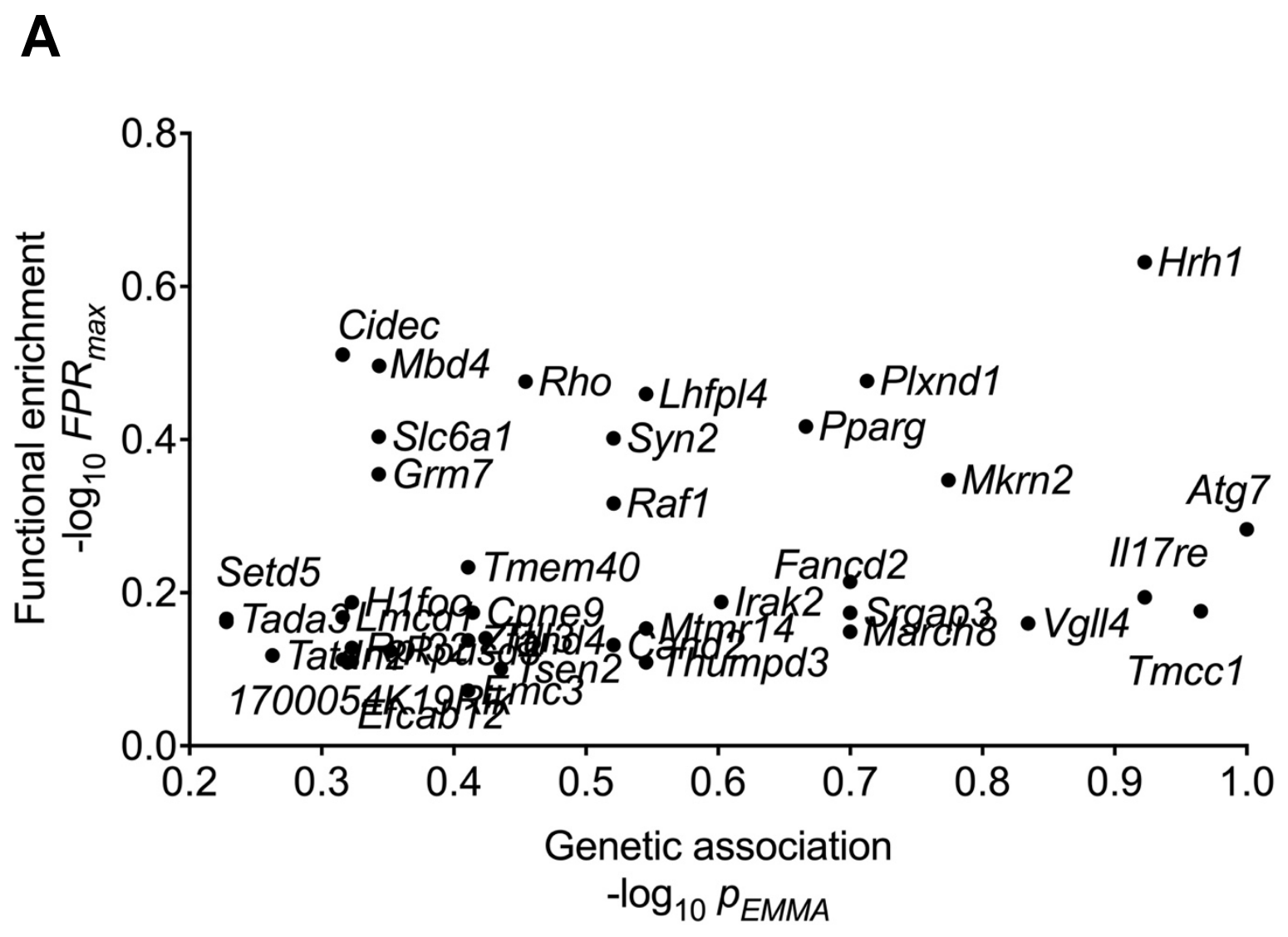




\section{B}

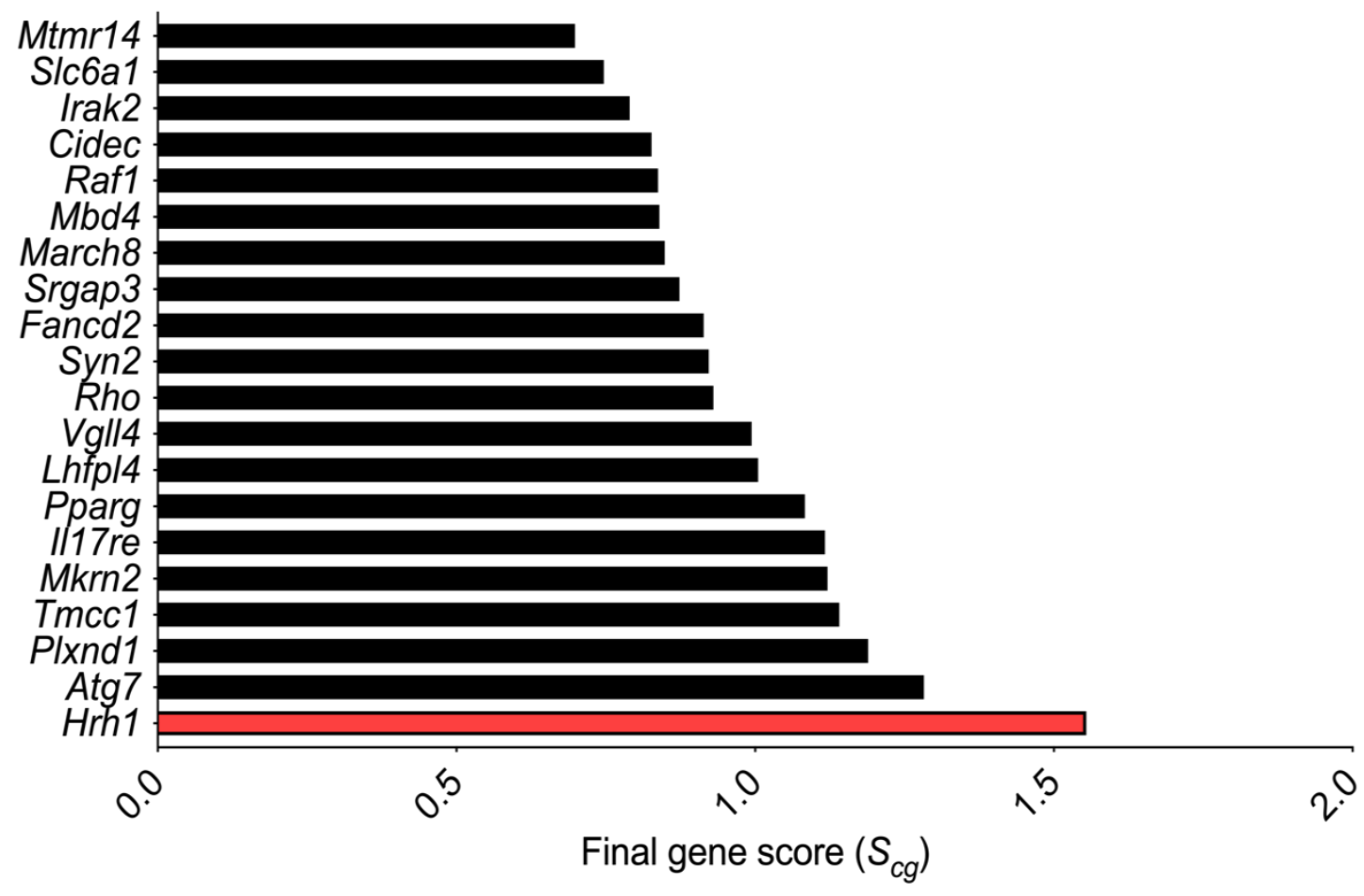


Supplementary Table 1. List of 50 inbred mouse strains used in genetic association testing.

Bphs Susceptible (41)

Bphs Resistant (9)

\begin{tabular}{ccccc}
\hline 129S1/SvImJ & C57BL/6J & LP/J & PL/J & AKR/J \\
129T2/SvEmsJ & C57BLKS/J & MA/MyJ & PWD/PhJ & C3H/HeJ \\
129X1/SvJ & C57BR/cdJ & MOLD/RkJ & PWK/PhJ & CAST/EiJ \\
A/J & C57L/J & MOLF/EiJ & RF/J & CBA/J \\
A/WySnJ & C58/J & NOD/ShiLtJ & RIIIS/J & I/LnJ \\
BALB/cJ & CZECHII/EiJ & NON/ShiLtJ & SJL/J & MRL/MpJ \\
BALB/cByJ & DBA/1J & NOR/LtJ & SM/J & MSM/MsJ \\
BPL/1J & DBA/2J & NU/J & SWR/J & SF/CamEiJ \\
C57BL/10J & FVB/NJ & NZB/BINJ & & SKIVE/EiJ \\
C57BL/10ScNJ & JF1/MsJ & NZW/LacJ & & \\
C57BL/6ByJ & LG/J & P/J & & \\
\hline
\end{tabular}


Supplementary Table 2. Genetic association analysis identifies variants on Chr6 associated with Bphss.

\begin{tabular}{|c|c|c|c|c|}
\hline Chr & bp (mm10) & SNP & Gene & $p$-value емма \\
\hline 6 & 114780885 & rs31440528 & I:Atg7 & 8.10E-07 \\
\hline 6 & 114732069 & rs31439505 & I:Atg7 & 2.39E-06 \\
\hline 6 & 114758979 & rs31445205 & I:Atg7 & 2.39E-06 \\
\hline \multicolumn{5}{|c|}{ Suggestive SNPs $(p<0.05)$} \\
\hline 6 & 110966239 & rs30498521 & I:Grm7 & 1.07E-03 \\
\hline 6 & 113466213 & rs37366170 & I:Il17re & 3.14E-03 \\
\hline 6 & 113521759 & rs36681994 & I:Emc3 & 3.14E-03 \\
\hline 6 & 113766702 & rs36921136 & I:Atp2b2 & 3.14E-03 \\
\hline 6 & 114427899 & rs46432555 & I:Hrh1 & $6.32 E-05$ \\
\hline 6 & 114792207 & rs31444358 & I:Atg7 & 8.71E-05 \\
\hline 6 & 114941577 & rs6248634 & NC:LOC105242742 & 3.14E-03 \\
\hline 6 & 114951759 & rs31456818 & Vgl/4 & 8.25E-06 \\
\hline 6 & 115008370 & rs6262329 & l:Tamm41 & 3.14E-03 \\
\hline 6 & 115181005 & rs31473897 & I:Syn2 & $6.72 \mathrm{E}-04$ \\
\hline 6 & 115286744 & rs31484360 & $N A$ & 8.71E-05 \\
\hline 6 & 115321034 & rs31484653 & NC:LOC105242744 & 1.31E-02 \\
\hline 6 & 115464239 & rs51526492 & I:Pparg & 8.71E-05 \\
\hline 6 & 115565855 & rs51720018 & I:Tsen2 & 3.14E-03 \\
\hline 6 & 115612395 & rs31487271 & I:Mkrn2 & 5.54E-04 \\
\hline 6 & 115663927 & rs31496654 & I:Raf1 & 2.79E-02 \\
\hline 6 & 115753510 & rs6160517 & I:Tmem40 & 3.14E-03 \\
\hline 6 & 115782690 & rs31504457 & l:Cand2 & $6.72 \mathrm{E}-04$ \\
\hline 6 & 115853377 & rs31503770 & U5:Mbd4 & 8.08E-03 \\
\hline 6 & 115879245 & rs31507517 & I:Ift122 & 1.71E-03 \\
\hline 6 & 115976241 & rs31518615 & I:Plxnd1 & 2.11E-02 \\
\hline 6 & 116120070 & rs31525210 & l:Tmcc1 & 3.14E-03 \\
\hline 6 & 116214868 & rs31533291 & I:Fam21 & $6.72 \mathrm{E}-04$ \\
\hline 6 & 116311087 & rs31535245 & I:Zfand4 & $1.08 \mathrm{E}-02$ \\
\hline 6 & 116402580 & rs31537093 & I:March8 & $6.72 \mathrm{E}-04$ \\
\hline 6 & 118643222 & rs31587804 & I:Cacna1c & 1.32E-02 \\
\hline 6 & 119353404 & rs13472337 & U3:Adipor2 & 3.86E-02 \\
\hline
\end{tabular}

This list was generated using a stringent cut-off $(p<3.81 E-06)$ and a moderate cut-off $(p<5.00 E-02)$ using Efficient Mixed Model Association (EMMA). Only the most significant SNP tagging a gene is shown. The functional location of variants is listed using the following notation: intronic (I), synonymous change (Cs), 3' untranslated region variant (U3), 5' untranslated region variant (U5), not characterized (NC) and no gene (NA). 
Supplementary Table 3. List of genetic variants identified $(p \leq 0.05)$ using imputed genotypes across Chr6:111.0-116.5 Mb.

\begin{tabular}{|c|c|c|c|c|}
\hline Chr & bp (mm10) & SNP & Gene & $p$-value emma \\
\hline 6 & 111003149 & rs223699795 & l:Grm7 & $8.12 E-03$ \\
\hline 6 & 112212190 & rs37480964 & NC:1700054K19Rik & 1.19E-02 \\
\hline 6 & 112309173 & rs232269259 & I:Lmcd1 & 1.19E-02 \\
\hline 6 & 112900380 & rs39644268 & I:Srgap3 & 5.45E-05 \\
\hline 6 & 113055745 & rs217254661 & Cn:Thumpd3 & 4.75E-04 \\
\hline 6 & 113114553 & rs262517352 & I:Setd5 & 4.09E-02 \\
\hline 6 & 113171903 & rs38534902 & Cs:Lhfp/4 & 4.75E-04 \\
\hline 6 & 113244289 & rs219248113 & I:Mtmr14 & 4.75E-04 \\
\hline 6 & 113302495 & rs246910229 & I:Cpne9 & 2.99E-03 \\
\hline 6 & 113366827 & rs236692255 & U3:Tada3 & 4.09E-02 \\
\hline 6 & 113408719 & rs251474270 & I:TtII3 & 2.61E-03 \\
\hline 6 & 113416087 & rs37807004 & I:Rpusd3 & 7.19E-03 \\
\hline 6 & 113422346 & rs214422450 & $N A$ & 1.70E-05 \\
\hline 6 & 113434320 & rs240625517 & I:Cidec & 1.19E-02 \\
\hline 6 & 113466530 & rs36373609 & l:Il17re & 2.39E-06 \\
\hline 6 & 113521759 & rs36681994 & I:Emc3 & 3.14E-03 \\
\hline 6 & 113575822 & rs225851814 & I:Fancd2 & 5.45E-05 \\
\hline 6 & 113643111 & rs578496862 & I:Irak2 & 2.14E-04 \\
\hline 6 & 113701102 & rs217976133 & I:Tatdn2 & 2.51E-02 \\
\hline 6 & 113780687 & rs37734530 & I:Atp2b2 & 5.45E-05 \\
\hline 6 & 114046481 & rs583881076 & I:Gm15083 & $8.12 E-03$ \\
\hline 6 & 114134236 & rs227411521 & I:Slc6a1 & 8.12E-03 \\
\hline 6 & 114370888 & rs579728563 & LOC105242741 & $8.12 E-03$ \\
\hline 6 & 114423235 & rs46923527 & I:Hrh1 & 2.39E-06 \\
\hline 6 & 114780885 & rs31440528 & l:Atg7 & 8.10E-07 \\
\hline 6 & 114951759 & rs31456818 & I:Vgll4 & $8.25 E-06$ \\
\hline 6 & 115008370 & rs6262329 & NC:Tamm41 & 3.14E-03 \\
\hline 6 & 115062105 & rs586311125 & Gm36190 & 8.12E-03 \\
\hline 6 & 115134140 & rs261281000 & I:Gm17733 & $8.12 E-03$ \\
\hline 6 & 115181005 & rs31473897 & I:Syn2 & $6.72 \mathrm{E}-04$ \\
\hline 6 & 115310919 & rs31485016 & LOC105242743 & 4.03E-02 \\
\hline 6 & 115321034 & rs31484653 & LOC105242744 & 1.31E-02 \\
\hline 6 & 115464239 & rs51526492 & I:Pparg & 8.71E-05 \\
\hline 6 & 115511777 & rs46370506 & Gm36301 & 1.71E-03 \\
\hline 6 & 115533127 & rs261206240 & I:Gm36355 & 2.22E-03 \\
\hline 6 & 115545283 & rs212720020 & I:Tsen2 & 2.22E-03 \\
\hline 6 & 115591207 & rs586340907 & I:Mkrn2 & $1.92 \mathrm{E}-05$ \\
\hline 6 & 115638313 & rs31494668 & Cs:Raf1 & 6.70E-04 \\
\hline 6 & 115753510 & rs6160517 & I:Tmem40 & 3.14E-03 \\
\hline
\end{tabular}




\begin{tabular}{|c|c|c|c|c|}
\hline 6 & 115782690 & rs31504457 & I:Cand2 & 6.72E-04 \\
\hline 6 & 115808296 & rs224376952 & U5:Rp/32 & 1.08E-02 \\
\hline 6 & 115811422 & rs249935404 & I:Efcab12 & 1.08E-02 \\
\hline 6 & 115853377 & rs31503770 & U5:Mbd4 & 8.08E-03 \\
\hline 6 & 115865708 & rs582751726 & l:Ift122 & 1.71E-03 \\
\hline 6 & 115938833 & rs31509385 & U3:Rho & 1.71E-03 \\
\hline 6 & 115944960 & rs31515230 & U5:H1foo & 1.08E-02 \\
\hline 6 & 115988747 & rs31519252 & I:Plxnd1 & 4.56E-05 \\
\hline 6 & 116104121 & rs235864765 & I:Tmcc1 & $1.32 \mathrm{E}-06$ \\
\hline 6 & 116214868 & rs31533291 & I:Fam21 & $6.72 \mathrm{E}-04$ \\
\hline 6 & 116266396 & rs31533962 & I:Zfand4 & 3.14E-03 \\
\hline 6 & 116383638 & rs31534014 & I:March8 & 5.45E-05 \\
\hline
\end{tabular}

This list was generated using a moderate cut-off $(p<5.00 \mathrm{E}-02)$ using Efficient Mixed Model Association (EMMA). Only the most significant SNP tagging a gene is listed. The functional location of variants is listed using the following notation: intronic (I), synonymous change (Cs), nonsynonymous change (Cn), 3' untranslated region variant (U3), 5' untranslated region variant (U5), not characterized (NC) and no gene (NA). 
Supplementary Table 4. List of genes predicted to be functionally associated with Bphs physiological processes ranked by negative log of false positive rate.

\begin{tabular}{|c|c|c|c|c|c|c|c|c|}
\hline 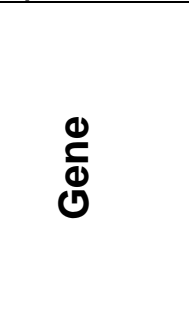 & 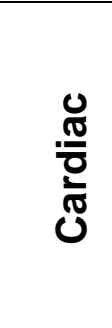 & 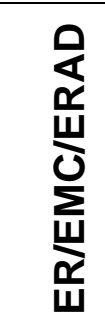 & $\begin{array}{l}\frac{\Upsilon}{U} \\
0 \\
0\end{array}$ & 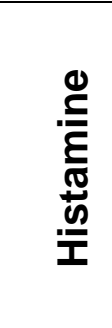 & $\frac{x}{\mathfrak{n}}$ & $\stackrel{I}{\stackrel{I}{F}}$ & $\stackrel{n}{>}$ & $\frac{\underline{\alpha}}{0}$ \\
\hline C3ar1 & 1.38 & 1.22 & 1.32 & 1.71 & 1.56 & 2.89 & 2.36 & 2.89 \\
\hline Plxna1 & 1.10 & 2.24 & 0.64 & 0.43 & 0.60 & 1.03 & 0.53 & 2.24 \\
\hline Tnfrsf1a & 1.35 & 1.35 & 1.22 & 1.07 & 1.33 & 2.08 & 1.18 & 2.08 \\
\hline Ret & 1.81 & 2.03 & 1.04 & 1.06 & 1.17 & 0.88 & 1.20 & 2.03 \\
\hline Tgfa & 1.25 & 2.03 & 0.88 & 0.90 & 0.87 & 1.01 & 1.09 & 2.03 \\
\hline Aqp1 & 1.89 & 1.43 & 0.90 & 0.85 & 0.81 & 1.21 & 1.11 & 1.89 \\
\hline Hrh1 & 1.01 & 1.83 & 0.72 & 0.70 & 0.92 & 0.67 & 0.69 & 1.83 \\
\hline Kcna1 & 1.65 & 1.81 & 1.70 & 0.94 & 1.06 & 0.86 & 0.93 & 1.81 \\
\hline Wnt7a & 0.93 & 1.81 & 0.68 & 0.69 & 0.78 & 1.20 & 0.49 & 1.81 \\
\hline$E m \times 1$ & 1.17 & 1.79 & 1.37 & 1.06 & 1.51 & 0.98 & 0.94 & 1.79 \\
\hline Pex5 & 1.40 & 1.73 & 0.71 & 0.69 & 0.91 & 0.97 & 1.00 & 1.73 \\
\hline Npy & 1.11 & 1.70 & 0.70 & 0.53 & 0.87 & 0.77 & 0.49 & 1.70 \\
\hline Ptpn6 & 0.93 & 1.24 & 1.24 & 1.02 & 1.28 & 1.67 & 1.24 & 1.67 \\
\hline Ogg1 & 0.85 & 1.66 & 0.41 & 0.45 & 0.53 & 0.75 & 0.45 & 1.66 \\
\hline Clec4e & 0.62 & 0.84 & 0.85 & 0.67 & 0.81 & 1.64 & 0.67 & 1.64 \\
\hline Fgf23 & 0.88 & 1.12 & 1.40 & 1.43 & 1.03 & 1.07 & 1.63 & 1.63 \\
\hline Atp2b2 & 0.97 & 1.58 & 0.90 & 0.57 & 0.64 & 0.38 & 0.50 & 1.58 \\
\hline Ghrhr & 1.07 & 1.52 & 1.58 & 0.94 & 1.13 & 0.94 & 0.94 & 1.58 \\
\hline Apobec1 & 0.59 & 1.49 & 0.56 & 0.67 & 0.85 & 1.57 & 0.82 & 1.57 \\
\hline НохаЗ & 0.95 & 1.42 & 1.08 & 0.96 & 1.13 & 1.18 & 1.57 & 1.57 \\
\hline Cxcl12 & 1.57 & 1.26 & 0.70 & 0.61 & 0.91 & 0.90 & 0.80 & 1.57 \\
\hline Nr2c2 & 1.33 & 1.56 & 0.76 & 1.39 & 0.87 & 0.86 & 0.74 & 1.56 \\
\hline Gata2 & 1.13 & 1.55 & 0.84 & 0.69 & 0.93 & 0.95 & 0.75 & 1.55 \\
\hline Snca & 1.41 & 1.54 & 1.49 & 1.24 & 1.23 & 0.79 & 1.20 & 1.54 \\
\hline Cacna1c & 1.43 & 1.27 & 1.54 & 1.12 & 0.71 & 0.65 & 0.77 & 1.54 \\
\hline Mitf & 1.20 & 1.53 & 1.48 & 1.00 & 1.00 & 1.23 & 1.07 & 1.53 \\
\hline $\mathrm{Cd} 4$ & 1.14 & 1.13 & 1.19 & 1.53 & 1.40 & 1.37 & 0.96 & 1.53 \\
\hline Hoxa13 & 1.33 & 1.53 & 1.27 & 0.99 & 1.09 & 1.22 & 1.00 & 1.53 \\
\hline Slc2a3 & 0.81 & 1.52 & 0.68 & 0.46 & 0.79 & 1.09 & 0.54 & 1.52 \\
\hline Dok1 & 0.70 & 1.52 & 0.58 & 0.75 & 0.74 & 1.28 & 0.71 & 1.52 \\
\hline Vhl & 1.30 & 1.50 & 1.13 & 0.94 & 1.19 & 1.38 & 1.13 & 1.50 \\
\hline II17ra & 0.59 & 1.50 & 0.58 & 0.73 & 0.83 & 1.34 & 0.52 & 1.50 \\
\hline Kcna5 & 1.49 & 1.00 & 0.65 & 0.71 & 0.70 & 0.72 & 0.61 & 1.49 \\
\hline Clec4d & 0.43 & 0.85 & 0.55 & 0.74 & 0.82 & 1.49 & 0.60 & 1.49 \\
\hline
\end{tabular}




\begin{tabular}{|c|c|c|c|c|c|c|c|c|}
\hline Adcyap1r1 & 1.41 & 1.48 & 0.87 & 0.58 & 0.80 & 0.80 & 0.53 & 1.48 \\
\hline Hoxa1 & 1.03 & 1.48 & 0.89 & 0.90 & 0.81 & 0.98 & 0.89 & 1.48 \\
\hline Cidec & 1.48 & 0.85 & 0.83 & 0.75 & 0.78 & 1.00 & 0.53 & 1.48 \\
\hline Aicda & 0.64 & 0.76 & 1.47 & 0.92 & 0.66 & 0.63 & 0.67 & 1.47 \\
\hline Bid & 0.91 & 0.95 & 0.81 & 1.47 & 1.06 & 0.79 & 0.87 & 1.47 \\
\hline II12rb2 & 0.85 & 0.68 & 1.40 & 1.46 & 0.99 & 1.01 & 0.90 & 1.46 \\
\hline Hoxa2 & 1.32 & 1.45 & 0.71 & 1.07 & 0.96 & 0.94 & 1.09 & 1.45 \\
\hline Mbd4 & 0.53 & 1.44 & 0.82 & 0.51 & 0.69 & 0.64 & 0.53 & 1.44 \\
\hline TIx2 & 0.94 & 1.42 & 0.51 & 0.68 & 0.66 & 0.76 & .47 & 1.42 \\
\hline Ntf3 & 1.36 & 1.39 & 0.88 & 0.74 & 0.96 & 0.78 & 0.67 & 1.39 \\
\hline Cav3 & 1.39 & 0.85 & 0.59 & 0.45 & 0.70 & 0.81 & 0.52 & 1.39 \\
\hline Sftpb & 0.83 & 1.38 & 0.51 & 0.55 & 0.58 & 0.95 & 0.48 & 1.38 \\
\hline Plxnd1 & 1.16 & 1.38 & 0.63 & 0.46 & 0.94 & 0.83 & 1.00 & 1.38 \\
\hline Rho & 0.93 & 1.38 & 1.30 & 0.89 & 0.90 & 0.89 & 0.70 & 1.38 \\
\hline Ноха9 & 0.80 & 1.35 & 1.04 & 0.77 & 0.71 & 0.75 & 0.64 & 35 \\
\hline Kcmf1 & 0.61 & 1.35 & 0.37 & 0.41 & 0.23 & 0.51 & 0.28 & 1.35 \\
\hline Ptms & 0.94 & 1.35 & 0.28 & 0.13 & 0.22 & 0.67 & 0.34 & 1.35 \\
\hline Lhfpl4 & 0.45 & 1.33 & 0.37 & 0.24 & 0.33 & 0.45 & 0.31 & 1.33 \\
\hline Tacr1 & 1.18 & 1.28 & 1.33 & 1.06 & 1.25 & 1.08 & 0.87 & 33 \\
\hline Hoxa4 & 0.74 & 1.32 & 0.83 & 0.46 & 0.63 & 0.52 & 0.44 & 1.32 \\
\hline Hoxa11 & 0.97 & 1.31 & 0.88 & 0.83 & 0.60 & 0.96 & 0.71 & 1.31 \\
\hline Cd8a & 0.80 & 0.75 & 1.01 & 0.97 & 1.14 & 1.29 & 0.66 & 1.29 \\
\hline Mgll & 1.10 & 1.29 & 0.58 & 0.71 & 0.54 & 0.64 & 0.55 & 1.29 \\
\hline$A b t b 1$ & 0.31 & 1.28 & 0.22 & 0.12 & 0.22 & 0.25 & 0.30 & 1.28 \\
\hline Crhr2 & 1.26 & 1.27 & 1.05 & 0.73 & 0.90 & 0.64 & 0.65 & 1.27 \\
\hline Add2 & 0.97 & 1.05 & 1.25 & 1.05 & 0.98 & 0.72 & 0.96 & 1.25 \\
\hline$M x d 1$ & 0.59 & 1.24 & 0.47 & 0.41 & 0.63 & 1.21 & 0.48 & 1.24 \\
\hline Iqsec1 & 0.36 & 1.24 & 0.34 & 0.27 & 0.26 & 0.39 & 0.13 & 1.24 \\
\hline Reg3g & 0.46 & 0.32 & 0.78 & 0.62 & 0.78 & 1.24 & 0.45 & 1.24 \\
\hline Adamts9 & 0.47 & 1.22 & 0.53 & 0.44 & 0.62 & 0.71 & 0.51 & 1.22 \\
\hline Grid2 & 1.15 & 1.16 & 1.22 & 0.88 & 0.82 & 0.39 & 0.82 & 1.22 \\
\hline Asprv1 & 0.55 & 0.85 & 0.64 & 0.49 & 0.87 & 1.22 & 0.42 & 1.22 \\
\hline Tspan9 & 0.49 & 1.22 & 0.16 & 0.14 & 0.21 & 0.63 & 0.31 & 1.22 \\
\hline Oxtr & 1.21 & 1.21 & 1.14 & 0.71 & 0.75 & 0.55 & 0.67 & 1.21 \\
\hline Cntn4 & 0.80 & 1.21 & 0.87 & 0.40 & 0.51 & 0.39 & 0.20 & 1.21 \\
\hline Pparg & 1.14 & 0.95 & 1.21 & 1.05 & 0.82 & 0.78 & 1.08 & 1.21 \\
\hline Ltbr & 0.72 & 1.00 & 0.32 & 0.35 & 0.50 & 1.21 & 0.62 & 1.21 \\
\hline Trh & 0.74 & 1.20 & 0.62 & 0.59 & 0.58 & 0.72 & 0.41 & 1.20 \\
\hline Atoh1 & 1.15 & 0.73 & 1.20 & 1.19 & 1.00 & 1.18 & 0.82 & 1.20 \\
\hline Lrig1 & 0.45 & 1.19 & 0.42 & 0.33 & 0.42 & 0.43 & 0.41 & 1.19 \\
\hline Gdf3 & 0.90 & 0.88 & 0.77 & 0.73 & 0.80 & 1.19 & 0.57 & 1.19 \\
\hline Smyd1 & 1.17 & 1.03 & 0.72 & 0.55 & 0.58 & 0.52 & 0.65 & 1.17 \\
\hline $\operatorname{Reg} 2$ & 1.08 & 0.62 & 1.17 & 1.17 & 0.72 & 0.91 & 0.53 & 1.17 \\
\hline
\end{tabular}




\begin{tabular}{|c|c|c|c|c|c|c|c|c|}
\hline Slc6a1 & .74 & 1.17 & 0.70 & 0.42 & 0.69 & 0.31 & 0.42 & 1.17 \\
\hline Ctnna2 & .74 & 1.17 & 0.90 & 0.61 & 0.69 & 0.51 & 0.46 & 1.17 \\
\hline Syn2 & 0.77 & 1.16 & 0.87 & 0.49 & 0.53 & 0.68 & .31 & L.16 \\
\hline Sspo & 0.76 & 0.74 & 0.64 & 0.59 & .73 & 1.16 & & \\
\hline Ccnd2 & .96 & 1.15 & .59 & 0.76 & .85 & 1.07 & 63 & \\
\hline C1s1 & .44 & 1.14 & .51 & 0.32 & .35 & 0.64 & 37 & \\
\hline Rad52 & 0.51 & 1.14 & 0.46 & 0.46 & 0.53 & 0.42 & .46 & L. 1 \\
\hline Gp9 & 0.59 & 0.72 & 1.02 & 0.59 & 0.73 & 1.14 & .47 & \\
\hline Dctn1 & .44 & 1.14 & .40 & 0.24 & .48 & 0.41 & 31 & \\
\hline Atn1 & 83 & 1.13 & .64 & 0.46 & .47 & 0.54 & & \\
\hline$H 1 f x$ & .61 & 1.13 & 0.23 & 0.28 & .43 & 0.35 & .22 & L.1 \\
\hline Vax2 & .11 & 1.00 & 0.78 & 0.90 & 0.72 & 0.93 & & $\perp$ \\
\hline Rmnd5a & .29 & 1.11 & 0.18 & 0.15 & .44 & 0.25 & .09 & . \\
\hline Gpr27 & .96 & 1.09 & .71 & 0.42 & .59 & 0.60 & & 09 \\
\hline Hoxa5 & 0.94 & 0.83 & 0.82 & 0.85 & 0.98 & 0.61 & & \\
\hline$A 2 m$ & 0.53 & 0.47 & 0.62 & 0.44 & 0.54 & 1.08 & & \\
\hline Cecr2 & 0.43 & 1.07 & 0.36 & 0.32 & .41 & 0.41 & .41 & .07 \\
\hline Prokr1 & .91 & 0.94 & 1.07 & 0.82 & 0.80 & 3 & & 1.07 \\
\hline Zfp777 & 0.51 & 1.07 & 0.26 & 0.22 & .27 & 0.50 & & \\
\hline Ggcx & 0.78 & 1.07 & 0.37 & 0.50 & 8 & 0.53 & & \\
\hline Tspan11 & 0.38 & 1.06 & 0.38 & 0.36 & 0.28 & 0.44 & 0.29 & .0 \\
\hline Rybp & 0.73 & 1.06 & 0.45 & 0.34 & 0.41 & 0.72 & & 1.06 \\
\hline Ift122 & 0.46 & 1.05 & 5 & & & & & \\
\hline Usp18 & 0.93 & 0.67 & 0.48 & 0.59 & .88 & 1.05 & & \\
\hline Hpgds & 0.84 & 0.65 & 1.05 & 0.90 & 1.01 & 0.83 & 0.80 & 0 \\
\hline Hoxa10 & 0.90 & 0.91 & 0.61 & 0.63 & 0.56 & 1.05 & 0.61 & 1.05 \\
\hline Foxp1 & 0.58 & 1.04 & 0.53 & 0.70 & 0.61 & 0.74 & & 1.04 \\
\hline Slc6a6 & .84 & 1.03 & 0.45 & 0.40 & 5 & 0.58 & & \\
\hline Grm7 & 0.40 & 1.03 & 0.28 & 0.33 & 0.32 & 0.44 & 0.26 & 1.03 \\
\hline Figla & 0.65 & 1.02 & 0.60 & 0.47 & 0.55 & 0.67 & 0.36 & 1.02 \\
\hline Fgf6 & 1.02 & 1.02 & 0.67 & 0.61 & 0.62 & 0.62 & 0.54 & 1.02 \\
\hline Podxl2 & 0.40 & 1.01 & 0.27 & 0.31 & 0.30 & 0.39 & & 01 \\
\hline Cd163 & 0.19 & 0.31 & 1.01 & 0.31 & 0.37 & 0.34 & 0.29 & L.O \\
\hline Antxr1 & 0.59 & 0.79 & 1.01 & 0.56 & 0.84 & 0.68 & 0.77 & L. 0 \\
\hline Sema4f & 0.57 & 1.01 & 0.81 & 0.40 & 0.56 & 0.37 & 0.37 & 1.0 \\
\hline Hoxa7 & 0.55 & 1.01 & 0.54 & 0.54 & 0.62 & 0.52 & 50 & L.O \\
\hline รур26b1 & 0.68 & 1.01 & 0.70 & 0.67 & 0.58 & 0.56 & 0.63 & L.O \\
\hline Ghrl & 1.01 & 0.89 & 0.85 & 0.81 & 0.67 & 0.39 & 0.65 & .0 \\
\hline Mkrn2 & 0.59 & 1.00 & 0.28 & 0.39 & 0.29 & 0.35 & 0.27 & 1.00 \\
\hline Tuba8 & 0.82 & 1.00 & 0.32 & 0.34 & 0.42 & 0.51 & 0.32 & 1.0 \\
\hline Mfap5 & 0.78 & 0.56 & 0.43 & 0.42 & 0.40 & 0.99 & 0.42 & 0.9 \\
\hline Rtkn & 0.36 & 0.98 & 0.24 & 0.30 & 0.42 & 0.35 & 0.38 & 0.9 \\
\hline Alms1 & 0.62 & 0.80 & 0.69 & 0.89 & 0.97 & 0.37 & 0.85 & 0.9 \\
\hline
\end{tabular}




\begin{tabular}{|c|c|c|c|c|c|c|c|c|}
\hline Ноха6 & 0.35 & 0.97 & 0.37 & 0.24 & 0.32 & 0.45 & 0.26 & 0.97 \\
\hline Wnk1 & 0.57 & 0.96 & 0.33 & 0.41 & 0.39 & 0.64 & 0.43 & 0.96 \\
\hline Mpp6 & 0.18 & 0.96 & 0.23 & 0.21 & 0.28 & 0.25 & 0.15 & 0.96 \\
\hline Actg2 & 0.48 & 0.57 & 0.30 & 0.45 & 0.41 & 0.96 & 0.33 & 0.96 \\
\hline Gmcl1 & 0.35 & 0.96 & 0.31 & 0.28 & 0.24 & 0.38 & .30 & .96 \\
\hline Clstn3 & 0.45 & 0.96 & 0.29 & 0.30 & 0.24 & 0.29 & .38 & .96 \\
\hline Kcna6 & 0.78 & 0.95 & 0.93 & 0.50 & 0.64 & 0.50 & 0.50 & .95 \\
\hline Cntnap2 & 0.41 & 0.95 & 0.42 & 0.31 & 0.39 & 0.25 & 0.25 & 5 \\
\hline Bola3 & 0.36 & 0.95 & 0.35 & 0.16 & 0.08 & 0.31 & .20 & .95 \\
\hline Edem1 & 0.25 & 0.35 & 0.36 & 0.25 & 0.27 & 0.95 & .31 & 95 \\
\hline Pcgf1 & 0.18 & 0.94 & 0.22 & 0.19 & 0.19 & 0.24 & 0.20 & 0.94 \\
\hline Gimap5 & 0.56 & 0.94 & 0.57 & 0.53 & 0.55 & 0.65 & 0.62 & 0.94 \\
\hline Clec4n & 0.34 & 0.47 & 0.42 & 0.53 & 0.68 & 0.94 & .81 & 0.94 \\
\hline Rnf103 & 0.21 & 0.94 & 0.28 & 0.28 & 0.29 & 0.43 & 34 & .94 \\
\hline Kdm5a & 0.49 & 0.93 & 0.34 & 0.50 & 0.52 & 0.53 & 0.47 & 0.93 \\
\hline$E v \times 1$ & 0.58 & 0.41 & 0.93 & 0.64 & 0.57 & 0.55 & 0.44 & .93 \\
\hline Slc6a11 & 0.36 & 0.93 & 0.31 & 0.31 & 0.36 & 0.32 & 0.28 & 0.93 \\
\hline Timp4 & 0.58 & 0.92 & 0.44 & 0.34 & 0.34 & 0.46 & 0.40 & 0.92 \\
\hline KIf15 & 0.92 & 0.79 & 0.49 & 0.50 & 0.57 & 0.45 & 0.51 & 0.92 \\
\hline Dnajb8 & 0.68 & 0.62 & 0.92 & 0.53 & 0.63 & 0.62 & 0.55 & 0.92 \\
\hline Raf1 & 0.48 & 0.92 & 0.53 & 0.73 & 0.73 & 0.65 & 0.64 & 0.92 \\
\hline Itpr1 & 0.74 & 0.82 & 0.34 & 0.31 & 0.45 & 0.91 & 0.36 & 0.91 \\
\hline rmem176a & 0.47 & 0.60 & 0.26 & 0.27 & 0.46 & 0.91 & 0.36 & 0.91 \\
\hline Creb5 & 0.73 & 0.91 & 0.47 & 0.65 & 0.65 & 0.58 & 0.48 & 0.91 \\
\hline Egr4 & 0.59 & 0.91 & 0.45 & 0.42 & 0.41 & 0.60 & 0.42 & 0.91 \\
\hline Aoc1 & 0.63 & 0.84 & 0.55 & 0.42 & 0.72 & 0.91 & 0.46 & 0.91 \\
\hline Aldh1/1 & 0.57 & 0.90 & 0.29 & 0.32 & 0.21 & 0.51 & 0.29 & 0.90 \\
\hline LoxI3 & 0.45 & 0.90 & 0.56 & 0.38 & 0.45 & 0.61 & 0.36 & 0.90 \\
\hline Atp6v1b1 & 0.32 & 0.89 & 0.59 & 0.34 & 0.46 & 0.42 & 0.41 & 0.89 \\
\hline Slc6a13 & 0.50 & 0.89 & 0.33 & 0.34 & 0.40 & 0.48 & 0.29 & 0.89 \\
\hline Bhlhe40 & 0.83 & 0.60 & 0.42 & 0.44 & 0.47 & 0.89 & 0.47 & 0.89 \\
\hline Rarres2 & 0.71 & 0.88 & 0.49 & 0.34 & 0.31 & 0.53 & 0.39 & 0.88 \\
\hline Fbln2 & 0.69 & 0.43 & 0.44 & 0.36 & 0.44 & 0.88 & 0.47 & 0.88 \\
\hline Gpr162 & 0.58 & 0.88 & 0.56 & 0.38 & 0.48 & 0.64 & 0.34 & 0.88 \\
\hline Skap2 & 0.36 & 0.54 & 0.42 & 0.32 & 0.45 & 0.88 & 0.24 & 0.88 \\
\hline II5ra & 0.47 & 0.55 & 0.87 & 0.55 & 0.53 & 0.52 & 0.56 & 0.87 \\
\hline Reg3a & 0.41 & 0.49 & 0.87 & 0.57 & 0.56 & 0.36 & 0.38 & 0.87 \\
\hline Aak1 & 0.51 & 0.87 & 0.55 & 0.39 & 0.47 & 0.24 & 0.32 & 0.87 \\
\hline C1ra & 0.60 & 0.55 & 0.37 & 0.38 & 0.60 & 0.87 & 0.40 & 0.87 \\
\hline Reg1 & 0.51 & 0.55 & 0.86 & 0.65 & 0.54 & 0.60 & 0.43 & 0.86 \\
\hline Magi1 & 0.50 & 0.69 & 0.86 & 0.32 & 0.35 & 0.48 & 0.40 & 0.86 \\
\hline Bmp10 & 0.85 & 0.84 & 0.68 & 0.58 & 0.61 & 0.86 & 0.49 & 0.86 \\
\hline Gng12 & 0.25 & 0.33 & 0.30 & 0.30 & 0.16 & 0.86 & 0.29 & 0.86 \\
\hline
\end{tabular}




\begin{tabular}{|c|c|c|c|c|c|c|c|c|}
\hline P3h3 & 0.41 & 0.86 & 0.48 & 0.31 & 0.42 & 0.56 & 0.25 & 0.86 \\
\hline Mcm2 & 0.39 & 0.44 & 0.65 & 0.42 & 0.86 & 0.48 & 0.56 & 0.86 \\
\hline Clec4a2 & 0.41 & 0.57 & 0.47 & 0.69 & 0.60 & 0.86 & 0.46 & 0.86 \\
\hline Akap3 & 0.40 & 0.46 & 0.85 & 0.44 & 0.46 & 0.48 & 0.42 & 0.85 \\
\hline Vmn1r12 & 0.15 & 0.16 & 0.85 & 0.24 & 0.19 & 0.27 & 0.18 & 0.85 \\
\hline Wbp1 & 0.47 & 0.85 & 0.23 & 0.10 & 0.11 & 0.39 & 0.08 & 0.85 \\
\hline Stambp & 0.54 & 0.85 & 0.34 & 0.34 & 0.42 & 0.43 & 0.38 & 0.85 \\
\hline $\operatorname{Lag} 3$ & 0.59 & 0.85 & 0.60 & 0.56 & 0.76 & 0.66 & 0.57 & 0.85 \\
\hline Grip2 & 0.38 & 0.85 & 0.46 & 0.40 & 0.35 & 0.41 & 0.42 & 0.85 \\
\hline Rab43 & 0.64 & 0.84 & 0.53 & 0.32 & 0.31 & 0.58 & 0.39 & 0.84 \\
\hline Capg & 0.35 & 0.76 & 0.43 & 0.61 & 0.52 & 0.84 & 0.53 & 0.84 \\
\hline Zfp384 & 0.39 & 0.83 & 0.42 & 0.33 & 0.17 & 0.41 & 0.33 & 0.83 \\
\hline Rimklb & 0.46 & 0.83 & 0.40 & 0.36 & 0.28 & 0.43 & 0.19 & 0.83 \\
\hline Nfe2/3 & 0.67 & 0.83 & 0.49 & 0.52 & 0.46 & 0.70 & 0.42 & 0.83 \\
\hline Eif2ak3 & 0.56 & 0.78 & 0.83 & 0.68 & 0.83 & 0.77 & 0.71 & 0.83 \\
\hline Cntn3 & 0.55 & 0.42 & 0.83 & 0.44 & 0.50 & 0.32 & 0.36 & 0.83 \\
\hline Atg7 & 0.58 & 0.82 & 0.64 & 0.46 & 0.56 & 0.62 & 0.56 & 0.82 \\
\hline KIrg1 & 0.55 & 0.82 & 0.71 & 0.55 & 0.55 & 0.64 & 0.39 & 0.82 \\
\hline Rasgef1a & 0.42 & 0.80 & 0.76 & 0.28 & 0.28 & 0.48 & 0.15 & 0.80 \\
\hline Aup1 & 0.51 & 0.80 & 0.23 & 0.18 & 0.18 & 0.40 & 0.32 & 0.80 \\
\hline Nop2 & 0.27 & 0.39 & 0.18 & 0.27 & 0.16 & 0.80 & 0.19 & 0.80 \\
\hline$V w f$ & 0.58 & 0.80 & 0.65 & 0.43 & 0.57 & 0.60 & 0.72 & 0.80 \\
\hline Dysf & 0.67 & 0.67 & 0.43 & 0.38 & 0.40 & 0.80 & 0.44 & 0.80 \\
\hline Nat8f1 & 0.51 & 0.80 & 0.33 & 0.29 & 0.49 & 0.46 & 0.19 & 0.80 \\
\hline Prr15 & 0.44 & 0.79 & 0.61 & 0.36 & 0.50 & 0.64 & 0.33 & 0.79 \\
\hline Nanog & 0.41 & 0.54 & 0.50 & 0.47 & 0.32 & 0.79 & 0.40 & 0.79 \\
\hline $\operatorname{Reg} 3 b$ & 0.40 & 0.32 & 0.78 & 0.47 & 0.65 & 0.56 & 0.40 & 0.78 \\
\hline Gt(ROSA)26Sor & 0.34 & 0.37 & 0.60 & 0.78 & 0.75 & 0.37 & 0.63 & 0.78 \\
\hline 1700003E16Rik & 0.36 & 0.78 & 0.27 & 0.25 & 0.13 & 0.40 & 0.25 & 0.78 \\
\hline Necap1 & 0.26 & 0.77 & 0.26 & 0.20 & 0.27 & 0.29 & 0.19 & 0.77 \\
\hline Tacstd2 & 0.42 & 0.37 & 0.44 & 0.39 & 0.55 & 0.77 & 0.34 & 0.77 \\
\hline Wipf3 & 0.39 & 0.77 & 0.32 & 0.32 & 0.44 & 0.40 & 0.21 & 0.77 \\
\hline Gadd45a & 0.70 & 0.70 & 0.50 & 0.64 & 0.70 & 0.77 & 0.66 & 0.77 \\
\hline Neurod6 & 0.65 & 0.77 & 0.71 & 0.45 & 0.55 & 0.57 & 0.49 & 0.77 \\
\hline Mturn & 0.56 & 0.77 & 0.49 & 0.34 & 0.43 & 0.65 & 0.34 & 0.77 \\
\hline Slc41a3 & 0.48 & 0.77 & 0.39 & 0.32 & 0.38 & 0.23 & 0.34 & 0.77 \\
\hline Gimap4 & 0.44 & 0.76 & 0.51 & 0.46 & 0.61 & 0.50 & 0.45 & 0.76 \\
\hline Gnb3 & 0.55 & 0.46 & 0.76 & 0.37 & 0.44 & 0.43 & 0.28 & 0.76 \\
\hline Repin1 & 0.42 & 0.76 & 0.30 & 0.25 & 0.30 & 0.42 & 0.15 & 0.76 \\
\hline Prok2 & 0.47 & 0.76 & 0.53 & 0.38 & 0.32 & 0.46 & 0.35 & 0.76 \\
\hline Erc1 & 0.40 & 0.76 & 0.38 & 0.33 & 0.18 & 0.41 & 0.26 & 0.76 \\
\hline Ano2 & 0.33 & 0.75 & 0.32 & 0.19 & 0.37 & 0.31 & 0.39 & 0.75 \\
\hline Arpc4 & 0.46 & 0.41 & 0.22 & 0.16 & 0.53 & 0.75 & 0.17 & 0.75 \\
\hline
\end{tabular}




\begin{tabular}{|c|c|c|c|c|c|c|c|c|}
\hline Hdhd5 & 0.44 & 0.74 & 0.63 & 0.45 & 0.44 & 0.15 & 0.41 & 0.74 \\
\hline Chn2 & 0.40 & 0.74 & 0.34 & 0.30 & 0.36 & 0.28 & 0.34 & 0.74 \\
\hline Zfp467 & 0.42 & 0.74 & 0.16 & 0.31 & 0.50 & 0.57 & 0.24 & 0.74 \\
\hline Retsat & 0.54 & 0.73 & 0.31 & 0.29 & 0.17 & 0.41 & 0.26 & 0.73 \\
\hline Phc1 & 0.39 & 0.73 & 0.49 & 0.40 & 0.50 & 0.21 & 0.50 & 0.73 \\
\hline Dрра3 & 0.71 & 0.57 & 0.57 & 0.67 & 0.73 & 0.67 & 0.50 & 0.73 \\
\hline Gapdh & 0.73 & 0.59 & 0.33 & 0.28 & 0.43 & 0.37 & 0.39 & 0.73 \\
\hline Mlf2 & 0.43 & 0.73 & 0.25 & 0.19 & 0.42 & 0.41 & 0.18 & 0.73 \\
\hline Mug1 & 0.52 & 0.73 & 0.43 & 0.62 & 0.71 & 0.62 & 0.47 & 0.73 \\
\hline Ezh2 & 0.31 & 0.59 & 0.23 & 0.36 & 0.72 & 0.32 & 0.36 & 0.72 \\
\hline Fxyd4 & 0.64 & 0.72 & 0.47 & 0.48 & 0.47 & 0.58 & 0.58 & 0.72 \\
\hline Scnn1a & 0.65 & 0.72 & 0.66 & 0.57 & 0.47 & 0.51 & 0.57 & 0.72 \\
\hline Hnrnpa2b1 & 0.19 & 0.35 & 0.25 & 0.20 & 0.72 & 0.22 & 0.21 & 0.72 \\
\hline Vmn1r45 & 0.25 & 0.21 & 0.72 & 0.30 & 0.24 & 0.18 & 0.30 & 0.72 \\
\hline Cd8b1 & 0.46 & 0.65 & 0.43 & 0.43 & 0.59 & 0.72 & 0.49 & 0.72 \\
\hline Htra2 & 0.43 & 0.71 & 0.29 & 0.40 & 0.61 & 0.42 & 0.44 & 0.71 \\
\hline$C d 9$ & 0.33 & 0.60 & 0.28 & 0.34 & 0.24 & 0.71 & 0.45 & 0.71 \\
\hline Aplf & 0.40 & 0.71 & 0.33 & 0.42 & 0.43 & 0.37 & 0.30 & 0.71 \\
\hline Noto & 0.48 & 0.70 & 0.40 & 0.36 & 0.53 & 0.57 & 0.44 & 0.70 \\
\hline Cycs & 0.43 & 0.70 & 0.26 & 0.64 & 0.70 & 0.25 & 0.41 & 0.70 \\
\hline Txnrd3 & 0.37 & 0.70 & 0.26 & 0.26 & 0.40 & 0.29 & 0.22 & 0.70 \\
\hline Pcbp1 & 0.18 & 0.21 & 0.18 & 0.22 & 0.69 & 0.20 & 0.19 & 0.69 \\
\hline C1rl & 0.26 & 0.34 & 0.69 & 0.23 & 0.26 & 0.27 & 0.24 & 0.69 \\
\hline Mad2I1 & 0.24 & 0.46 & 0.19 & 0.32 & 0.69 & 0.28 & 0.31 & 0.69 \\
\hline Vmn2r26 & 0.47 & 0.69 & 0.51 & 0.46 & 0.46 & 0.48 & 0.36 & 0.69 \\
\hline Pde1c & 0.38 & 0.68 & 0.52 & 0.29 & 0.37 & 0.17 & 0.30 & 0.68 \\
\hline Tmem121b & 0.42 & 0.68 & 0.50 & 0.37 & 0.38 & 0.17 & 0.29 & 0.68 \\
\hline Adipor2 & 0.60 & 0.68 & 0.45 & 0.45 & 0.36 & 0.38 & 0.38 & 0.68 \\
\hline Atoh8 & 0.40 & 0.57 & 0.67 & 0.35 & 0.22 & 0.41 & 0.41 & 0.67 \\
\hline Tmem40 & 0.41 & 0.60 & 0.50 & 0.37 & 0.47 & 0.67 & 0.33 & 0.67 \\
\hline Vmn1r41 & 0.42 & 0.32 & 0.67 & 0.53 & 0.49 & 0.44 & 0.42 & 0.67 \\
\hline Elmod3 & 0.54 & 0.66 & 0.26 & 0.18 & 0.31 & 0.24 & 0.05 & 0.66 \\
\hline Tgoln1 & 0.38 & 0.66 & 0.27 & 0.32 & 0.36 & 0.55 & 0.21 & 0.66 \\
\hline Iffo1 & 0.33 & 0.66 & 0.34 & 0.33 & 0.07 & 0.28 & 0.21 & 0.66 \\
\hline Plekhg6 & 0.49 & 0.66 & 0.38 & 0.40 & 0.36 & 0.58 & 0.41 & 0.66 \\
\hline Sfxn5 & 0.37 & 0.66 & 0.32 & 0.32 & 0.21 & 0.32 & 0.19 & 0.66 \\
\hline Cd207 & 0.39 & 0.51 & 0.61 & 0.47 & 0.65 & 0.48 & 0.45 & 0.65 \\
\hline Emg1 & 0.18 & 0.65 & 0.18 & 0.24 & 0.50 & 0.22 & 0.19 & 0.65 \\
\hline Chd4 & 0.26 & 0.65 & 0.38 & 0.29 & 0.43 & 0.40 & 0.45 & 0.65 \\
\hline Rab11fip5 & 0.41 & 0.65 & 0.29 & 0.22 & 0.23 & 0.54 & 0.33 & 0.65 \\
\hline$L b \times 2$ & 0.41 & 0.65 & 0.45 & 0.41 & 0.43 & 0.43 & 0.45 & 0.65 \\
\hline Fkbp9 & 0.29 & 0.18 & 0.28 & 0.15 & 0.45 & 0.65 & 0.25 & 0.65 \\
\hline 700063H04Rik & 0.40 & 0.36 & 0.65 & 0.30 & 0.24 & 0.20 & 0.36 & 0.65 \\
\hline
\end{tabular}




\begin{tabular}{|c|c|c|c|c|c|c|c|c|}
\hline Snx10 & 0.33 & 0.24 & 0.25 & 0.29 & 0.46 & 0.65 & 0.26 & 0.65 \\
\hline Gpnmb & 0.38 & 0.62 & 0.51 & 0.36 & 0.50 & 0.64 & 0.39 & 0.64 \\
\hline Tpra1 & 0.31 & 0.64 & 0.27 & 0.14 & 0.41 & 0.39 & 0.16 & 0.64 \\
\hline Wnt5b & 0.46 & 0.64 & 0.38 & 0.36 & 0.30 & 0.57 & 0.28 & 0.64 \\
\hline Ccdc142 & 0.29 & 0.64 & 0.31 & 0.21 & 0.21 & 0.36 & 0.12 & 0.64 \\
\hline Rab7 & 0.26 & 0.37 & 0.32 & 0.21 & 0.45 & 0.64 & 0.19 & 0.64 \\
\hline $\mathrm{Cd} 27$ & 0.46 & 0.49 & 0.61 & 0.55 & 0.64 & 0.53 & 0.49 & 0.64 \\
\hline Usp5 & 0.47 & 0.63 & 0.32 & 0.25 & 0.09 & 0.41 & 0.14 & 0.63 \\
\hline Nod1 & 0.30 & 0.63 & 0.38 & 0.30 & 0.39 & 0.36 & .33 & .63 \\
\hline Fgd5 & 0.48 & 0.63 & 0.40 & 0.29 & 0.25 & 0.41 & .39 & .63 \\
\hline Mob1a & 0.46 & 0.63 & 0.29 & 0.33 & 0.34 & 0.51 & 0.25 & 0.63 \\
\hline Fbxo41 & 0.44 & 0.63 & 0.30 & 0.24 & 0.42 & 0.41 & 0.25 & 0.63 \\
\hline Mrpl53 & 0.19 & 0.63 & 0.26 & 0.17 & 0.22 & 0.24 & 0.15 & 0.63 \\
\hline Uroc1 & 0.48 & 0.63 & 0.46 & 0.36 & 0.33 & 0.46 & 36 & 0.6 \\
\hline Copg1 & 0.23 & 0.30 & 0.18 & 0.23 & 0.33 & 0.62 & 0.23 & 0.62 \\
\hline Zfp9 & 0.30 & 0.62 & 0.40 & 0.26 & 0.29 & 0.34 & 0.21 & 0.62 \\
\hline Nap1/5 & 0.38 & 0.62 & 0.43 & 0.27 & 0.27 & 0.27 & 0.29 & 0.62 \\
\hline Chl1 & 0.39 & 0.45 & 0.48 & 0.41 & 0.62 & 0.43 & 0.38 & 0.6 \\
\hline Slc6a12 & 0.62 & 0.51 & 0.58 & 0.41 & 0.42 & 0.41 & 0.39 & 0. \\
\hline Iqsec3 & 0.22 & 0.40 & 0.62 & 0.32 & 0.34 & 0.18 & 0.15 & 0 \\
\hline Fancd2 & 0.53 & 0.56 & 0.43 & 0.50 & 0.62 & 0.29 & 0.45 & 0.62 \\
\hline Hdac11 & 0.31 & 0.62 & 0.27 & 0.15 & 0.26 & 0.18 & 0.29 & 0.62 \\
\hline Rassf4 & 0.38 & 0.62 & 0.40 & 0.28 & 0.28 & 0.60 & 0.29 & 0.62 \\
\hline Vmn1r47 & 0.36 & 0.35 & 0.62 & 0.40 & 0.52 & 0.44 & 0.42 & 0.62 \\
\hline Ninj2 & 0.54 & 0.52 & 0.45 & 0.36 & 0.43 & 0.62 & 0.32 & 0.62 \\
\hline Washc2 & 0.25 & 0.61 & 0.28 & 0.18 & 0.25 & 0.40 & 0.16 & 0.61 \\
\hline Parp11 & 0.30 & 0.61 & 0.37 & 0.25 & 0.28 & 0.31 & 0.30 & 0.61 \\
\hline mem176b & 0.40 & 0.48 & 0.29 & 0.54 & 0.35 & 0.61 & 0.33 & 0.61 \\
\hline Lrrc23 & 0.55 & 0.43 & 0.43 & 0.41 & 0.46 & 0.61 & 0.44 & 0.61 \\
\hline Vopp1 & 0.22 & 0.61 & 0.50 & 0.35 & 0.20 & 0.37 & 0.36 & 0.61 \\
\hline Tex261 & 0.30 & 0.61 & 0.24 & 0.21 & 0.13 & 0.35 & 0.28 & 0.61 \\
\hline Tuba3a & 0.29 & 0.60 & 0.24 & 0.27 & 0.26 & 0.49 & 0.23 & 0.60 \\
\hline Vmn1r42 & 0.35 & 0.29 & 0.60 & 0.43 & 0.36 & 0.35 & 0.35 & 0.60 \\
\hline Tril & 0.41 & 0.60 & 0.42 & 0.28 & 0.41 & 0.48 & 0.33 & 0.60 \\
\hline Eno2 & 0.35 & 0.60 & 0.33 & 0.29 & 0.42 & 0.38 & 0.40 & 0.60 \\
\hline Ino80b & 0.32 & 0.60 & 0.33 & 0.23 & 0.08 & 0.35 & 0.17 & 0.60 \\
\hline Immt & 0.32 & 0.60 & 0.18 & 0.28 & 0.28 & 0.35 & 0.15 & 0.60 \\
\hline Smyd5 & 0.21 & 0.60 & 0.50 & 0.14 & 0.30 & 0.35 & 0.18 & 0.60 \\
\hline Fbxl14 & 0.24 & 0.29 & 0.18 & 0.33 & 0.23 & 0.59 & 0.17 & 0.59 \\
\hline Alox5 & 0.41 & 0.47 & 0.51 & 0.48 & 0.59 & 0.58 & 0.49 & 0.59 \\
\hline Tapbpl & 0.44 & 0.59 & 0.51 & 0.32 & 0.45 & 0.51 & 0.28 & 0.59 \\
\hline Gkn1 & 0.24 & 0.57 & 0.59 & 0.34 & 0.43 & 0.34 & 0.23 & 0.59 \\
\hline Prickle2 & 0.37 & 0.59 & 0.35 & 0.28 & 0.37 & 0.30 & 0.25 & 0.59 \\
\hline
\end{tabular}




\begin{tabular}{|c|c|c|c|c|c|c|c|c|}
\hline Cacna2d4 & 0.26 & 0.58 & 0.35 & 0.24 & 0.22 & 0.25 & 0.35 & 0.58 \\
\hline Atp6v0e2 & 0.30 & 0.58 & 0.30 & 0.20 & 0.36 & 0.22 & 0.21 & 0.58 \\
\hline Ankrd26 & 0.47 & 0.48 & 0.56 & 0.58 & 0.54 & 0.35 & 0.51 & 0.58 \\
\hline Fam221a & 0.18 & 0.39 & 0.58 & 0.15 & 0.12 & 0.18 & 0.20 & .58 \\
\hline Creld1 & 0.33 & 0.58 & 0.29 & 0.14 & 0.26 & 0.33 & 0.16 & .58 \\
\hline Vamp1 & 0.38 & 0.58 & 0.37 & 0.35 & 0.41 & 0.55 & 0.34 & 0.58 \\
\hline Cntn6 & 0.37 & 0.58 & 0.52 & 0.43 & 0.33 & 0.32 & .33 & 0.58 \\
\hline 4921507P07Rik & 0.40 & 0.58 & 0.25 & 0.25 & 0.09 & 0.43 & .30 & .58 \\
\hline Krcc1 & 0.22 & 0.57 & 0.19 & 0.20 & 0.17 & 0.29 & 0.09 & .57 \\
\hline$D q \times 1$ & 0.36 & 0.53 & 0.57 & 0.27 & 0.36 & 0.35 & 0.29 & 0.57 \\
\hline Acrbp & 0.28 & 0.57 & 0.48 & 0.30 & 0.46 & 0.31 & 0.25 & 0.57 \\
\hline Pole4 & 0.15 & 0.25 & 0.24 & 0.24 & 0.57 & 0.17 & 0.20 & .57 \\
\hline St3gal5 & 0.36 & 0.57 & 0.31 & 0.33 & 0.22 & 0.28 & 0.22 & .57 \\
\hline Tet3 & 0.36 & 0.57 & 0.36 & 0.31 & 0.19 & 0.38 & 0.14 & 0.57 \\
\hline Vmn1r20 & 0.16 & 0.23 & 0.57 & 0.20 & 0.14 & 0.21 & 0.21 & 0.57 \\
\hline Vmn1r25 & 0.24 & 0.24 & 0.57 & 0.38 & 0.42 & 0.46 & 0.34 & 0.57 \\
\hline Ing4 & 0.41 & 0.57 & 0.39 & 0.31 & 0.44 & 0.44 & 0.29 & .57 \\
\hline Gkn2 & 0.35 & 0.38 & 0.56 & 0.42 & 0.45 & 0.43 & 0.37 & 0.56 \\
\hline Hoxa11os & 0.55 & 0.39 & 0.38 & 0.39 & 0.56 & 0.44 & 0.39 & 0.56 \\
\hline Vmn1r27 & 0.10 & 0.27 & 0.56 & 0.28 & 0.18 & 0.15 & 0.22 & 0.56 \\
\hline Tcf7l1 & 0.40 & 0.56 & 0.43 & 0.43 & 0.48 & 0.30 & 0.49 & 0.56 \\
\hline II17re & 0.40 & 0.56 & 0.47 & 0.39 & 0.32 & 0.45 & 0.42 & 0.56 \\
\hline Spsb2 & 0.46 & 0.56 & 0.39 & 0.33 & 0.29 & 0.42 & 0.43 & 0.56 \\
\hline Vmn1r15 & 0.43 & 0.37 & 0.54 & 0.39 & 0.56 & 0.37 & 0.35 & 0.56 \\
\hline Vmn1r26 & 0.21 & 0.25 & 0.56 & 0.26 & 0.14 & 0.15 & 0.28 & 0.56 \\
\hline Anxa4 & 0.31 & 0.35 & 0.32 & 0.26 & 0.19 & 0.56 & 0.32 & 0.56 \\
\hline Mrpl51 & 0.31 & 0.56 & 0.45 & 0.28 & 0.10 & 0.28 & 0.14 & 0.56 \\
\hline Lrrn1 & 0.43 & 0.55 & 0.55 & 0.36 & 0.43 & 0.47 & 0.31 & 0.55 \\
\hline Gfpt1 & 0.44 & 0.44 & 0.48 & 0.35 & 0.17 & 0.55 & 0.33 & 0.55 \\
\hline Arl8b & 0.24 & 0.34 & 0.55 & 0.21 & 0.18 & 0.41 & 0.29 & 0.55 \\
\hline$Z x d c$ & 0.43 & 0.55 & 0.49 & 0.27 & 0.21 & 0.44 & 0.23 & 0.55 \\
\hline Fabp1 & 0.55 & 0.46 & 0.44 & 0.43 & 0.51 & 0.52 & 0.40 & 0.55 \\
\hline Reg3d & 0.23 & 0.32 & 0.55 & 0.44 & 0.45 & 0.49 & 0.42 & 0.55 \\
\hline Vmn1r46 & 0.32 & 0.32 & 0.55 & 0.42 & 0.46 & 0.40 & 0.39 & 0.55 \\
\hline Frmd4b & 0.34 & 0.50 & 0.46 & 0.25 & 0.23 & 0.55 & 0.35 & 0.55 \\
\hline Fam136a & 0.13 & 0.25 & 0.22 & 0.30 & 0.54 & 0.20 & 0.19 & 0.54 \\
\hline Irak2 & 0.27 & 0.54 & 0.35 & 0.21 & 0.31 & 0.39 & 0.24 & 0.54 \\
\hline H1foo & 0.45 & 0.54 & 0.39 & 0.36 & 0.40 & 0.47 & 0.23 & 0.54 \\
\hline Zfp239 & 0.31 & 0.32 & 0.54 & 0.32 & 0.40 & 0.16 & 0.33 & 0.54 \\
\hline Mmrn1 & 0.27 & 0.26 & 0.54 & 0.32 & 0.38 & 0.37 & 0.43 & 0.54 \\
\hline Efcc1 & 0.38 & 0.36 & 0.54 & 0.36 & 0.19 & 0.41 & 0.31 & 0.54 \\
\hline Mthfd2 & 0.26 & 0.47 & 0.26 & 0.46 & 0.45 & 0.54 & 0.30 & 0.54 \\
\hline Ndnf & 0.25 & 0.35 & 0.53 & 0.26 & 0.40 & 0.30 & 0.29 & 0.53 \\
\hline
\end{tabular}




\begin{tabular}{|c|c|c|c|c|c|c|c|c|}
\hline Npvf & 0.28 & 0.30 & 0.53 & 0.43 & 0.44 & 0.24 & 0.35 & 0.53 \\
\hline Olfr215 & 0.26 & 0.53 & 0.32 & 0.31 & 0.20 & 0.32 & 0.23 & 052 \\
\hline Krba1 & 0.24 & 0.53 & 0.16 & 0.20 & 0.27 & 0.14 & 0.24 & 0.53 \\
\hline Tmem150a & 0.48 & 0.53 & 0.27 & 0.28 & 0.40 & 0.35 & 0.26 & .5 \\
\hline$C b \times 3$ & 0.30 & 0.53 & 0.24 & 0.31 & 0.27 & 0.45 & 0.33 & 0.53 \\
\hline Fam13a & 0.52 & 0.38 & 0.37 & 0.23 & 0.20 & 0.45 & 0.35 & $\tau$ \\
\hline Prmt8 & 0.40 & 0.52 & 0.36 & 0.29 & 0.29 & 0.42 & 0.17 & \\
\hline Pianp & 0.26 & 0.40 & 0.52 & 0.32 & 0.30 & 0.22 & 0.25 & .5 \\
\hline Clec4f & 0.50 & 0.49 & 0.41 & 0.44 & 0.43 & 0.52 & 0.33 & 0.52 \\
\hline Kbtbd12 & 0.37 & 0.35 & 0.52 & 0.38 & 0.45 & 0.24 & 0.37 & 0.5 \\
\hline Clec4a3 & 0.32 & 0.43 & 0.52 & 0.34 & 0.37 & 0.33 & 0.32 & \\
\hline Abcg2 & 0.25 & 0.31 & 0.36 & 0.52 & 0.38 & 0.32 & 0.32 & 0.5 \\
\hline Spr & 0.47 & 0.51 & 0.29 & 0.16 & 0.24 & 0.29 & 0.18 & 51 \\
\hline Foxj2 & 0.37 & 0.51 & 0.40 & 0.26 & 0.44 & 0.39 & 0.41 & 0.5 \\
\hline Ppp1r17 & 0.43 & 0.40 & 0.51 & 0.32 & 0.42 & 0.34 & 0.34 & \\
\hline Vmn1r40 & 0.32 & 0.30 & 0.51 & 0.38 & 0.45 & 0.45 & 0.33 & \\
\hline Ptcd3 & 0.19 & 0.34 & 0.46 & 0.51 & 0.51 & 0.17 & 0.08 & 1 \\
\hline II17rc & 0.51 & 0.50 & 0.32 & 0.27 & 0.45 & 0.36 & 0.36 & 0.5 \\
\hline M1ap & 0.36 & 0.51 & 0.39 & 0.37 & 0.36 & 0.38 & 0.44 & 0.5 \\
\hline Gimap9 & 0.30 & 0.43 & 0.51 & 0.31 & 0.34 & 0.37 & 0.27 & \\
\hline ВC048671 & 0.22 & 0.38 & 0.51 & 0.35 & 0.38 & 0.22 & 0.42 & \\
\hline Inmt & 0.49 & 0.50 & 0.49 & 0.41 & 0.42 & 0.51 & 0.38 & 0.5 \\
\hline Gm5111 & 0.36 & 0.49 & 0.32 & 0.26 & 0.42 & 0.51 & 0.23 & 0. \\
\hline Tmcc1 & 0.30 & 0.51 & 0.27 & 0.15 & 0.35 & 0.36 & 0.22 & 0 \\
\hline Chst13 & 0.33 & 0.35 & 0.51 & & 0.27 & 0.41 & 0.14 & \\
\hline Arhgap25 & 0.27 & 0.29 & 0.51 & 0.35 & 0.43 & 0.28 & 0.42 & 0.5 \\
\hline Sec61a1 & 0.35 & 0.51 & 0.27 & 0.36 & 0.33 & 0.50 & 0.43 & 0.5 \\
\hline Cnbp & 0.18 & 0.23 & 0.18 & 0.22 & 0.51 & 0.20 & 0.23 & 0.51 \\
\hline Cul1 & 0.23 & 0.37 & 0.18 & 0.21 & 0.50 & 0.21 & 0.28 & 0. \\
\hline Cpne9 & 0.33 & 0.50 & 0.42 & 0.28 & 0.40 & 0.46 & 0.32 & 0.50 \\
\hline Srgap3 & 0.40 & 0.50 & 0.40 & 0.34 & 0.34 & 0.33 & 0.27 & 0.50 \\
\hline Vamp8 & 0.37 & 0.44 & 0.31 & 0.29 & 0.34 & 0.50 & 0.38 & 0.50 \\
\hline Zfp956 & 0.21 & 0.50 & 0.43 & 0.23 & 0.15 & 0.34 & 0.22 & 0.50 \\
\hline Evala & 0.45 & 0.50 & 0.36 & 0.33 & 0.20 & 0.45 & 0.14 & 0.50 \\
\hline Cfap100 & 0.39 & 0.50 & 0.38 & 0.07 & 0.23 & 0.43 & 0.26 & 0.50 \\
\hline Tpi1 & 0.43 & 0.50 & 0.18 & 0.13 & 0.27 & 0.31 & 0.21 & 0.50 \\
\hline Ankrd53 & 0.23 & 0.50 & 0.41 & 0.19 & 0.28 & 0.32 & 0.25 & 0.50 \\
\hline Smarcad1 & 0.50 & 0.43 & 0.47 & 0.46 & 0.41 & 0.21 & 0.48 & 0.50 \\
\hline Kdm3a & 0.33 & 0.39 & 0.38 & 0.50 & 0.28 & 0.32 & 0.40 & 0.50 \\
\hline Csgalnact2 & 0.23 & 0.49 & 0.22 & 0.20 & 0.22 & 0.24 & 0.21 & 0.49 \\
\hline Gimap7 & 0.35 & 0.43 & 0.49 & 0.38 & 0.47 & 0.42 & 0.38 & 0.49 \\
\hline Cops7a & 0.20 & 0.49 & 0.22 & 0.21 & 0.29 & 0.29 & 0.14 & 0.49 \\
\hline Tmem43 & 0.44 & 0.39 & 0.31 & 0.31 & 0.28 & 0.49 & 0.20 & 0.4 \\
\hline
\end{tabular}




\begin{tabular}{|c|c|c|c|c|c|c|c|c|}
\hline Pdia4 & 0.23 & 0.49 & 0.27 & 0.22 & 0.19 & 0.25 & 0.15 & 0.49 \\
\hline Tra2a & 0.27 & 0.49 & 0.21 & 0.16 & 0.23 & 0.27 & 0.35 & 0.49 \\
\hline Gsdme & 0.36 & 0.49 & 0.35 & 0.31 & 0.39 & 0.37 & 0.36 & 0.49 \\
\hline Serbp1 & 0.18 & 0.48 & 0.18 & 0.24 & 0.34 & 0.49 & 0.26 & 0.49 \\
\hline Lmcd1 & 0.33 & 0.38 & 0.49 & 0.35 & 0.09 & 0.37 & 0.35 & 0.49 \\
\hline Tmf1 & 0.31 & 0.48 & 0.26 & 0.20 & 0.13 & 0.25 & 0.28 & .48 \\
\hline Vmn1r29 & 0.26 & 0.36 & 0.43 & 0.33 & 0.48 & 0.21 & 0.36 & 0.48 \\
\hline Mical3 & 0.34 & 0.48 & 0.43 & 0.17 & 0.21 & 0.42 & 0.31 & 0.48 \\
\hline Vmn1r49 & 0.29 & 0.48 & 0.40 & 0.35 & 0.36 & 0.39 & 0.33 & 0.48 \\
\hline M6pr & 0.37 & 0.38 & 0.27 & 0.48 & 0.48 & 0.41 & 0.43 & 0.48 \\
\hline Tada3 & 0.30 & 0.48 & 0.34 & 0.29 & 0.14 & 0.45 & 0.14 & 0.48 \\
\hline Exoc6b & 0.22 & 0.48 & 0.31 & 0.28 & 0.28 & 0.43 & 0.35 & 0.48 \\
\hline Gars & 0.18 & 0.23 & 0.20 & 0.19 & 0.48 & 0.30 & 0.19 & 0.48 \\
\hline Vmn1r13 & 0.26 & 0.31 & 0.47 & 0.43 & 0.48 & 0.33 & 0.46 & 0.48 \\
\hline Brk1 & 0.18 & 0.22 & 0.26 & 0.18 & 0.48 & 0.24 & 0.21 & 0.48 \\
\hline Lsm3 & 0.15 & 0.48 & 0.24 & 0.17 & 0.17 & 0.18 & 0.25 & 0.48 \\
\hline Vmn1r44 & 0.37 & 0.35 & 0.48 & 0.42 & 0.45 & 0.46 & 0.40 & 0.48 \\
\hline Depp1 & 0.35 & 0.39 & 0.48 & 0.28 & 0.26 & 0.27 & 0.32 & 0.48 \\
\hline Atp6v1e1 & 0.29 & 0.34 & 0.48 & 0.23 & 0.32 & 0.33 & 0.20 & 0.48 \\
\hline Scrn1 & 0.42 & 0.47 & 0.25 & 0.26 & 0.34 & 0.38 & 0.21 & 0.47 \\
\hline Eif4e3 & 0.47 & 0.44 & 0.36 & 0.19 & 0.38 & 0.40 & 0.22 & 0.47 \\
\hline Vamp5 & 0.39 & 0.44 & 0.47 & 0.22 & 0.33 & 0.16 & 0.20 & 0.47 \\
\hline Vmn1r14 & 0.24 & 0.27 & 0.47 & 0.38 & 0.42 & 0.14 & 0.43 & 0.47 \\
\hline Nup210 & 0.32 & 0.39 & 0.47 & 0.24 & 0.14 & 0.33 & 0.25 & 0.47 \\
\hline Nat8f2 & 0.22 & 0.31 & 0.47 & 0.36 & 0.39 & 0.34 & 0.32 & 0.47 \\
\hline Vmn1r7 & 0.25 & 0.47 & 0.30 & 0.28 & 0.28 & 0.29 & 0.15 & 0.47 \\
\hline Setd5 & 0.36 & 0.47 & 0.42 & 0.16 & 0.26 & 0.42 & 0.15 & 0.47 \\
\hline $\operatorname{lgf2bp3}$ & 0.37 & 0.35 & 0.47 & 0.34 & 0.41 & 0.44 & 0.30 & 0.47 \\
\hline Ppp4r2 & 0.33 & 0.39 & 0.30 & 0.26 & 0.19 & 0.47 & 0.28 & 0.47 \\
\hline Mrps25 & 0.14 & 0.19 & 0.21 & 0.24 & 0.47 & 0.11 & 0.11 & 0.47 \\
\hline Vgll4 & 0.44 & 0.46 & 0.40 & 0.35 & 0.28 & 0.07 & 0.40 & 0.46 \\
\hline Tax1bp1 & 0.25 & 0.46 & 0.45 & 0.38 & 0.39 & 0.32 & 0.41 & 0.46 \\
\hline 931417E11Rik & 0.34 & 0.39 & 0.46 & 0.36 & 0.37 & 0.24 & 0.44 & 0.46 \\
\hline Lrrtm1 & 0.37 & 0.46 & 0.44 & 0.40 & 0.29 & 0.23 & 0.37 & 0.46 \\
\hline Olfr212 & 0.16 & 0.23 & 0.46 & 0.26 & 0.25 & 0.38 & 0.26 & 0.46 \\
\hline Cct7 & 0.18 & 0.20 & 0.18 & 0.18 & 0.46 & 0.20 & 0.19 & 0.46 \\
\hline Avl9 & 0.25 & 0.46 & 0.28 & 0.32 & 0.15 & 0.20 & 0.19 & 0.46 \\
\hline Vmn1r10 & 0.21 & 0.35 & 0.46 & 0.39 & 0.43 & 0.09 & 0.41 & 0.46 \\
\hline Sumf1 & 0.29 & 0.35 & 0.29 & 0.46 & 0.43 & 0.38 & 0.42 & 0.46 \\
\hline Osbp/3 & 0.36 & 0.42 & 0.17 & 0.19 & 0.27 & 0.46 & 0.11 & 0.46 \\
\hline Slc4a5 & 0.35 & 0.43 & 0.36 & 0.31 & 0.39 & 0.45 & 0.19 & 0.45 \\
\hline Brpf1 & 0.16 & 0.43 & 0.19 & 0.11 & 0.14 & 0.45 & 0.12 & 0.45 \\
\hline Chchd6 & 0.14 & 0.38 & 0.45 & 0.24 & 0.28 & 0.23 & 0.08 & 0.45 \\
\hline
\end{tabular}




\begin{tabular}{|c|c|c|c|c|c|c|c|c|}
\hline Dguok & 0.21 & 0.21 & 0.35 & 0.26 & 0.18 & 0.45 & 0.17 & 0.45 \\
\hline 1810044D09Rik & 0.45 & 0.41 & 0.44 & 0.36 & 0.28 & 0.27 & 0.34 & 0.45 \\
\hline Lrtm2 & 0.32 & 0.45 & 0.42 & 0.31 & 0.19 & 0.07 & 0.25 & 0.45 \\
\hline Nat8 & 0.44 & 0.38 & 0.34 & 0.36 & 0.21 & 0.34 & 0.42 & 0.44 \\
\hline Lrrc61 & 0.37 & 0.44 & 0.33 & 0.27 & 0.16 & 0.29 & 0.25 & 0.44 \\
\hline Lancl2 & 0.27 & 0.32 & 0.23 & 0.24 & 0.44 & 0.14 & 0.21 & .44 \\
\hline Mtmr14 & 0.30 & 0.44 & 0.30 & 0.29 & 0.14 & 0.28 & 0.34 & .44 \\
\hline Arl6ip5 & 0.18 & 0.32 & 0.42 & 0.18 & 0.32 & 0.44 & 0.19 & .44 \\
\hline Tmsb10 & 0.26 & 0.33 & 0.33 & 0.18 & 0.44 & 0.42 & 0.29 & 0.44 \\
\hline Nat8f4 & 0.25 & 0.44 & 0.32 & 0.34 & 0.22 & 0.28 & 0.33 & .44 \\
\hline 4930544G11Rik & 0.33 & 0.35 & 0.25 & 0.25 & 0.27 & 0.44 & 0.25 & 0.44 \\
\hline Gprin3 & 0.33 & 0.44 & 0.35 & 0.26 & 0.24 & 0.40 & 0.25 & 0.44 \\
\hline Gm10319 & 0.11 & 0.17 & 0.44 & 0.16 & 0.19 & 0.11 & 0.23 & 0.44 \\
\hline Hk2 & 0.36 & 0.39 & 0.27 & 0.44 & 0.21 & 0.40 & 0.23 & 0.44 \\
\hline 4930590J08Rik & 0.33 & 0.37 & 0.25 & 0.25 & 0.33 & 0.44 & 0.19 & 0.44 \\
\hline 5430402013Rik & 0.19 & 0.25 & 0.36 & 0.32 & 0.44 & 0.26 & 0.32 & 0.44 \\
\hline Jagn1 & 0.18 & 0.23 & 0.44 & 0.18 & 0.21 & 0.31 & 0.19 & 0.44 \\
\hline B4galnt3 & 0.28 & 0.44 & 0.23 & 0.19 & 0.31 & 0.42 & 0.20 & 0.44 \\
\hline march8 & 0.25 & 0.27 & 0.18 & 0.21 & 0.22 & 0.43 & 0.17 & 0.43 \\
\hline Lpar5 & 0.27 & 0.37 & 0.25 & 0.25 & 0.33 & 0.43 & 0.30 & 0.43 \\
\hline Ggct & 0.30 & 0.28 & 0.28 & 0.26 & 0.43 & 0.16 & 0.13 & 0.43 \\
\hline Gimap1 & 0.28 & 0.37 & 0.27 & 0.30 & 0.43 & 0.28 & 0.39 & 0.43 \\
\hline Lmod3 & 0.42 & 0.41 & 0.43 & 0.32 & 0.14 & 0.23 & 0.21 & 0.43 \\
\hline Foxi3 & 0.26 & 0.24 & 0.28 & 0.25 & 0.38 & 0.43 & 0.15 & 0.43 \\
\hline Nat8f3 & 0.42 & 0.33 & 0.42 & 0.40 & 0.43 & 0.33 & 0.35 & 0.43 \\
\hline Dcp1b & 0.36 & 0.43 & 0.29 & 0.29 & 0.03 & 0.24 & 0.40 & 0.43 \\
\hline Vmn1r53 & 0.27 & 0.43 & 0.36 & 0.28 & 0.26 & 0.26 & 0.25 & 0.43 \\
\hline Fkbp14 & 0.37 & 0.42 & 0.28 & 0.33 & 0.28 & 0.43 & 0.21 & 0.43 \\
\hline Pradc1 & 0.18 & 0.34 & 0.18 & 0.36 & 0.42 & 0.19 & 0.10 & 0.42 \\
\hline Gimap3 & 0.33 & 0.38 & 0.39 & 0.37 & 0.42 & 0.37 & 0.42 & 0.42 \\
\hline Setmar & 0.28 & 0.42 & 0.18 & 0.19 & 0.26 & 0.33 & 0.16 & 0.42 \\
\hline Reep1 & 0.38 & 0.42 & 0.39 & 0.28 & 0.30 & 0.10 & 0.31 & 0.42 \\
\hline Vmn1r9 & 0.23 & 0.20 & 0.35 & 0.32 & 0.42 & 0.27 & 0.18 & 0.42 \\
\hline Vmn1r50 & 0.30 & 0.36 & 0.42 & 0.35 & 0.27 & 0.24 & 0.30 & 0.42 \\
\hline Zfp746 & 0.21 & 0.42 & 0.23 & 0.21 & 0.16 & 0.26 & 0.21 & 0.42 \\
\hline Crbn & 0.19 & 0.42 & 0.20 & 0.15 & 0.21 & 0.19 & 0.20 & 0.42 \\
\hline$X p c$ & 0.29 & 0.42 & 0.26 & 0.39 & 0.33 & 0.34 & 0.38 & 0.42 \\
\hline Gxylt2 & 0.34 & 0.37 & 0.27 & 0.27 & 0.22 & 0.42 & 0.28 & 0.42 \\
\hline Trnt1 & 0.15 & 0.18 & 0.16 & 0.15 & 0.42 & 0.14 & 0.14 & 0.42 \\
\hline Herc6 & 0.33 & 0.41 & 0.33 & 0.29 & 0.40 & 0.42 & 0.29 & 0.42 \\
\hline Vmn2r25 & 0.24 & 0.25 & 0.35 & 0.26 & 0.16 & 0.42 & 0.22 & 0.42 \\
\hline Itprid1 & 0.20 & 0.31 & 0.28 & 0.27 & 0.15 & 0.42 & 0.26 & 0.42 \\
\hline Tia1 & 0.20 & 0.29 & 0.35 & 0.29 & 0.41 & 0.20 & 0.41 & 0.41 \\
\hline
\end{tabular}




\begin{tabular}{|c|c|c|c|c|c|c|c|c|}
\hline Nat8f5 & 0.34 & 0.41 & 0.35 & 0.28 & 0.34 & 0.24 & 0.28 & 0.41 \\
\hline Clec4b1 & 0.24 & 0.30 & 0.41 & 0.40 & 0.40 & 0.32 & 0.40 & 0.41 \\
\hline Kbtbd8 & 0.22 & 0.24 & 0.35 & 0.19 & 0.41 & 0.27 & 0.16 & 0.41 \\
\hline Mug2 & 0.32 & 0.41 & 0.30 & 0.33 & 0.25 & 0.32 & 0.27 & 0.41 \\
\hline Znrf2 & 0.34 & 0.41 & 0.25 & 0.16 & 0.32 & 0.27 & 0.29 & 0.41 \\
\hline Cpvl & 0.28 & 0.41 & 0.33 & 0.29 & 0.25 & 0.21 & 0.33 & 0.41 \\
\hline Thnsl2 & 0.41 & 0.34 & 0.29 & 0.30 & 0.32 & 0.40 & 0.13 & 0.41 \\
\hline Bms1 & 0.18 & 0.27 & 0.24 & 0.17 & 0.41 & 0.21 & 0.19 & 0.41 \\
\hline C1rb & 0.27 & 0.35 & 0.39 & 0.32 & 0.32 & 0.41 & 0.16 & 0.41 \\
\hline Gimap6 & 0.32 & 0.38 & 0.41 & 0.29 & 0.36 & 0.30 & 0.35 & 0.41 \\
\hline Hibadh & 0.37 & 0.30 & 0.26 & 0.41 & 0.24 & 0.34 & 0.19 & 0.41 \\
\hline Usp39 & 0.17 & 0.41 & 0.26 & 0.18 & 0.38 & 0.18 & 0.17 & 0.41 \\
\hline Ccser1 & 0.35 & 0.41 & 0.27 & 0.25 & 0.22 & 0.27 & 0.18 & 0.41 \\
\hline Eogt & 0.41 & 0.31 & 0.24 & 0.29 & 0.38 & 0.29 & 0.38 & 0.41 \\
\hline Prrt3 & 0.34 & 0.39 & 0.41 & 0.30 & 0.30 & 0.34 & 0.22 & 0.41 \\
\hline TtII3 & 0.22 & 0.33 & 0.41 & 0.32 & 0.33 & 0.17 & 0.37 & 0.41 \\
\hline Tmem72 & 0.40 & 0.35 & 0.40 & 0.29 & 0.36 & 0.30 & 0.25 & 0.40 \\
\hline Sec13 & 0.13 & 0.21 & 0.16 & 0.22 & 0.40 & 0.20 & 0.12 & 0.40 \\
\hline Cracr2a & 0.34 & 0.26 & 0.37 & 0.30 & 0.29 & 0.21 & 0.40 & 0.40 \\
\hline Chchd4 & 0.31 & 0.40 & 0.23 & 0.30 & 0.15 & 0.21 & 0.17 & 0.40 \\
\hline Ppm1k & 0.36 & 0.40 & 0.28 & 0.25 & 0.32 & 0.18 & 0.22 & 0.40 \\
\hline Eefsec & 0.15 & 0.40 & 0.20 & 0.16 & 0.15 & 0.34 & 0.14 & 0.40 \\
\hline Jazf1 & 0.27 & 0.40 & 0.25 & 0.22 & 0.33 & 0.30 & 0.12 & 0.40 \\
\hline Camk1 & 0.31 & 0.33 & 0.35 & 0.18 & 0.13 & 0.40 & 0.25 & 0.40 \\
\hline Zfand4 & 0.25 & 0.35 & 0.40 & 0.27 & 0.25 & 0.18 & 0.17 & 0.40 \\
\hline 10069B03Rik & 0.24 & 0.24 & 0.40 & 0.33 & 0.30 & 0.13 & 0.36 & 0.40 \\
\hline Shq1 & 0.12 & 0.28 & 0.29 & 0.27 & 0.40 & 0.19 & 0.21 & 0.40 \\
\hline V1ra8 & 0.23 & 0.25 & 0.30 & 0.20 & 0.18 & 0.40 & 0.23 & 0.40 \\
\hline Rad18 & 0.21 & 0.37 & 0.40 & 0.29 & 0.29 & 0.21 & 0.31 & 0.40 \\
\hline Gm765 & 0.19 & 0.33 & 0.36 & 0.32 & 0.27 & 0.34 & 0.40 & 0.40 \\
\hline Lsm5 & 0.11 & 0.21 & 0.28 & 0.19 & 0.40 & 0.19 & 0.20 & 0.40 \\
\hline Pdzrn3 & 0.32 & 0.36 & 0.17 & 0.10 & 0.39 & 0.25 & 0.33 & 0.39 \\
\hline Tafa4 & 0.24 & 0.34 & 0.39 & 0.32 & 0.25 & 0.18 & 0.31 & 0.39 \\
\hline Polr1a & 0.33 & 0.39 & 0.23 & 0.24 & 0.16 & 0.38 & 0.11 & 0.39 \\
\hline Vmn1r33 & 0.27 & 0.22 & 0.30 & 0.30 & 0.35 & 0.28 & 0.39 & 0.39 \\
\hline Paip2b & 0.19 & 0.39 & 0.18 & 0.21 & 0.39 & 0.27 & 0.25 & 0.39 \\
\hline Mindy4 & 0.28 & 0.39 & 0.29 & 0.25 & 0.13 & 0.21 & 0.23 & 0.39 \\
\hline 130060K24Rik & 0.25 & 0.26 & 0.39 & 0.24 & 0.14 & 0.27 & 0.38 & 0.39 \\
\hline Gcfc2 & 0.22 & 0.32 & 0.39 & 0.21 & 0.15 & 0.26 & 0.26 & 0.39 \\
\hline Doxl2 & 0.29 & 0.29 & 0.33 & 0.26 & 0.25 & 0.39 & 0.20 & 0.39 \\
\hline Vmn1r48 & 0.18 & 0.24 & 0.27 & 0.27 & 0.20 & 0.39 & 0.26 & 0.39 \\
\hline Dnah6 & 0.39 & 0.37 & 0.33 & 0.30 & 0.12 & 0.34 & 0.24 & 0.39 \\
\hline Slc25a26 & 0.28 & 0.39 & 0.29 & 0.28 & 0.24 & 0.20 & 0.27 & 0.39 \\
\hline
\end{tabular}




\begin{tabular}{|c|c|c|c|c|c|c|c|c|}
\hline Sh2d6 & .32 & 0.39 & 0.27 & 0.28 & 0.20 & 0.31 & 0.24 & 39 \\
\hline Mrp/35 & 0.13 & 0.20 & 0.13 & 0.28 & 0.38 & 0.28 & 0.19 & 0.38 \\
\hline Uba3 & .24 & 0.35 & 0.19 & 0.31 & 0.38 & 0.22 & .33 & \\
\hline Rpn1 & 0.18 & 0.38 & 0.23 & 0.20 & 0.24 & 0.23 & .20 & \\
\hline C1s2 & 0.11 & 0.17 & 0.38 & 0.30 & 0.15 & 0.15 & .27 & \\
\hline Gimap8 & 0.29 & .29 & .27 & .31 & .35 & .27 & 38 & \\
\hline Wdr54 & 0.23 & .38 & 0.33 & .22 & .35 & 0.20 & 32 & \\
\hline Isy1 & 0.15 & 0.34 & 0.38 & 0.20 & 0.22 & 0.26 & .25 & \\
\hline Pyurf & 0.25 & 0.38 & 0.22 & 0.19 & 0.14 & 0.19 & .10 & \\
\hline Cand2 & 0.28 & .38 & 0.27 & .24 & .24 & 0.25 & .28 & \\
\hline Ncapd2 & 0.10 & .38 & 0.18 & .32 & .18 & 0.34 & 18 & \\
\hline Zfp786 & 0.29 & .31 & 0.33 & .31 & .32 & 0.33 & 38 & \\
\hline Vmn1r11 & 0.23 & 0.34 & 0.33 & 0.34 & 0.38 & 0.14 & .33 & \\
\hline Suclg2 & 0.37 & .30 & 0.38 & .22 & .18 & 0.26 & .15 & \\
\hline Tafa1 & 0.23 & .28 & 0.38 & .24 & 3 & 0.16 & .28 & \\
\hline Pex26 & 0.25 & .38 & 0.20 & 0.28 & 21 & 0.37 & .18 & \\
\hline D6Ertd527e & 0.22 & 0.38 & 0.35 & 0.26 & 0.19 & 0.28 & 21 & \\
\hline Vmn1r19 & 0.17 & 0.38 & 0.27 & 0.21 & 0.30 & 0.17 & .23 & \\
\hline Prdm5 & 0.37 & 37 & 0.28 & 31 & 35 & 0.25 & 31 & \\
\hline Zfp398 & 0.29 & 0.37 & 0.34 & 0.35 & 4 & 0.21 & .30 & \\
\hline Tigar & 0.35 & 0.37 & 0.27 & 0.20 & 0.09 & 0.26 & .24 & \\
\hline$B c / 2 / 13$ & 0.36 & 0.37 & 0.35 & 0.21 & 0.26 & 0.33 & 0.29 & 0.37 \\
\hline Vmn1r30 & 0.24 & 0.36 & 0.37 & 0.34 & 0.33 & 0.24 & .32 & 0.37 \\
\hline Rp/32 & 0.29 & & 0.37 & 0.18 & 0.12 & 0.29 & .33 & \\
\hline Vmn1r39 & 0.30 & 0.33 & 0.22 & 0.24 & 0.37 & 0.23 & 0.26 & \\
\hline Dusp11 & 0.22 & 0.23 & 0.22 & 0.19 & 0.17 & 0.37 & 0.25 & 0.37 \\
\hline Nat8f6 & 0.28 & 0.37 & 0.25 & 0.20 & 0.26 & 0.34 & 0.20 & 0.37 \\
\hline Slc25a18 & 0.27 & 0.37 & 0.33 & 0.26 & 0.28 & 0.30 & 0.32 & 0.3 \\
\hline & 0.26 & 0.37 & 0.33 & 0.31 & 0.16 & 0.34 & 0.28 & 0.37 \\
\hline Fancd2os & 0.33 & 0.37 & 0.22 & 0.23 & 0.21 & 0.19 & 0.34 & 0.3 \\
\hline Gkn3 & 0.26 & 0.31 & 0.36 & 0.20 & 0.20 & 0.26 & 0.23 & 0.36 \\
\hline Hoxaas3 & 0.13 & 0.18 & 0.14 & 0.21 & 0.20 & 0.17 & 0.36 & 0.00 \\
\hline Lpcat3 & 0.25 & 0.29 & 0.24 & 0.28 & 0.21 & 0.36 & .12 & .36 \\
\hline O00015/10R & 0.33 & 0.29 & 0.32 & 0.29 & 0.21 & 0.36 & 0.32 & .3 \\
\hline Vmn1r43 & 0.29 & 0.24 & 0.27 & 0.27 & 0.36 & 0.16 & 0.30 & 0.3 \\
\hline Рсуох1 & 0.31 & 0.36 & 0.34 & 0.17 & 0.35 & 0.15 & 0.22 & 0.50 \\
\hline Zfp248 & 0.31 & 0.36 & 0.33 & 0.28 & 0.19 & 0.34 & 0.29 & .3 \\
\hline Vmn1r5 & 0.22 & 0.21 & 0.31 & 0.32 & 0.20 & 0.10 & 0.36 & 0.3 \\
\hline Kbtbd2 & 0.21 & 0.36 & 0.24 & 0.22 & 0.17 & 0.23 & 0.19 & 0.36 \\
\hline Vmn1r8 & 0.24 & 0.22 & 0.29 & 0.29 & 0.36 & 0.14 & 0.25 & 0.3 \\
\hline Hmces & 0.25 & 0.36 & 0.18 & 0.21 & 0.18 & 0.26 & 0.19 & .3 \\
\hline Clec4a1 & 0.27 & 0.30 & 0.36 & 0.32 & 0.30 & 0.31 & 0.22 & 0. \\
\hline Herc3 & 0.25 & 0.31 & 0.23 & 0.23 & 0.26 & 0.36 & 0.17 & 0.3 \\
\hline
\end{tabular}




\begin{tabular}{|c|c|c|c|c|c|c|c|c|}
\hline Rpusd3 & 0.25 & 0.36 & 0.28 & 0.21 & 0.22 & 0.12 & 0.31 & 0.36 \\
\hline Ccdc174 & 0.26 & 0.31 & 0.22 & 0.18 & 0.18 & 0.36 & 0.20 & 0.36 \\
\hline Тех37 & 0.25 & 0.27 & 0.36 & 0.31 & 0.33 & 0.17 & 0.27 & 0.36 \\
\hline Lrrtm4 & 0.26 & 0.28 & 0.36 & 0.27 & 0.28 & 0.31 & 0.31 & 0.36 \\
\hline 0610030E20Rik & 0.19 & 0.35 & 0.36 & 0.28 & 0.18 & 0.35 & 0.26 & 0.36 \\
\hline Tprkb & .17 & 0.27 & 0.35 & 0.27 & 0.16 & 0.33 & 0.24 & 0.35 \\
\hline Zfp282 & 0.14 & 0.35 & 0.26 & 0.23 & 0.23 & 0.18 & 0.18 & .35 \\
\hline Mat2a & 0.24 & 0.31 & 0.35 & 0.19 & 0.13 & 0.25 & 0.19 & 0.35 \\
\hline Cdca3 & 0.20 & 0.32 & 0.34 & 0.20 & 0.35 & 0.35 & 0.20 & 0.35 \\
\hline Stk31 & .35 & 0.25 & 0.34 & 0.34 & 0.31 & 0.15 & 0.32 & .35 \\
\hline Vmn2r24 & 0.22 & 0.19 & 0.30 & 0.30 & 0.18 & 0.26 & 0.35 & 0.35 \\
\hline C87436 & 0.22 & 0.35 & 0.25 & 0.28 & 0.16 & 0.25 & 0.19 & .35 \\
\hline Nagk & 0.27 & 0.32 & 0.24 & 0.18 & 0.13 & 0.35 & 0.16 & 0.35 \\
\hline Olfr214 & 0.22 & 0.21 & 0.35 & 0.31 & 0.21 & 0.24 & 0.31 & 0.35 \\
\hline Vmn1r38 & 0.18 & 0.35 & 0.24 & 0.26 & 0.23 & 0.26 & 0.32 & 0.35 \\
\hline Phb2 & 0.21 & 0.35 & 0.18 & 0.24 & 0.25 & 0.09 & 0.14 & 0.35 \\
\hline Vmn1r23 & 0.24 & 0.21 & 0.31 & 0.26 & 0.26 & 0.28 & 0.35 & 0.35 \\
\hline Rnu7 & 0.18 & 0.35 & 0.18 & 0.15 & 0.22 & 0.17 & 0.30 & 0.35 \\
\hline Rpia & 0.13 & 0.34 & 0.30 & 0.28 & 0.24 & 0.21 & 0.16 & 0.34 \\
\hline Vmn1r54 & 0.24 & 0.25 & 0.28 & 0.29 & 0.34 & 0.17 & 0.32 & 0.34 \\
\hline Mkrn2os & 0.32 & 0.30 & 0.28 & 0.24 & 0.15 & 0.34 & 0.15 & 0.34 \\
\hline Malsu1 & 0.15 & 0.23 & 0.34 & 0.19 & 0.18 & 0.24 & 0.18 & 0.34 \\
\hline Vmn2r27 & 0.21 & 0.28 & 0.22 & 0.20 & 0.29 & 0.34 & 0.20 & 0.34 \\
\hline Tatdn2 & 0.28 & 0.34 & 0.27 & 0.21 & 0.12 & 0.34 & 0.31 & 0.34 \\
\hline Rny3 & 0.22 & 0.21 & 0.20 & 0.20 & 0.20 & 0.34 & 0.30 & 0.34 \\
\hline Ssu2 & 0.31 & 0.32 & 0.34 & 0.30 & 0.25 & 0.32 & 0.29 & 0.34 \\
\hline Vmn2r20 & 0.21 & 0.29 & 0.28 & 0.34 & 0.18 & 0.17 & 0.27 & 0.34 \\
\hline Vmn1r21 & 0.23 & 0.28 & 0.26 & 0.17 & 0.15 & 0.34 & 0.19 & 0.34 \\
\hline Vmn1r32 & 0.06 & 0.20 & 0.34 & 0.25 & 0.24 & 0.21 & 0.21 & 0.34 \\
\hline Zfp638 & 0.18 & 0.22 & 0.29 & 0.21 & 0.21 & 0.14 & 0.34 & 0.34 \\
\hline Ccdc77 & 0.14 & 0.24 & 0.29 & 0.25 & 0.34 & 0.17 & 0.17 & 0.34 \\
\hline Vmn1r37 & 0.27 & 0.33 & 0.30 & 0.25 & 0.23 & 0.26 & 0.32 & 0.33 \\
\hline Olfr213 & 0.24 & 0.28 & 0.28 & 0.29 & 0.13 & 0.33 & 0.29 & 0.33 \\
\hline Vmn2r23 & 0.21 & 0.20 & 0.22 & 0.26 & 0.24 & 0.33 & 0.12 & 0.33 \\
\hline Vmn2r19 & 0.26 & 0.24 & 0.30 & 0.27 & 0.33 & 0.31 & 0.24 & 0.33 \\
\hline Snrnp27 & 0.14 & 0.33 & 0.18 & 0.18 & 0.26 & 0.22 & 0.21 & 0.33 \\
\hline Tamm41 & 0.10 & 0.21 & 0.30 & 0.21 & 0.33 & 0.18 & 0.19 & 0.33 \\
\hline Vmn2r21 & 0.17 & 0.26 & 0.29 & 0.33 & 0.20 & 0.16 & 0.24 & 0.33 \\
\hline Ruvbl1 & 0.18 & 0.30 & 0.21 & 0.21 & 0.33 & 0.20 & 0.21 & 0.33 \\
\hline 4933431G14Rik & 0.24 & 0.24 & 0.33 & 0.25 & 0.29 & 0.16 & 0.24 & 0.33 \\
\hline Vmn1r28 & 0.17 & 0.29 & 0.20 & 0.29 & 0.33 & 0.19 & 0.14 & 0.33 \\
\hline Rad51ap1 & 0.17 & 0.33 & 0.24 & 0.29 & 0.27 & 0.06 & 0.29 & 0.33 \\
\hline 1700054K19Rik & 0.17 & 0.15 & 0.33 & 0.28 & 0.19 & 0.11 & 0.22 & 0.33 \\
\hline
\end{tabular}




\begin{tabular}{|c|c|c|c|c|c|c|c|c|}
\hline Rny1 & 0.24 & 0.21 & 0.12 & 0.16 & 0.28 & 0.33 & 0.13 & 0.33 \\
\hline Dyrk4 & 0.26 & 0.32 & 0.26 & 0.25 & 0.22 & 0.23 & 0.30 & 0.32 \\
\hline$N t 5 c 3$ & 0.23 & 0.32 & 0.24 & 0.17 & 0.23 & 0.16 & 0.20 & .32 \\
\hline Gm9871 & 0.17 & 0.16 & 0.32 & 0.28 & 0.30 & 0.06 & 0.19 & 0.32 \\
\hline Hnrnpf & 0.18 & 0.32 & 0.21 & 0.18 & 0.27 & 0.28 & 0.19 & .32 \\
\hline Mrpl19 & .14 & 0.22 & 0.32 & 0.24 & 0.29 & 0.18 & 0.18 & 32 \\
\hline Efcab12 & 0.30 & 0.29 & 0.32 & 0.21 & 0.13 & 0.09 & 0.21 & 32 \\
\hline Rbsn & 0.23 & 0.32 & 0.28 & 0.15 & 0.18 & 0.20 & 0.21 & .32 \\
\hline Thumpd3 & 0.17 & 0.32 & 0.17 & 0.26 & 0.22 & 0.22 & 0.14 & .32 \\
\hline Grcc10 & .30 & 0.31 & 0.27 & 0.21 & 0.22 & 0.20 & 0.24 & 31 \\
\hline Clec4b2 & .28 & 0.27 & 0.18 & 0.28 & 0.25 & 0.24 & 0.31 & 31 \\
\hline Zfp422 & 0.17 & 0.24 & 0.20 & 0.26 & 0.31 & 0.19 & 0.15 & 31 \\
\hline Vmn1r22 & 0.22 & 0.31 & 0.28 & 0.27 & 0.13 & 0.25 & 0.28 & .31 \\
\hline Chmp3 & .15 & 0.31 & 0.26 & 0.19 & 0.12 & 0.27 & 0.20 & .31 \\
\hline 930417013Rik & 0.24 & 0.15 & 0.15 & .28 & 0.07 & 0.31 & 0.19 & 0.31 \\
\hline Zfp637 & 0.18 & 0.30 & 0.18 & 0.18 & 0.17 & 0.31 & 0.16 & 0.31 \\
\hline Vmn1r35 & 0.25 & 0.25 & 0.31 & 0.30 & 0.13 & 0.22 & 0.14 & 0.31 \\
\hline Suclg1 & 0.22 & 0.23 & 0.17 & 0.31 & 0.18 & 0.09 & 0.19 & 0.31 \\
\hline Vmn1r6 & 0.23 & 0.21 & 0.28 & 0.26 & 0.18 & 0.23 & 0.31 & 0.31 \\
\hline 2610300M13Rik & 0.11 & 0.24 & 0.30 & 0.19 & 0.21 & 0.11 & 0.19 & 0.30 \\
\hline Plekha8 & 0.25 & 0.30 & 0.24 & 0.23 & 0.19 & 0.30 & 0.19 & 0.30 \\
\hline Zfp862-ps & 0.22 & 0.30 & 0.12 & 0.21 & 0.25 & 0.13 & 0.16 & 0.30 \\
\hline Svs1 & 0.24 & 0.30 & 0.25 & 0.25 & 0.22 & 0.23 & 0.22 & 0.30 \\
\hline 1700069P05Rik & 0.17 & 0.23 & 0.25 & 0.28 & 0.30 & 0.16 & 0.25 & 0.30 \\
\hline Vmn1r51 & 0.30 & 0.27 & 0.22 & 0.23 & 0.14 & 0.27 & 0.24 & 0.30 \\
\hline D6Wsu163e & 0.19 & 0.30 & 0.28 & 0.16 & 0.21 & 0.24 & 0.18 & 0.30 \\
\hline 6330415B21Rik & 0.22 & 0.24 & 0.24 & 0.28 & 0.24 & 0.21 & 0.30 & 0.30 \\
\hline Vmn1r4 & 0.23 & 0.24 & 0.30 & 0.19 & 0.19 & 0.19 & 0.26 & 0.30 \\
\hline Zfp775 & 0.25 & 0.30 & 0.20 & 0.23 & 0.17 & 0.23 & 0.18 & 0.30 \\
\hline Tsen2 & 0.29 & 0.24 & 0.24 & 0.14 & 0.17 & 0.28 & 0.09 & 0.29 \\
\hline Mogs & 0.19 & 0.29 & 0.17 & 0.17 & 0.13 & 0.12 & 0.16 & 0.29 \\
\hline Tnip3 & 0.21 & 0.29 & 0.26 & 0.28 & 0.19 & 0.22 & 0.23 & 0.29 \\
\hline Olfr211 & 0.19 & 0.24 & 0.26 & 0.29 & 0.17 & 0.22 & 0.23 & 0.29 \\
\hline Vmn1r34 & 0.19 & 0.24 & 0.28 & 0.22 & 0.26 & 0.26 & 0.14 & 0.28 \\
\hline Vmn1r16 & 0.19 & 0.15 & 0.23 & 0.26 & 0.22 & 0.21 & 0.28 & 0.28 \\
\hline 9530062K07Rik & 0.24 & 0.22 & 0.28 & 0.12 & 0.19 & 0.21 & 0.23 & 0.28 \\
\hline Vmn1r36 & 0.24 & 0.25 & 0.28 & 0.22 & 0.18 & 0.18 & 0.24 & 0.28 \\
\hline Ndufa9 & 0.22 & 0.23 & 0.16 & 0.28 & 0.14 & 0.18 & 0.19 & 0.28 \\
\hline 1700026J14Rik & 0.16 & 0.20 & 0.19 & 0.13 & 0.15 & 0.28 & 0.20 & 0.28 \\
\hline Snrpg & 0.18 & 0.21 & 0.17 & 0.25 & 0.28 & 0.16 & 0.15 & 0.28 \\
\hline Clec4a4 & 0.17 & 0.14 & 0.28 & 0.20 & 0.22 & 0.23 & 0.25 & 0.28 \\
\hline Vmn1r24 & 0.28 & 0.26 & 0.26 & 0.21 & 0.18 & 0.15 & 0.24 & 0.28 \\
\hline 1700030F04Rik & 0.13 & 0.20 & 0.27 & 0.16 & 0.10 & 0.25 & 0.27 & 0.27 \\
\hline
\end{tabular}




$\begin{array}{ccccccccc}\text { Vmn1r52 } & 0.23 & 0.27 & 0.16 & 0.25 & 0.19 & 0.26 & 0.26 & 0.27 \\ \text { 2610306M01Rik } & 0.16 & 0.27 & 0.26 & 0.23 & 0.26 & 0.10 & 0.15 & 0.27 \\ \text { Zfp212 } & 0.19 & 0.25 & 0.27 & 0.25 & 0.16 & 0.18 & 0.22 & 0.27 \\ \text { Vmn2r22 } & 0.16 & 0.22 & 0.22 & 0.27 & 0.18 & 0.14 & 0.25 & 0.27 \\ \text { Ccdc126 } & 0.20 & 0.27 & 0.25 & 0.21 & 0.18 & 0.20 & 0.21 & 0.27 \\ \text { Vmn1r17 } & 0.16 & 0.24 & 0.25 & 0.24 & 0.17 & 0.24 & 0.26 & 0.26 \\ \text { Rnf181 } & 0.21 & 0.24 & 0.21 & 0.21 & 0.14 & 0.26 & 0.19 & 0.26 \\ \text { Vmn1r31 } & 0.18 & 0.26 & 0.26 & 0.23 & 0.15 & 0.21 & 0.22 & 0.26 \\ \text { 1700065L07Rik } & 0.10 & 0.25 & 0.17 & 0.21 & 0.11 & 0.16 & 0.19 & 0.25 \\ \text { Vmn1r18 } & 0.19 & 0.16 & 0.23 & 0.22 & 0.20 & 0.24 & 0.15 & 0.24 \\ \text { Tigd2 } & 0.22 & 0.22 & 0.17 & 0.21 & 0.18 & 0.24 & 0.20 & 0.24 \\ \text { Nfu1 } & 0.17 & 0.22 & 0.16 & 0.19 & 0.23 & 0.12 & 0.20 & 0.23 \\ \text { Rprl1 } & 0.22 & 0.12 & 0.18 & 0.14 & 0.23 & 0.14 & 0.12 & 0.23 \\ \text { 1700049E22Rik } & 0.16 & 0.22 & 0.17 & 0.14 & 0.10 & 0.17 & 0.10 & 0.22 \\ \text { 1700094M24Rik } & 0.20 & 0.17 & 0.22 & 0.13 & 0.11 & 0.11 & 0.09 & 0.22 \\ \text { Emc3 } & 0.18 & 0.21 & 0.16 & 0.16 & 0.18 & 0.20 & 0.17 & 0.21 \\ \text { 1700124L16Rik } & 0.13 & 0.13 & 0.15 & 0.20 & 0.05 & 0.08 & 0.19 & 0.20 \\ \text { Rpl34-ps1 } & 0.14 & 0.15 & 0.07 & 0.14 & 0.16 & 0.09 & 0.13 & 0.16\end{array}$

Genes are ranked according to the maximum individual score from any phenotype module. PTX, pertussis toxin; T1H, Type 1 hypersensitivity; VP, vascular permeability; GPCR, G-protein coupled receptor, ER, endoplasmic reticulum. EMC, endoplasmic membrane protein complex; ERAD, endoplasmic reticulum-associated degradation. 
Supplementary Table 5. Details of primers used in this study.

Microsatellite primers

\begin{tabular}{llll}
\hline Name & Mbp & Forward & Reverse \\
D6Mit17 & 71.06 & 5'-ggcttgccaacaaaactgat-3' & 5'-gggtttccccttcaaatgt-3' \\
D6Mit8 & 83.66 & 5'-tgcacagcagctcattctct-3' & 5'-ggaaggaaggagtggggtag-3' \\
D6Mit65 & 101.33 & 5'-ctccgcaaacatgtgtatatgt-3' & 5'-ggactcaaacttgctcactgg-3' \\
D6Mit149 & 105.95 & 5'-acatgcatgcacaactccat-3' & 5'-tttttgtgggctgcatgta-3' \\
D6Mit105 & 107.74 & 5'-ctgctccactacttctattcctgg-3' & 5'-caaagccttatatattacacctcacc-3' \\
D6Mit115 & 116.61 & 5'-ccatttaataagtgatccctctgg-3' & 5'-tgtcacaccacaatgggc-3' \\
D6Mit254 & 125.30 & 5'-agtgtccctagggggtgg-3' & 5'-ggggccttagaggtagcaac-3' \\
\hline
\end{tabular}

Sequence-specific primers

\begin{tabular}{lllll}
\hline Name & Mbp & Forward1 & Forward2 & Reverse \\
rs36743061 & 81.89 & 5'-ctgcagagatgactaacttccacac-3' & 5'-ctgcagagatgactaacttccacaa-3' & 5'-gacggggcagcaaatcttat-3' \\
rs30936839 & 89.22 & 5'-tttatggagagcagcatggag-3' & 5'-tttatggagagcagcatggac-3' & 5'-tactgctgtggacagccaac-3' \\
rs29868697 & 108.45 & 5'-ccacactggtcaggcctc-3' & 5'-ccacactggtcaggcctt-3' & 5'-attgaaagctcccagcagaa-3' \\
rs6257334 & 119.91 & 5'-agttgcttctgttctcattgctatg-3' & 5'-agttgcttctgttctcattgctatt-3' & 5'-tctagctggggtgcattacc-3' \\
\hline
\end{tabular}

Hrh1 primers

\begin{tabular}{llll}
\hline Name & Mbp & Forward & Reverse \\
Hrh1 WT & 114.30 & 5'-tgaagtatctggctctgagtgg-3' & 5'-ccatccgatggctccctccctgggag-3' \\
Hrh1 KO & 114.30 & 5'-tgaagtatctggctctgagtgg-3' & 5'-tctatcgccttcttgaccgag-3'
\end{tabular}


Supplementary Table 6. List of datasets retrieved from mouse phenome database (www.phenome.jax.org) to collate SNP information across all studied mouse strains [41, 42, 66-71].

\begin{tabular}{|c|c|c|c|c|c|}
\hline Data set & Procedure & What's in this data set & Panel & Sex & Year \\
\hline Broad2 & genotyping & $\begin{array}{l}\text { SNP profiling, } 131,000+ \\
\text { genomic locations, 1-19, X. }\end{array}$ & inbred & & 2009 \\
\hline CGD-MDA1 & genotyping & $\begin{array}{l}\text { SNP profiling, } 470,000+ \\
\text { genomic locations, 1- } \\
19, \mathrm{X}, \mathrm{Y}, \mathrm{MT} .\end{array}$ & inbred & $\mathrm{m}$ & 2014 \\
\hline CGD-MDA2 & genotyping & $\begin{array}{c}\text { SNP profiling, } 470,000+ \\
\text { genomic locations, 1- } \\
19, X, Y, M T .\end{array}$ & BXD w/par & $\mathrm{m}$ & 2014 \\
\hline CGD-MDA3 & genotyping & $\begin{array}{c}\text { SNP profiling, } 470,000+ \\
\text { genomic locations, 1- } \\
19, X, Y, M T .\end{array}$ & ILSXISS w/par & $\mathrm{m}$ & 2014 \\
\hline CGD-MDA4 & genotyping & $\begin{array}{c}\text { SNP profiling, } 470,000+ \\
\text { genomic locations, 1- } \\
19, X, Y, M T .\end{array}$ & $\begin{array}{l}\text { AXB, BXA, } \\
\text { BXH, CXB, } \\
\text { AKXL w/par }\end{array}$ & $\mathrm{m}$ & 2014 \\
\hline CGD-MDA5 & genotyping & $\begin{array}{c}\text { SNP profiling, 470,000+ } \\
\text { genomic locations, 1- } \\
\text { 19,X,Y,MT. }\end{array}$ & $\begin{array}{l}\text { B6.A, B6.PWD } \\
\text { consomic } \\
\text { panels }\end{array}$ & $\mathrm{m}$ & 2014 \\
\hline Perlegen2 & genotyping & $\begin{array}{l}\text { SNP profiling, 8,100,000+ } \\
\text { genomic locations, 1- } \\
\text { 19,X,Y,MT. }\end{array}$ & inbred & $\mathrm{m}$ & 2005 \\
\hline Sanger4 & genotyping & $\begin{array}{l}\text { SNP profiling, } \\
\text { 80,000,000+ genomic } \\
\text { locations. SNPs and } \\
\text { indels. } 1-19, \mathrm{X} \text {. }\end{array}$ & inbred & both & 2017 \\
\hline UCLA1 & genotyping & $\begin{array}{l}\text { SNP profiling, } 132,000+ \\
\text { genomic locations, } 1-19, \mathrm{X}\end{array}$ & HMDP & both & 2018 \\
\hline $\begin{array}{l}\text { UNC- } \\
\text { GMUGA1 }\end{array}$ & genotyping & $\begin{array}{c}\text { SNP profiling, 130,000+ } \\
\text { genomic locations, 1- } \\
\text { 19,X,Y,MT. }\end{array}$ & CC w/par & $\mathrm{m}$ & 2020 \\
\hline $\begin{array}{l}\text { UNC- } \\
\text { MMUGA2 }\end{array}$ & genotyping & $\begin{array}{c}\text { SNP profiling, } 76,000+ \\
\text { genomic locations, 1- } \\
19, \mathrm{X}, \mathrm{MT}\end{array}$ & CC w/par & both & 2017 \\
\hline
\end{tabular}


Supplementary Figure 1. Mouse family tree (adapted from Petkov et al. [22]) showing the phylogenetic relationships among 102 inbred and wild-derived inbred strains. Group 1, Bagg albino derivatives; Group 2, Swiss mice; Group 3, Japanese and New Zealand inbred strains; Group 4, C57/58 strains; Group 5, Castle mice; Group 6, C.C. Little DBA and related strains; Group 7, wild-derived strains. Strains with Hrh1r allele are highlighted and their Bphs susceptibility color coded. Red $=$ Bphs $^{\text {s }}$, Green $=$ Bphs $^{r}$, and Black $=$ Bphs unknown (Bphs?).

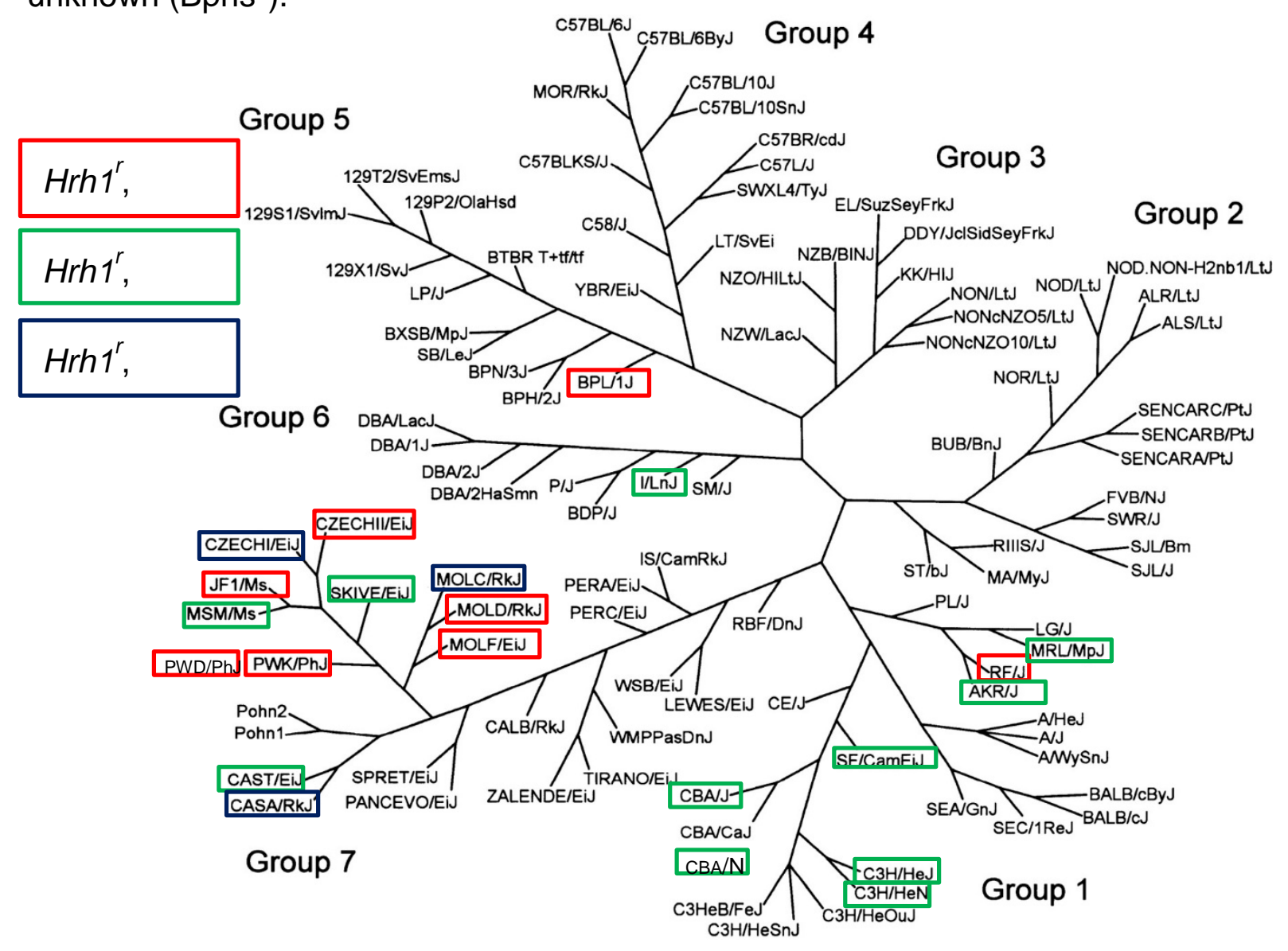


Supplementary Figure 2. The predicted candidates for Bphse overlaps with Bphs/Hrh1, Histh3, and Histh4 in agreement with the genetic data that a functional LD on Chr6 encodes genes that control both $B$. pertussis/PTX-dependent and age- and inflammationdependent susceptibility to HA-shock.

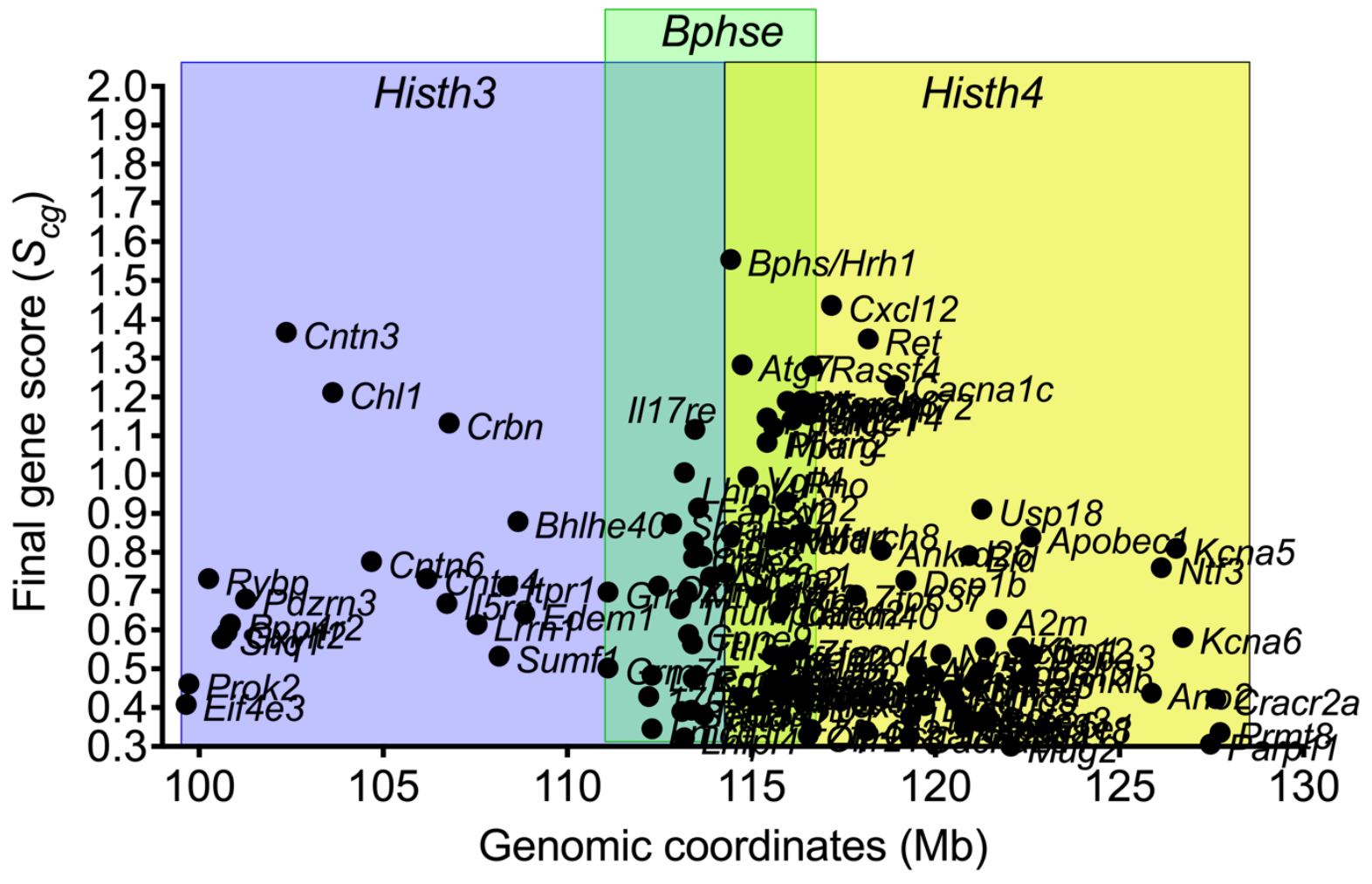

